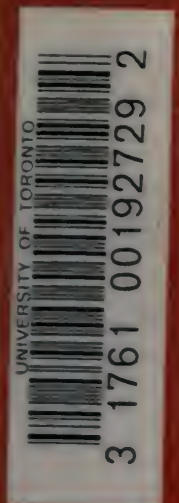


Digitized by the Internet Archive in 2007 with funding from Microsoft Corporation 





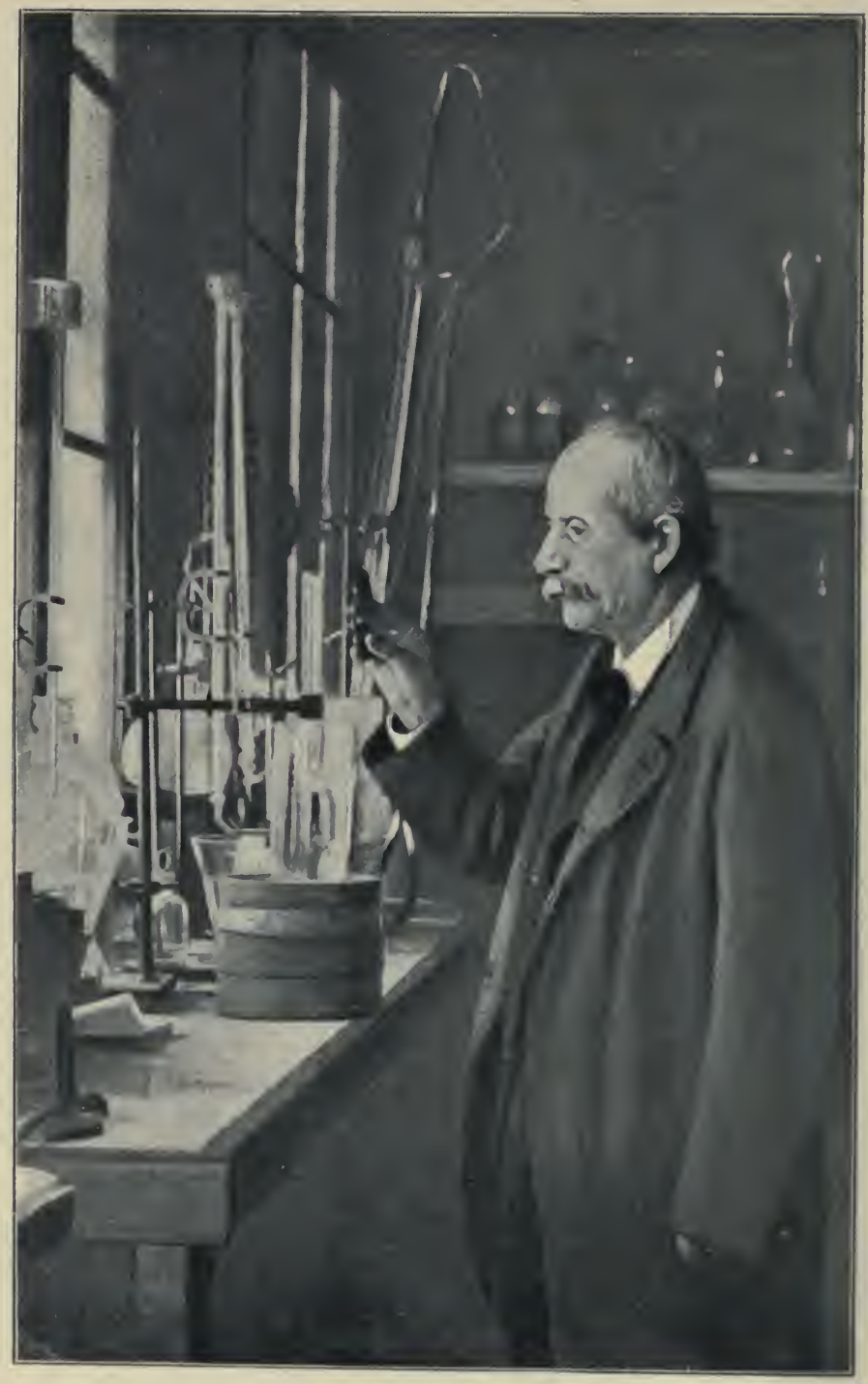

PROFESSOR MARCELLIN BERTHELOT

Founder of Synthetic Chemistry, in his laboratory at the College de France, Paris. 


\section{NEW CONCEPTIONS \\ IN SCIENCE}

WITH A FOREWORD ON THE RELATIONS OF SCIENCE AND PROGRESS

\section{BY \\ CARL SNYDER}

Man's happiness and nohle aims have rested before now on false foundations. The wisest thing to do, then, is go on enjoying the supreme gifts vouchsafed to us, life and the faculty of seeing the reality. Science will always remain the gratification of the noblest craving of our nature, curiosity : it will always supply man with the sole means of improving his lot.

RENan : L'Avenir de la Science.

ILLUSTRATED WITH PORTRAITS AND SKETCHES

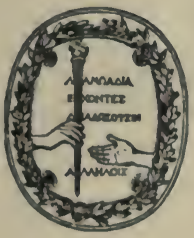

LONDON AND NEW YORK HARPER \& BROTHERS PUBLISHERS 1904 
SECOND, AND REVISED, EDITION

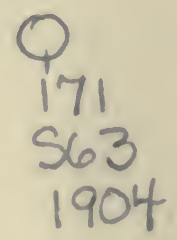

Copyright, 1903, by Harper \& Brothers. All rights reserved. Published June, rgo3.

Printed in United States of A merica. 
FOR

THE FRIENDSHIP OF MY MOTHER 

The ordinary run of men live among phenomena of which they care nothing and know less. They see bodies fall to the earth, they hear sounds, they kindle fires, they see the heavens roll above them, but of the causes and inner workings of the whole they are ignorant, and with their ignorance they are content.

Sir Oliver Lodge. 



\section{CONTENTS}

\section{A FOREWORD}

\section{ON THE RELATIONS OF SCIENCE AND PROGRESS}

An object-lesson: The great school of science at Alexandria, 300 B.C., and its relative failure through the lack of accurate instruments, or appreciation of mechanical devices-The intimate relations of mechanics to modern civilization-The present achievements of the scientific method-The rôle of science in the future: its aims, its task . . . . . . . . . . Page 3

\section{THE WORLD BEYOND OUR SENSES}

Researches which reveal how little we know of the real world around us, as it is presented to us by our primitive senses-How these primal senses are being extended, and new senses are being added . . . . . . . Page 4I

\section{THE FINITE UNIVERSE}

The facts which indicate that the stellar universe is not " infinite," but of definite size, shape, and mass, measurable and weighable - The means by which its boundaries are being fixed and its form determined, and the inferences that may be drawn from our present knowledge . . . . . . . . . . Page 73 


\section{WHAT THIS WORLD IS MADE OF}

The limits of the divisibility of substances, and the conclusions to which the study of their limits has led-What familiar things like soap-bubbles and gold-leaf may tell us of the size of molecules and atoms . . Page 103

\section{PROGRESS TOWARDS AN EXPLANATION OF ELECTRICITY}

Benjamin Franklin's ideas, and how they seem, in the light of recent developments, to offer the best explanation of this mysterious "fluid"-The electrical atom . Page I 3 r

\section{THE SEARCH FOR PRIMAL MATTER}

What are the atoms made of ?-A detailed account of the ingenious experiments of Sir William Crookes, Professor J. J. Thomson, and others, disclosing the existence of particles of matter a thousand times smaller than the smallest atom-The nature of these "corpuscles" . Page $\mathbf{1 4 5}$

\section{THE RISE OF SYNTHETIC CHEMISTRY AND ITS FOUNDER}

The fertile career of M. Berthelot, the greatest of living chemists - What he has accomplished; what he hopes synthetic chemistry may do . . . . Page 169

\section{BORDERING THE MYSTERIES OF LIFE AND MIND}

The remarkable discoveries of Professor Loeb, of artificial parthenogenesis, and the relations of electricity and the life-processes - Professor Albert P. Mathew's experiments on the nerves, and his explanation of nervous action . . . . . . . . . . . . . Page 199 
THE NEWEST IDEAS AS TO WHAT IS LIFE

Recent investigations which seem to show that life is a form of fermentation-The rôle of the ferments or enzymes in the bodily functions-The possibility of reversing the life-processes, and growing backward . Page 229

\section{HOW THE BRAIN THINKS}

The chemistry and structure of the brain, and how recent discoveries are being applied to an explanation of the physical process of thought . . . . Page 25I

\section{THE WAY THE HUMAN BODY FIGHTS DISEASE}

The discovery of the serums or anti-toxins, by Pasteur and his pupils-Metchnikoff's theory of the devouringcells, and their battles with the microbes-The new chemical theories of Ehrlich . . . . . . Page 273

THE SPIRIT-RAPPERS, THE TELEPATHS, AND THE GALVANOMETER

The light that modern science may throw on psychic problems-A description of marvellous new instruments of measurement, which are thousands or millions of times more sensitive than our primal senses-The argument that might be drawn from some of their performances

\section{WIRELESS TELEGRAPHY}

The discoveries which made it possible, and a description of the apparatus used - Signor Marconi not its inventor. 


\section{CONTENTS}

AMERICA'S INFERIOR POSITION IN THE SCIENTIFIC WORLD

A review of the newest acquisitions to human knowledge, and the men and the countries that are foremost in this work-The astonishing activity of Germany and other European countries, as compared with America-The work of the Royal Institution of London, the Pasteur Institute in Paris, and the need of such research institutions in this country . . . . . . . Page 33I

INDEX . . . . . . . . . Page 357 


\section{LIST OF ILLUSTRATIONS}

Professor Marcellin Berthelot.-Founder of Synthetic Chemistry, in his laboratory at the Collège de France, Paris . . . . . . . . Frontispiece

Hero's Steam-Turbine.-Earliest-known steam-engine, invented about 130 B.c. . . . . . . . page

Hero's Magical Altar.-When a fire was built upon the altar, the doors of the temple swung open . page

ARchimedes.-Greatest inventive genius of antiquity, born at Syracuse, 287 B.c.; killed by a Roman soldier, 212 B.c. . . . . . . . . f facing $p$.

Professor Samuel Pierrepont Langley.-Secretary of the Smithsonian Institution at Washington, inventor of the bolometer. . . . . facing $p$.

Professor W. C. Röntgen. - University of Munich, discoverer of the X-rays . . . . facing $p$. 80

Lord Kelvin (Sir William Thomson).-Famous for his researches in electricity and the constitution of matter. . . . . . . . . . . . . facing $p$.

SiR William Crookes.-Chemist and philosopher, distinguished for his work in the field of molecular physics . . . . . . . . . . facing $p$.

Propessor J. J. THOMson.-Discoverer of the ultraatomic state of matter, in the Cavendish Physical Laboratory, Cambridge, England . . facing p. 164 


\section{LIST OF ILLUSTRATIONS}

Professor Jacques Loeb.-Discoverer of artificial parthenogenesis. . . . . . . . . f facing p.

Elias Metchnikoff.-Pasteur Institute, Paris, famous for his researches in immunity . . facing p. 278

Professor Henri Becquerel.-Discoverer of the "Becquerel rays," or radioactive substances, in his laboratory at the Jardin des Plantes, Paris, facing p. 296

Heinrich Hertz.-Discoverer of electrical oscillations, or Hertz waves, which have given us wireless telegraphy; died 1894 . . . . . . . facing $p$. 314

Sir Oliver Lodge. - Principal of the University of Birmingham, one of the first to demonstrate the possibility of wireless telegrahy . . . facing p. 336 


\section{ON THE RELATIONS OF SCIENCE AND PROGRESS}


It may be doubted if even-handed justice, as free from fulsome panegyric as from captious depreciation, has ever yet been dealt out to the sages of antiquity who, for eight centuries, from the time of Thales to that of Galen, toiled at the foundations of physical science.

HuXley, Methods and Results, art. "The Progress of Science.

How high a value the Greeks put upon strict logical thought is shown by the conception of Plato, whose pupil was Aristotle, according to which a man untrained to mathematics was not to be reckoned as a man of intelligence (homo sapiens), but rather of a sort standing nearer to the animals.

\section{Lehmann, Physik und Politik.}

In the year 1600 , Bruno was burned at the stake for teaching that our earth is not the centre of the universe. In 1700 , Newton was pronounced "impious and heretical" by a large school of philosophers for declaring that the force which holds the planets in their orbits is universal gravitation. In 1800 , Laplace and Herschel are honored for teaching that gravitation built up the system which it still controls; that our universe is but a miror nebula, our sun but a minor star, our earth a mere atom of matter, our race only one of myriad races peopling an infinity of worlds. Doctrines which but the span of two human lives before would have brought their enunciators to the stake were now pronounced not impious, but sublime.

Henry Saith Williams, Nineteenth-Century Science. 


\section{ON THE RELATIONS OF SCIENCE AND PROGRESS}

Along the southern shore of the Mediterranean, near the mouth of the Nile, there is a slight indentation partly enclosed by the island of Pharos. It is an admirable harbor, and was known from antiquity as Pirate's Bay. It had been, from the remotest ages, a refuge for the sea-rovers of Phœnicia, and later those of Greece.

Perhaps it was fitting that it was here, when Alexander became master of the world, he decreed the building of a city to bear his name. It was planned much as was the "model town" of Pullman, near Chicago; but it was to be a city, a capital, a world-capital, and it was built with a royal disregard of cost. It was begun in the year $33^{2}$ B.c. The most celebrated architect and engineer of the time was Dinokrates, who had gained a high reputation in rebuilding the Temple of Diana at Ephesus; he was chosen not merely to lay it out, but, so to speak, to design it, de toute pièce. Alexander died, but the work was carried out as he 
had conceived it by his successors in Egypt, the ambitious Ptolemy Soter, and the still more enlightened Ptolemy Philadelphus.

With Alexander the supremacy of Athens in the Greek world definitively passed; Alexandria was its successor. Its growth was more rapid than that of Chicago in our own day. In a short time it had become the centre of commerce and learning of the Greek world. In its symmetry, its grandiose beauty, its spirit, its prevalent atmosphere of freedom, of scepticism, of advancement, of polish, it must have been the Paris of the pre-Christian era, a "City of Light." It was laid out in straight, parallel streets, like Berlin, or Chicago again; one of them, 200 feet wide, ran westward from the Canopic Gate to the Necropolis. "This street was decorated with magnificent houses, temples, and public buildings, and was intersected by another of the same breadth and magnificence running from north to south." On a peninsula which stretched out into the Mediterranean, towards the east of the city, arose the splendid palace of the Ptolemies. Near it were the Cæsarium, where divine honors were paid to the emperors; the courts of justice; the great $\mathrm{Mu}$ seum, or university, and the still more famous Library.

This library at one time contained more than 700,000 volumes, chiefly inscribed upon papyrus. 
The enormous work of transcription was done by an army of slaves, and the libraries of the known world were laid under tribute. This magnificent collection, one of the greatest in history, was sacked and in large part destroyed, not by Mohammedans, but by a Christian rabble under the lead of an ignorant monk named Theophilus, some six centuries after its founding. Of the original library there was little left to be burned when, 300 years later still, the city was taken by the caliph Omar.

The great Museum, or university, was directly connected with the royal palace. It contained sumptuous dining-halls, and lecture-rooms for the professors, and the number of attending students rose to 14,000 . It counted among its professors not merely linguists and grammarians, philosophers and rhetoricians, but many of the founders of natural science. Here flourished, through more than six hundred years, that long line of astronomers and mathematicians, geographers and geometers, physicists and physicians, beginning with Euclid and not ended with Ptolemy, which made illustrious the Alexandrian school-which made Alexandria, indeed, a veritable city of science. Here it was that Euclid, about 300 B.C., wrote his treatise, The Elements of Geometry, which is still in use, with but slight changes, in our public schools. 


\section{NEW CONCEPTIONS IN SCIENCE}

Here Aristarchus first attempted to estimate the relative distances of the sun and the moon, and their magnitudes as well. Here lived Eratosthenes, keeper for a time of the great library, a man of the most varied talents, the first great physiographer, and the first to attempt, on correct principles, a measurement of the size of the earth. As to his computation, it appears to have been not greatly in error - roughly 30,000 instead of the correct figure of 25,000 miles in circumference. It is to be noted that this computation was made on the implicit faith that the earth is round.

It was, indeed, one of the strangest lapses in history that perfectly clear and just notions respecting the form of the earth and its motion round the sun should have grown up among men, have been passed from one century to another, and then disappeared from Christendom for a thousand years. These doctrines appear to have been accepted by the earliest astronomers of Alexandria as a part of current knowledge, almost as they are to-day. Pythagoras had taught the motion of the earth in the fifth century B.c. Not this alone, but one of his pupils, Nicetas of Syracuse, clearly taught the motion of the earth on its axis as well. There is a curious passage in Cicero which is worth transcribing: 


\section{SCIENCE AND PROGRESS}

Nicetas of Syracuse, as Theophrastus says, believed that the heavens, the sun, the moon, the stars - in brief, all things above-stand still; alone, the earth, of all things in the world, moves. Because it is rapidly turning and twisting upon its axis, it gives the effect of the whole sky moving, and that the earth stands. ${ }^{1}$

This was a long time before the famous, but probably apocryphal, "E pur si muove" (And yet it does move), of the aged Galileo.

Moreover, the ingenuity of mind displayed by some of these early investigators must ever command the admiration of intelligent men. At the risk of a slight digression, I will venture to note two instances which are most striking.

Aristarchus of Alexandria describes in his treatise, On the Magnitude and Distances of the Sun and the Moon, still extant, his methods of calculation. If the moon shines by the light of the sun, to an observer on a line between these two bodies the moon would always appear "full." But if the observer's position be shifted to a point on a line at right angles to this, and intersecting the earth and the moon, the latter's disk would appear just cut in two. The earth is at such a point when the moon appears to us "half full." By then measuring the angle formed by lines drawn from the earth to the sun and to the moon, it is possible to

'Academica, lib. iv., cap. 39. 
construct a right-angled triangle. The diagram below should make his method clear:

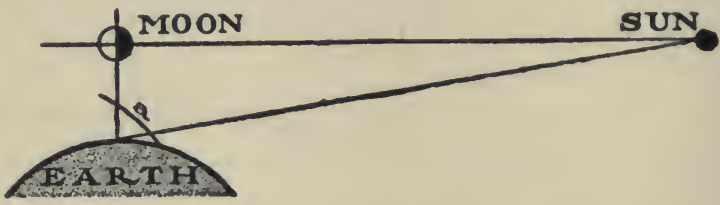

Aristarchus's estimate of the angle marked $\boldsymbol{a}$ was $87^{\circ}$, and he had then merely to measure the sides of his triangle to find that the distance of the sun from the earth was nineteen times that to the moon. Of course his result was wrong; we now know that the distance is 400 times. What the inquiring Alexandrian lacked was accurate instruments. The angle is actually $87^{\circ} 50^{\prime}$, and although the error of less than one degree seems small, when this is applied to a line approaching a right angle $\left(90^{\circ}\right)$ the resulting error is very great. But that does not diminish one's respect for the kind of a mind which could conceive such an idea. It will be noted that Aristarchus understood well that the moon does not shine by its own light. That the eclipses had shown thousands of years before.

The method employed by his successor, Eratosthenes, in his attempt to measure the size of the earth, was equally ingenious. In some fashion he learned that the ancient city of Syene, in Upper 
Egypt, lay on the tropic-that is to say, on the day of the summer solstice the gnomon cast no shadow, the rays of the sun shone to the bottom of a deep well. On that day the sun was in the zenith from Syene. Syene, he also computed, was on the same meridian as Alexandria. So on this day he measured the arc included between the sun and a point in the zenith from Alexandria. The figure shows his idea.

The arc A B, described by the angle $\boldsymbol{a}$ (it is exaggerated in the drawing) is, to all intents and purposes, the same as the arc D C. Eratosthenes estimated these at $7^{\circ} 12^{\prime}$, or $\frac{1}{50}$ the circumference of a circle. He had

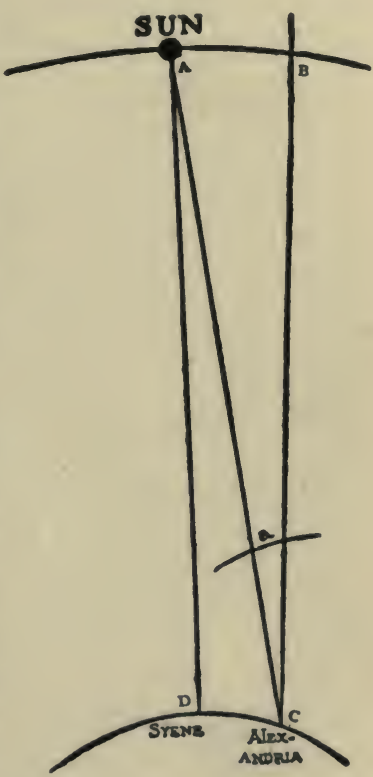
then but to find the distance, D C, between Syene and Alexandria. This the bematists, or surveyors of the Ptolemies, had set at about 5000 stadia. He computed the circumference of the earth, therefore, at fifty times this, or 250,000 stadia-roughly, 30,000 miles. Here, again, the result was vitiated, though in no 
large degree, by the lack of exact measurements. That is all that divides the astronomy of that day from our own.

These two acute and resourceful Alexandrians were the immediate predecessors of the true founder of astronomical science. That honor belongs to Hipparchus; it was he who discovered the precession of the equinoxes, who made the first catalogue of stars, who invented the planisphere, and first applied the methods of spherical trigonometry to the solution of astronomical problems. Whether the great Hipparchus was actually a professor in the Alexandrian school, as had been disputed, matters little. Spiritually, if not corporeally, he was of its line; its heritage was his; his work was continued by the savants of Alexandria, and culminated in the masterly expositions of Ptolemy (A.D. 130). The latter's conceptions of the world dominated the minds of men for 1500 years, and until Copernicus, Galileo, and Newton had come.

Alexandria must have been, likewise, the seat of the first great medical school. It was founded by Philadelphus upon the sure basis of anatomy, and its professors were authorized to practise dissection. To touch a corpse in Egypt was held to be an abomination, but the strong hand of Ptolemy resolutely carried out his design, which was to know not merely the true structure of the body but the 
mode in which its functions are carried forward. To this end vivisection was authorized not only upon animals but upon criminals condemned to death. Almost every branch of modern medicine -obstetrics, physiology, materia medica, and the like - was taught. The great temple of Serapis was used for a hospital, students being admitted to the bedside of the sick, just as in the present day.

It was at Alexandria, again, where lived Manetho, the annalist. Unlike the others, he was not a Greek; he was an Eygptian and a priest. It was his work which unlocked to foreigners the ancient history of his land. That chronicle, perverted, corrupted, and all but destroyed by the bishop Eusebius and his successors, in their fantastic efforts to bolster the Old Testament traditions, would have been of priceless value in confirming and illuminating the records of the tombs and monuments which in our own time have formed the materials for the study of Egyptology.

Here at Alexandria, too, lived Ctesibius, who laid the foundations of hydro-mechanics and was famous for the number and ingenuity of the hydraulic and pneumatic machines that he devised-the siphon, the ordinary hand fire-engine, and our common force-pump may be instanced. It was here that his pupil Hero, or Heron, another of the professors at the museum, invented the steam-engine. 


\section{NEW CONCEPTIONS IN SCIENCE}

Hero's engine was a sort of steam-turbine, ran without piston or cylinder, was simple in design, easy to build; a child could understand its opera-

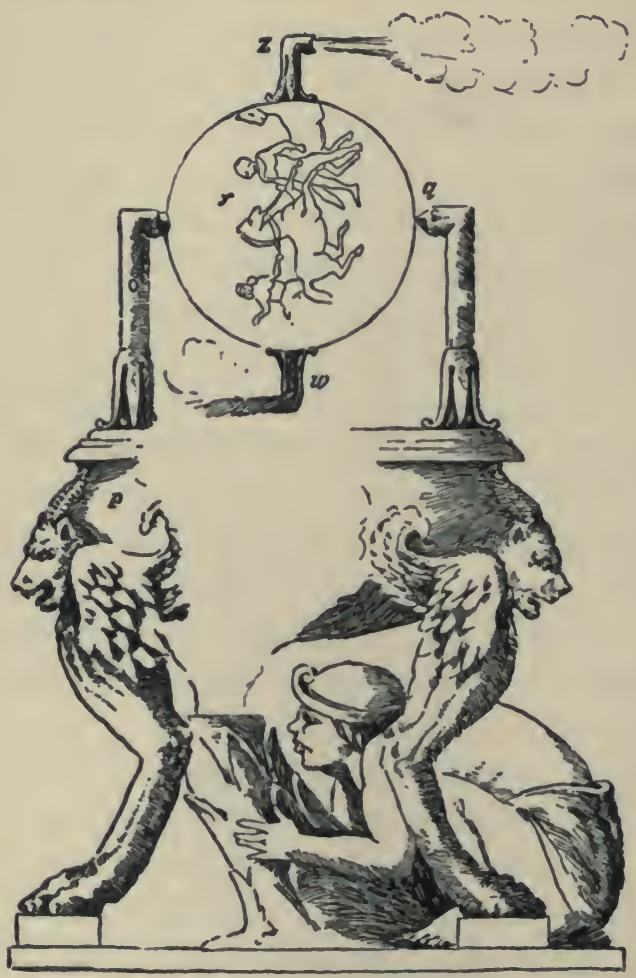

HERO'S STEAM-TURBINE

The steam was carried up from the closed caldron, $p$, through the tube, $o$, into the ball, $y$, and escaping from the nozzles, $w$ and $z$, caused the ball to revolve. 
tions. The little, revolving fountains which are set out upon the lawn or in the garden, and throw a circular stream, perforce of the push of the water as it comes from the revolving nozzles, work upon exactly the same principle.

This was about 200 B.c. The invention lay dormant for 2100 years. Hero's steam-turbine was reinvented some fifteen or twenty years ago by a Swedish engineer named de Laval. Since then several other forms of steam-turbines have been constructed, notably that of Parsons, which is installed on the swift-going Turbinia. If one may judge from the developments of the last ten years, Hero's device, modified and improved, is likely in part to drive out other forms of steam-engines.

The modern hot-air engines were developed from another ingenious device of this same Hero. On a hollow altar, containing air, a fire was kindled. The heated air within expanded and drove a column of water below into another vessel; in so doing a pulley arrangement was worked and the doors of the temple swung open. When the fire died and the air cooled, the device worked backward; the doors of the temple closed. It must have been thought a miracle then. The priests of those days were inventors and men of science.

The list of Alexandria's great men here given is but a slender detail - the mention of a few names 
NEW CONCEPTIONS IN SCIENCE

among many. Can it be doubted that the influence of such a centre of learning and activity was wide. I may cite but a single example.

At the far corner of the irregular triangle formed

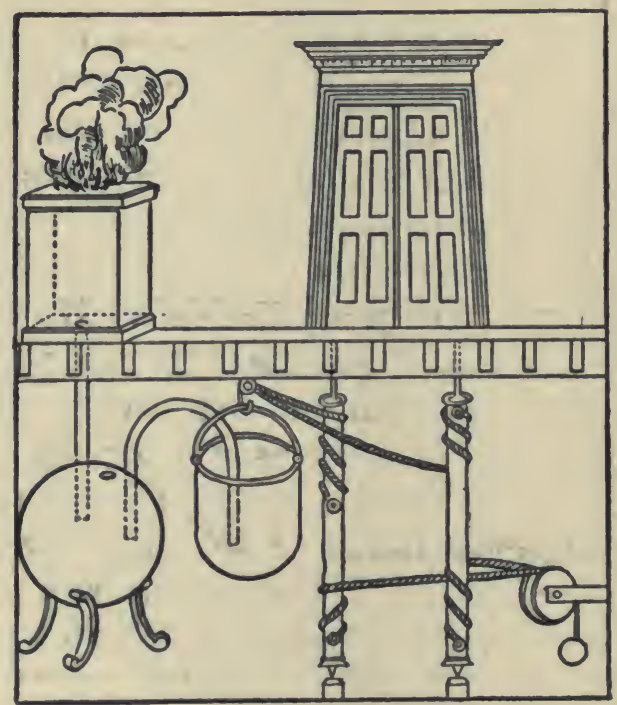

HERO'S MAGICAL ALTAR

When a fire was built upon the altar, the doors of the temple swung open.

by Athens, Alexandria, and the island of Sicily lay another Greek centre, the ancient city of Syracuse. Apart from its temples and its monuments, it is remembered to-day as the home of Archimedes, "the greatest mathematician and the greatest in- 
ventive genius of antiquity." The stories that have come down of his feats and his discoveries are legion, and many of them are familiar tales. There is hardly a school-boy who has not read how he detected the alloy in King Hiero's crown; how a weight of gold had been given by the King to an artificer to make over into a crown; how the King, suspecting a cheat, asked his friend Archimedes if he could tell whether base metal had been put in with the gold; how Archimedes, sorely puzzled, stepped one day into his bath, observed how the water ran over, forgot everything, and shouting

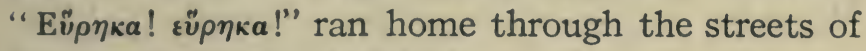
Syracuse with no clothes on at all.

Archimedes' observation set him to pondering the whole subject of the action of bodies in water; he became the founder of the science of hydrostatics. It was he who established the idea of specific gravity - that is, the weight of equal volumes of different materials. From this he was led to all sorts of investigations, and finally to that of the lever. Not that the lever had not been used, doubtless, by prehistoric man; but Archimedes seems to have been the first to give its theory. That he realized to the full his discovery, and that he possessed in the highest degree what Tyndall calls the "scientific imagination," is amply illustrated in the saying attributed to him: "Had 
I but a fulcrum whereon to rest, I could move the earth."

It is worth noting that here, and throughout his writings, Archimedes proceeds entirely from the assumption that the earth is a ball, and he mentions the attempts that had been made to measure its exact size; he alludes, too, to the astronomical system which we call Copernican - that the sun, not the earth, is the centre of things - although he died I $75^{\circ}$ years before Nicholas Copernik's book appeared.

Now here is a strange thing. Not only did Archimedes possess the modern solar theory in its general outlines, but he had in his hand the means of proving or disproving its truth. The story of the burning-mirrors, by which he destroyed the fleets of Rome sent to take Syracuse, has been doubted by some. But it is not the type of a story which comes naturally from pure invention. Moreover, Buffon showed that mirrors could be devised which would burn objects at a considerable distance. And we know that the galleys of Roman times were small compared with our great ships of war; they were of wood, and they came quite close to the walls of the city.

The burning-mirror depends upon exactly the same principle as the reflecting telescope-that is, the reflection of the rays of light and heat in straight 


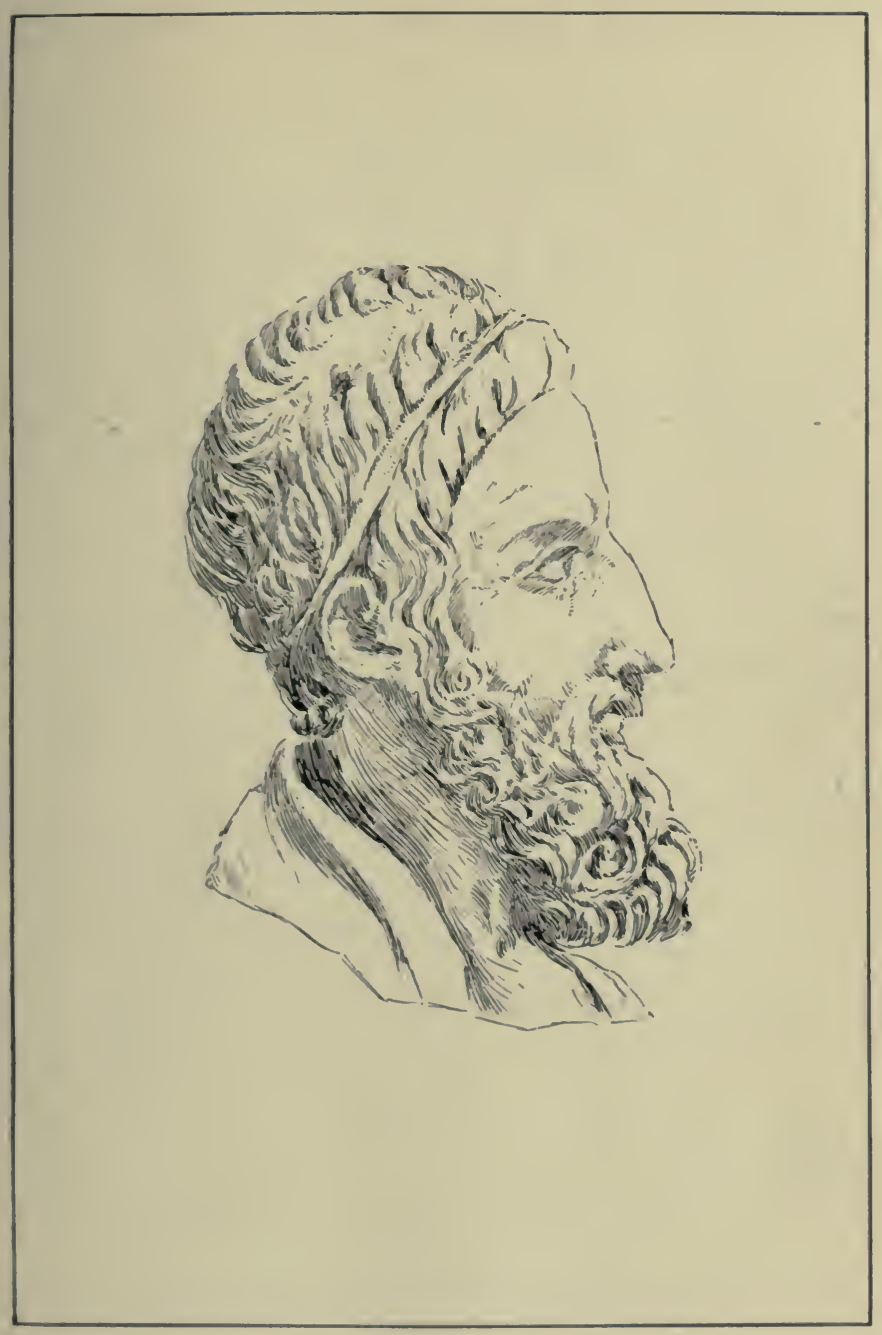

ARCHIMEDES

Createst inventive genius of antigituty, horn at Syracuse, 287 B.c.: killed by a Roman soldier, 212 s.c. 

lines. In the one instrument, as in the other, the rays are made to converge by being reflected from a concave surface. The laws of reflection appear to have been well known to the geometers of Plato's school; they are fully treated in the book on Optics ascribed to Euclid; they must certainly have been familiar to the greatest geometer of that time. So, too, the general nature of refraction; for burningglasses and magnifiers of crude form are mentioned by Pliny and others. Had he pushed his contrivance of burning-mirrors one step further he would have had a telescope. Galileo and the proof of the Copernican theory would have been antedated eighteen centuries. The extraordinary list of Archimedes' inventions-pulleys and windlasses, catapults, the water-screw or screw-pump, the endless screw, various hydraulic and compressed-air machines, great swift-acting cranes to seize the Roman galleys and swing them out of the water, and no end of others, attest his inventive genius. But all this seems to have been a diversion, a recreation, much of it done simply for his patron and friend, the King Hiero. He does not seem to have taken any especial interest in the study of natural phenomena, as Newton and Galileo did. He was not an experimental or observing genius; he was a mathematical giant, and that study absorbed all his interest.

Archimedes belonged to the generation next after 
Euclid, next before that of Hero. Eratosthenes and perhaps Ctesibius were his contemporaries. From Syracuse to Alexandria is near a thousand miles. In those days travel by boat or camel was slow; there was no steamship to carry, no mariner's compass to guide; but it was at Alexandria that Archimedes attended school, and there his youth was spent. He was of the intellectual lineage of Euclid; his work was a legitimate part of the glories of the Alexandrian school.

Such, in meagre, fragmentary outline, was the influence and the work of that splendid city and that fruitful time. And Alexandria came late. The foundling of the Macedonian came after AthensAthens with all its poets and philosophers, its heroes and its gods. A space of more than twenty-three centuries lies between us and the days of Pericles, and to Pericles and his contemporaries, to Euripides, to Phidias, to Plato, to Aristotle, the world must have seemed very old. Back of them were Nippur and Babylon, Memphis and Thebes, Mykenæ and Troy. And all this

" pomp of yesterday

Is one with Nineveh and Tyre."

$\mathrm{He}$ who will review the intellectual history of mankind, more especially in the light of recent ac- 
quisitions, will find his attention riveted by two notable facts. The first of these is the long range of time in which the human race has stood at about its present level; the second, the briefness of the period in which exact knowledge, based upon measures and experiment, has replaced guess-work and dreams. I wish, in a word, to set in contrast the great antiquity of civilization, as revealed by late archæological discovery, and how new are the methods and conceptions which we group under the vague name of science.

Civilization is very old. That is what the excavations and explorations along the Nile, and about Nineveh and Babylon, in the ruins of Troy and Mykenæ, and in Crete and Cyprus, have made clear. The Book of Job is probably the most ancient of the Bible; we think of Homer at the dawn almost of history, and the Vedas of India seem still more remote. Yet it is doubtful if any of these date from more than 600 or 800 B.C. We now have records of kings who ruled in Egypt 3800 or 4000 years before our era, and the inscriptions found in the ruins of the old Sumerian-Accadian capital along the Euphrates carry us back yet further. They were more distant to Homer, to Buddha, or to Job than Homer and Job from us.

In all the main features of life these remote ages differed less from one or, at most, two centuries ago 
than the days of Elizabeth or the New England Pilgrims differed from our own. They had vast libraries, inscribed, it is true, upon tablets of clay, but none the less carefully tabulated and indexed; their tapestries and dyes were as brilliant as anything we may now produce; their architecture, in their temples at least, surpassed any modern work in grandiose effect; they were sculptors and carvers; jewels and precious metals they had in profusion; they were miners and metal-workers, and even their plumbing arrangements did not differ much from those of the present time.

We must concede that neither mentally, morally, nor physically has the race varied greatly in six thousand and perhaps ten or fifteen thousand years. The intervening period has meant less change than is represented, say, in the advance from a bushman or a cave-dweller to a Zulu chieftain.

Again, in some regards-the temples, the sculpture, the poetry, the drama, the philosophy, the religion-the serene and healthful outlook upon life of the Greeks represents a stage of human culture that has hardly been since attained. As the curtain rises upon authentic history we are introduced to a race full brained, full armed. And they had behind them uncounted centuries of a relatively high civilization.

This is the first fact. On the other hand, it is scarce eight or nine generations since Bruno was 
burned for teaching the doctrines of Copernicus, since Galileo was imprisoned because he had proof that the Copernican theory was true. Six generations carry us back to the day when Newton revealed the simple mechanical principle on which our solar system, and no doubt every other, is run. There are men yet living who might have known Laplace and heard from his own lips the theory of how the system of planets, earth, and moon came into existence. It is only forty years since Darwin offered a mechanical explanation of how all things living - fern and fish, horse, ape, and man-came to be what they are. The doctrine of evolution, hazarded as a guess by Heraclitus two thousand years ago, has been developed and proved only in our own time. Even yet it cannot be said to have penetrated more than a slender number of minds, save in the vaguest way.

The last two or three centuries have acquired a wider knowledge of this world, and of the larger universe, than all the sixty or a hundred centuries preceding. I have elsewhere ${ }^{1}$ sketched what might be Newton's sensations were he now to return among men. For Newton, as for Empedocles 2300 years before, the primal elements were Earth, Air, Fire, and Water. He was something of a chemist,

1"The Spirit-Rappers, the Telepaths, and the Galvanometer," p. 291. 
and no doubt abreast of his time; but he had little knowledge of the real substances of which this world is made. His guesses about atoms were as vague as those of Democritus or Lucretius. With all his store of knowledge Newton could have taught less of new things to the mythical Hermes of the remotest days of old Egypt than he might learn to-day from Lord Kelvin or Professor Berthelot.

Yet this marvellous advance in no way implies any corresponding advance in the natural powers of the human mind. Opinion may vary as to the relative merits of individuals; no doubt Aristotle had no such acute intellect as Newton, yet, if we remember the curious and clumsy blunders of Aristotle, it should not be forgotten that Newton spent half his life quarrelling over doctrines of the Trinity, and that his theological puerilities form a large part of his writings. What is certain is that the eight centuries from Thales and Pythagoras to Euclid and Galen produced an astonishing array of minds of the first order. If Archimedes, Hipparchus, Ptolemy, and the rest, added less to the sum of solid knowledge than Galileo, Harvey, Descartes, and their successors, the cause must be sought in other things than the quality of gray substance. And if there has been no perceptible advance in the powers of the mind in 2000 or 3000 years, it is doubtful if another 3000 or even 6000 years, could 
their obscure history be unveiled, would reveal any striking difference.

Whence come, then, the great strides of the last ten or twelve generations? Many answers have been given, but the subject seems to have engaged chiefly men whose minds run to fine phrases or metaphysical subtleties. The cause may be summed up in a word: the invention and use of mechanical appliances.

The phrase is used broadly. Under mechanical appliances I include all that may contribute to exact measurement and to the extension of our primitive senses in any direction whatsoever. In this sense the calculus or the reactions of the chemists' test-tube must be reckoned as mechanical no less than the thermometer, the microscope, or the balance. I would include even such aids to calculation as the use of the zero, or cipher, algebra, the inventions of fluxions, logarithms, and the slide rule. The balance must have been known from the remotest ages, and some crude form of thermometer must have come with the very beginning of metallurgy, in the Bronze Age. But an accurate heatscale dates only from the time of Galileo. Strange as it may seem, the use of the zero-or, more strictly, a decimal system of counting-was not general in Christendom before the fourteenth century. It came to us from the Arabs, who in turn borrowed it 
from the Hindus. It is, therefore, probably the Hindu and not the Arabic system of notation, and belongs back centuries before our era. Algebra seems not to have been known to Archimedes, or even to Ptolemy; it appears not to have come into use before the days of the illustrious Hypatia. The foully murdered Alexandrian composed a commentary on the work of Diophantus, which is the earliest treatise recorded. The application of algebra to geometry we owe to Descartes, the contemporary of Galileo; the invention of the calculus to Leibnitz and Newton. Though the germ of the theory of logarithms appears to have been known to Archimedes, the first elaborate system was constructed by Baron Napier in 16r4. The telescope found its first notable triumph in the hands of Galileo, again; the barometer was the invention of his pupil, Torricelli. A convex lens of rock-crystal was found by Layard among the ruins of the palace of Nimrud; the principle of the microscope, then, was known in the most ancient times; but it found little practical use until it was taken up by Leeuwenhoek and Robert Hooke, who contested with Newton the discovery of the law of gravitation. The galvanometer, the first accurate measurer of electricity, belongs to the last century.

Strictly industrial inventions have contributed not less. The steam-engine, the voltaic pile, the 
dynamo, the gas machine, supplying the investigator with unlimited quantities of power, heat, light, and electricity, have made possible investigations which were hitherto impossible; and pure invention having often preceded theory, the study of these inventions has powerfully stimulated research. Even the commercial telephone has added to the laboratory one of its most delicate and resourceful instruments.

These mechanical aids and appliances are the pillars of modern science and of modern civilization. The whole extension of our knowledge beyond that of the savage depends upon the means of supplementing artificially our primitive senses. As I have endeavored to make clear in the pages that follow, ${ }^{1}$ the native senses give us but a slight notion of the real world about us; they are crude, coarse, inaccurate, unreliable, prone to delude. For the upbuilding of the vast body of verified and unified experience and experiment which we call science, there was required the invention of tools - of delicate instruments, and mechanical constructions of every sort. It is the acquirement and possession of these that alone differentiates us from the old days. Without them we should be no further ad-

'See especially "The World Beyond Our Senses," p. 41; and "The Spirit-Rappers, the Telepaths, and the Galvanometer," p. 291. 
vanced than Thales or Heraclitus - we should be speculating, dreaming still.

But it may be objected that many of these devices, in some form or other, were known to the ancients. Whence comes it, then, that the convex-lens of Nimrud's palace, the catapults and tackle of Archimedes, the force-pumps of Ctesibius, the ingenious measurements of Eratosthenes, the astronomical work of Hipparchus and Ptolemy, the dissections of Aristotle and Galen, bore so little fruit? Whence comes it that the light of the scientific method should have flamed for a time in Babylon, in Thebes, in Athens, in Alexandria, and then the world gone dark for a thousand dismal years?

He who is curious in such affairs may trace the sorry story in the caustic and relentless pages of Draper; ${ }^{1}$ how an enlightened civil power gave way for a time to an ignorant and bigoted theocracy, how "a wild astronomy supplanted that of Hipparchus; the miserable fictions of Eusebius subverted the chronology of Manetho and Eratosthenes; the geometry of Euclid and Apollonius was held to be of no use; the geography of Ptolemy a blunder; the great mechanical inventions of Archimedes incomparably surpassed by the miracles worked at

${ }^{1}$ History of Civilization in Europe, vol. i. 
the shrines of a hundred saints." It is interesting reading.

We may agree with Draper in his lament over this degrading influence, and applaud his eloquent denunciations of what he terms the Patristic spirit. But I do not share his belief that here was the sufficient cause of the Dark Time. The influence of the Christian Church was evil, incomparably evil. We are not out from under its baleful effects yet. But if the right conditions had been present, it would never have prevailed. The theological spirit is with us still; in point of mere numbers it is immeasurably stronger than ever. But there is now a balancing force. It was numbers that enlightenment lacked. It has them now. The eclipse of science was due to the fact that its adherents, its exponents, were too few. They were lost.

Consider for a moment that the Greek spirit was supreme for eight or ten centuries. From Thales to Ptolemy and Galen is a longer period by half than from the discovery of America to our own day. Consider the meagre list of great men of science, and the scantiness of their results, compared with the long roll that begins with Roger Bacon and ends not with Darwin.

Science in the old days lacked numbers. It lacked them because in the old order of society it had no solid means of support. The old order of 
society was military. Science, like literature and art, was dependent on royal favor, upon the whim of a few men. The greatness of the Alexandrian school was, in large part, due to the enlightened line of Greek kings that ruled in Egypt through three hundred years. The Ptolemies were its source of existence. With the Ptolemaic tradition it died.

Now the military basis of society, as Spencer and others have pointed out, is disappearing. In its stead, an industrial régime has come, an order of society in which co-operation has, in a measure, replaced autocratic rule. In the new order, wealth has piled as never before; there is a portion for the non-productive class large enough to support a vast army of investigators spread now throughout the world.

This is the reason that the conquests of the scientific method are no longer checked. It is not that the forces of ignorance have disappeared, not that the Church is less militant; it is that they have a balancing power to fight. This, and this alone, is the reason that we are not burning Brunos and threatening torture on Galileos now!

There was another subtle but contributing cause at work in the old days; it lay in the attitude of scientific men themselves. That was a disregard, a contempt, for practical things. Let us slip a page 
from old Plutarch, companion of all youth. He is speaking of the great fleet of galleys that Marcellus brought against Syracuse, and he says:

"But Archimedes despised all this, and confided in the superiority of his engines, though he did not think the inventing of them an object worthy of his serious studies, but reckoned them among the amusements of geometry. Nor had he gone so far but at the pressing instance of King Hiero, who entreated him to turn his art from abstracted notions to matters of sense, and to make his reasonings more intelligent to the generality of mankind, applying them to the uses of common life.

"The first that turned their thoughts to mechanics, a branch of knowledge which came afterwards to be so much admired, were Eudoxus and Archytas, who thus gave a variety and an agreeable turn to geometry, and confirmed certain problems by sensible experiments and by the use of instruments, which could not be demonstrated by way of theorem. But when Plato inveighed against them, with great indignation, as corrupting and debasing the excellence of geometry, by making her descend from incorporeal and intellectual to corporeal and sensible things, and obliging her to make use of matter, which requires much manual labor and is the object of servile trades, then mechanics were separated from geometry, and, being a long time despised by the philosopher, were considered as a branch of the military art." ${ }^{1}$

Compare this contemptuous sentimentality with the sturdy spirit of Lord Kelvin, who has made a fortune from his patents in cable telegraphy and in

'Plutarch's Lives, Langhorne trans., art. "Marcellus." 
instruments of navigation; with that of Pasteur, who turned aside from his studies to spend laborious years in stamping out the cattle-plague and hog-cholera and the vine-disease and the silkworm disease, and added millions to the wealth of his beloved France; with that of Professor Berthelot, who quits his laboratory to run an experimental farm on the borders of Paris, and has published volume after volume on scientific agriculture; with that of the excellent secretary of our Smithsonian Institution at Washington, Professor S. P. Langley, who, in his early career, finding no money forthcoming for his laboratory, invents the electric time system for railways, and with the proceeds equips his laboratory himself; with that of the late Professor Tyndall, who devoted a part of the gains from his lectures in the United States to the founding here of scholarships; with that of Professor Walther Nernst, the eminent director of the physico-chemical institute at Goottingen, who is reputed to have made a million from the sale of his patents in the Nernst electric lamp; with that of Professor Michel I. Pupin, of Columbia University, who derived a large sum from his inventions in submarine telegraphy and trans-oceanic telephoning; with that of Professor Behring, of Marburg, who gains a fortune from the sale of his diphtheria antitoxin, and with it founds a great institution for experimental medi- 
cine like to the Pasteur Institute in Paris. The times have changed.

But it was a rueful day for human progress and human freedom when the intellectual leader in the most cultured nation upon the earth could thus throw his influence to block the spread of the scientific method among the people. I set down the silly, supercilious attitude of Plato as likely to have been fraught with more of evil for the next succeeding thousand years of history than that of any Christian bishop.

Thankfully, that day is passed. No Plato's sneer, no threats of rack and stake, may now turn away men's minds from the investigation and the conquest of nature. There is a new order and a new thought. And to-day mechanics is the foundation upon which the whole superstructure of science rests. Men are striving now to explain the phenomena of mind in terms of physiology; we have what is called the physiological psychology. In turn, we endeavor to represent the physiological functions, the phenomena of life, in terms of chemistry ; the whole trend of biology is now oriented that way. Bio-chemistry is the study of the hour. In its turn again, chemical actions, the so-called chemical affinities, are being reduced to measures of electricity and heat, and simple gravitational attraction; we have the new physical chemistry, or what 
the French prefer to call mécanique chimique chemical mechanics. And, finally, the whole domain of physics-electricity, heat, light, magnetism-is coming under the bondage of one or two mechanical conceptions, a mechanics of the ether, or a mechanics of ultimate particles, the corpuscles, ${ }^{1}$ which are both matter and electricity at once. Perhaps eventually it will come to a compromise between the two. Either way, mechanics reigns. Mechanical conceptions are everywhere. "The stone which the builders rejected is become the head of the corner."

The end and aim of all scientific endeavor is to describe natural phenomena, including all visible and invisible things-matter, life, and mind-by simple mechanical laws, expressible in simple mathematical equations. We are yet very far from this - several hundred years, perhaps. A mathematical formula is as rare in a work on physiology to-day as it was in a work on physics a hundred years ago. In the stuff that passes for psychology it is not to be found at all.

But no one who has once gained a clear historical perspective may doubt the final result. Physical science will not stop short of a reduction of the universe and all it contains to the basis of me-

${ }^{1}$ See "The Explanation of Electricity," p. I $^{1}$; and "The Search for Primal Matter," p. 145. 
chanics; in more concrete terms, to the working of a machine.

Meanwhile the scientific spirit will penetrate yet deeper. The same methods which have taken from us the childish and fantastic notions of our ancestors, and brought in their stead clear and rational conceptions of this world, will help us further. They will make possible the scientific organization of industry, of politics, of morals-in brief, of the whole scheme of our daily lives.

In one great field the conquest is already complete. We may now change the tense of Tyndall's famous phrase and say: "Science has claimed, and it has wrested from theology, the entire domain of cosmological theory." There is not an intelligent man on the whole wide earth who longer believes that the Mosaic account of creation is true, or that the world was created in the year 4004 B.C., or that the sun stood still on Gibeon. We are past all that. This is something.

The scientific organization of industry, illustrated in the great trusts, is going on under our eyes. It should give no alarm. When the work is complete, public utility will necessitate governmental control, and from this to the complete unification of the whole machinery of production and distribution will be but a step. With this will come, too, the disappearance of the leisure and parasitic class gen- 
erally. The invidious distinctions of wealth, with their attendant vulgarity and their inevitably debasing influence, will disappear. Under a rational régime, men and women will satisfy their natural instinct for activity and work, while they will have ample time for that recreation and change which alone make life agreeable or supportable. Ostentatious riches and depressing poverty, greed and want, crime and prostitution, will cease to exist, and with it the physical and moral maiming and stunting of the children of the poor.

This alone will permit of more of genuine progress in a century than in three millenniums before. The general conditions of society have changed but little within a long time. For the more obvious form of chattel slavery we have substituted another of practically the same effect. And now, as in the antique days, the lower classes are the breeders. If the propagation of the race were left to the cultured and intelligent the race would die out, because, in general, the cultured and intelligent have few children, or none. With the present death rate, from four to five children per family are required to maintain the population. As the wellto-do classes have rarely more than one, two, or three, it is easy to see that the bulk is recruited from below. Families which struggle up from an inferior place to a higher level tend steadily to 
become infertile, like the nobility in monarchical countries. There is, then, a sort of a breeding level, and that level is low. Undoubtedly it is this which explains why it is that ten thousand years of history disclose so little improvement, so little real change.

With better industrial arrangements these conditions should disappear, and with them much else. We shall have - we are gaining slowly - a new criminology, more humane, and at the same time, possibly, more rigorous. The Hebraic scheme will be banished; we shall not punish, but we may not spare. The deformed, the defective, and diseased must be incessantly weeded out. Doubtless, too, present marriage relations will be greatly altered, for their present basis, the support of the woman and her offspring, will have ceased to be a necessary consideration.

Finally, we shall have a healthier morality. I quote an admirable passage from Professor Loeb's recent volume:

"The analysis of the instincts, from a purely physiological point of view, will ultimately furnish the data for a scientific ethics. Human happiness is based upon the possibility of a natural and harmonious satisfaction of the instincts. One of the most important of the instincts is not usually recognized as such-namely, the instinct of workmanship. Lawyers, criminologists, and philosophers frequently imagine that it is only want that makes man work. 
This is an erroneous view. We are instinctively forced to be active in the same way as ants or bees. The instinct of workmanship would be the greatest source of happiness if it were not for the fact that our present social and economic organization allows only a few to satisfy this instinct." 1

\section{And he adds, in a foot-note:}

"It is rather remarkable that we should still be under the influence of an ethics which considers the human instincts in themselves low and their gratification vicious. That such an ethics must have had a comforting effect upon the Orientals, whose instincts were inhibited or warped through the combined effects of an enervating climate, despotism, and miserable economic conditions, is intelligible, and it is perhaps due to a continuation of the unsatisfactory economic conditions that this ethics still prevails to some extent."

In some such wise one may vaguely conceive the society of the future. Is it afar off? No doubt. Is it but a chimera? I do not find it so. Probably its realization will be slow, and it will not be forwarded by hysteria.

But the foundations have been laid; and they are firm. The achievements of the last three hundred years are secure. We shall never more go backward. If the light of science die out from one land, it will be kept burning in another, for it extends now throughout all the earth. The slender band

${ }^{1}$ Comparative Physiology of the Brain, and Comparative Psy. chology. 
that bore it through the days of Athens and Alexandria has become an army. The Age of Darkness-the days when cannibals of holy mien had power hideously to torture, fiendishly to burn some of the noblest intellects that ever existed - will never return.

Modern progress, planted firmly upon machinery, upon the steam-engine, the steam-ship, the dynamo, the telegraph, the printing-press, and all manner of mechanical contrivances, will suffer no serious check. These priceless inventions, while adding infinitely to the variety and interest of life and lessening the hours of human toil, have bred a larger humanity and higher aims. Bringing a new industrial order, they have served to banish the distinctions of class, to make labor noble, to break down the barriers between nations, to extinguish * race hatreds, to abolish creeds, to bring together, in conscious solidarity, all the peoples of all lands.

These inventions, these discoveries, are the offspring of the scientific spirit; they form to-day a bulwark for its defence. To add to their number, or to the number of their applications, is the highest good towards which any man may strive. Shall we soon forget the glowing pages of Buckle, wherein this truth found such impassioned expression:

"The actions of bad men produce only temporary evil; the actions of good men only temporary good; and event- 


\section{NEW CONCEPTIONS IN SCIENCE}

ually the good and the evil altogether subside, are neutralized by subsequent generations, absorbed by the incessant movement of future ages. But the discoveries of great men never leave us; they are immortal, they contain those eternal truths which survive the shock of empires, outlive the struggles of rival creeds, and witness the decay of successive religions. All these have their different measures and their different standards; one set of opinions for one age, another set for another. The discoveries of genius alone remain; it is to them that we owe all that we now have; they are for all ages and all times; they are essentially cumulative, and giving birth to the additions which they subsequently receive, they thus influence the most distant posterity, and after the lapse of centuries produce more effect than at the moment of their promulgation." 1

Not, then, to the Cæsars and Alexanders; not to the bandits and plunderers who have reddened history; neither to the dreaming messiahs whose hallucinations have filled men's minds with empty fancies-not to these should rise our pantheons; but rather to those who, in the pursuit of science and of truth, have added to the intellectual wealth of mankind.

For they are the true gods, the real gods. Eos salutemus, et secuti laboremus!

${ }^{1}$ Buckle, History of Civilization, vol. i. 
THE WORLD BEYOND OUR SENSES 
When Kirchhoff thrust between the image of the sun from the heliostat and the tinted band of his spectroscope, a flame of sodium vapor, and, instead of the expected brightening, saw the band darkened, he left his laboratory hastily with the words: "That seems to me a fundamental fact." He had demonstrated that in the atmosphere of the distant sun, vapor of sodium was present; he had established a relation between this far-away star and the Fraunhofer lines.

WIENER, Die Erwciterung unscrer Sinne.

The domain of the senses, in nature, is almost infinitely small in comparison with the vast region accessible to thought which lies beyond them. From a few observations of a comet, when it comes within the range of his telescope, an astronomer can calculate its path in regions which no telescope can reach; and in like manner, by means of data furnished in the narrow world of the senses, we make ourselves at home in other and wider worlds, which are traversed by the intellect alone.

Tyndall, On Radiant Heat. 


\section{THE WORLD BEYOND OUR SENSES}

ThE world wherein lives Helen Keller would seem to us, translated there, singular enough. In her world floats no sound; the rustle of the forest, the roar of the cataract, the harmonies of Wagner, the magic of the spoken word enlist no thrill. Dawn and dusk, days and seasons are alike. The glory of the summer, the bourgeoning of the spring, the colors of October are known to her only through dim changes in the warmth of her skin. The places of the earth are all the same, the desert or the crowded Strand. Bagdad and the Yosemite differ for her only in their smell. Save for the reports of those around her, of the living world she knows little and could learn little more.

And we, dowered with the seeing eye and the listening ear, have pity for this stricken girl. Slightly we realize that in some sense we are all Helen Kellers, and that ours, too, is a Helen Keller world. Suppose, by some magic, our eyes might be opened so that we could see the filmy waves of light which reflect for us the landscape and the morning sky, 
the waves of sound which bear to us the carolling of the lark; suppose that in the dancing air we could see the myriad particles wildly chasing one another at a speed of nearly half a mile a second; that in the lump of sugar or grain of salt we could watch the twirly-whirly Sir Roger de Coverley of the atoms, partners skipping gayly one to the other like as on a ballroom floor; suppose we could watch the twinge of pain, the thrill of joy as it travels along the nerves, that we could see the "lines-of-force" which circle round a magnet and generate electricity in a dynamo; suppose that beyond the deepest red, or the faintest violet, all the colors of the spectrum might be opened to our view-would not such a world seem as weird to us as would our visible world, could Helen Keller's sightless eyes be touched to the light of day?

It is from our eyes that we learn most concerning the things about us. Were it not for them, the images we make of objects and events would be confused and crude enough. Beside our other senses, marvellous they seem. They measure and compare every little dot and stroke and turn on this printed page, so hopelessly bewildering to the untaught; and, alike, the gleam of a star, distant, it may be hundreds of thousands of millions of miles.

Yet beyond all that the eye may see, that ear may hear, that hands may feel, outside of taste or 
smell, outside of any native sense, there lies an unseen, unheard, unfelt universe, whose fringe we are just beginning to explore.

A flash, so to speak, from this supra-sensual world came with the discovery of the Röntgen rays. It is now eight years since we first learned that we may look straight into our bodies and see our bones, and that in this light even great books of philosophy become quite clear - transparent even; and the wonder has a little died. But they are still called $\mathrm{X}$-rays, for we still do not know what they are or where they belong.

What is tolerably sure is that there is a wide gap between the Röntgen light and common light, and the gap seems to lie far above the shortest little light-waves hitherto known. It is in the form of minute waves, more than microscopic undulations in the all-pervading ether of space, that physicists nowadays conceive light. And it is a difference in wave-length, merely, that makes what we call color. The red and the orange are long waves, not more than from 33,000 to 40,000 to a linear inch; the indigo and violet waves are only about half as long-from 50,000 to 60,000 per inch. In between are the yellow, green, blue, and all their insensible gradations.

It was Sir Isaac Newton's first notable discovery that white light is a compound of all the others, 
and that a sunbeam may be broken up into its component colors by means of an ordinary threecornered prism. A three-cornered glass of water or other liquid does much the same, and that is exactly what the rain-drops do when the sun strikes them right. The colored image produced by the prism is an artificial rainbow. Old Sir Isaac called it a spectrum, and the name has held. It is the same as our word spectre-an apparition.

Curious-minded men were not long in finding out that beyond either end of the visible spectrum curious things go on. For example, if a thermometer be held below the red end of this artificial rainbow, in the infra-red, as it is called, it gets hot, although there is not much heat in the visible part of the spectrum. The quite unbearable heat you get with a burning-glass is due to these invisible heatrays, and not to the light at all. So, again, it is possible to split up a sunbeam with a prism, and then focus only the invisible infra-red part of the spectrum, and get almost as much heat as though you had focussed the entire body of the light.

Of course if our eyes were sensitive to these invisible " heat-rays," as they are to the "light-rays," we could "see" with heat just as well as with light. Indeed, we can conceive of a race of men fitted with eyes sensible to the heat-rays, and only to them. To such a race our day would be bright as to us, 
THE WORLD BEYOND OUR SENSES

for in the sunlight are both light and heat rays; but they might also sit and read in a room with a warm stove that to us would be pitch dark. Their windows might be made of thin plates of hard rubber, to us entirely opaque, and they might look at the sun and the moon through telescopes with lenses made of the same material. Theirs would be a world beyond our senses.

So, too, with the other end of the spectrum, the beyond-the-violet end. When Daguerre and others found that upon certain delicate salts, like nitrate of silver, light has a chemical action, they opened the way for an exploration of the ultra-violet. For it did not take long to find out that here again it was a question of invisible forces. A large part of the waves which affect a photographic plate does not affect the eye at all. So it is possible, by means of a prism and a little screen, to stop-out all the visible part of the spectrum, and still take photographs just as usual. There are the so-called actinic or chemical rays, and in a chemist's hands they are capable of a variety of actions. Had they been known two or three centuries ago, men would surely have thought they had found the philosopher's stone, for these rays will turn one kind of phosphorus into another and quite different kind; they will produce violent explosions, and make substances conduct electricity which otherwise do not. 


\section{NEW CONCEPTIONS IN SCIENCE}

The rays of the ultra-violet seem to have healing powers, for under their influence cancers may disappear and other skin diseases be similarly treated. Their rôle in nature, too, is most vital, for it is these rays which in the green leaves of the plant turn carbonic acid and water into sugars and starches - the first of these conversions of the inert materials of the air and the soil into food, the first step towards the organization of life.

These ultra-violet rays go through many substances impervious to visible light, so that if we had a race of men with eyes attuned to these rays they, too, might live in rooms black as ink to us. In some sense theirs, too, would be another world than ours.

Has any one the notion that while these suprasensual domains may exist, after all, they do not amount to much? Let him construct for himself a scale, that he may have a clear idea of precisely how much his chief and most highly developed sense, the sense of sight, really takes in.

Waves of light are measured in millionths of a millimetre-that is, in units of about one-twentyfive-millionth of an inch. They are called micromicrons, and written with the two Greek letters $\mu \mu$, for short. One $\mu \mu$ bears the same relationship to an inch as does an inch to fifteen miles.

The largest red rays visible measure about 8 1 $о \mu \mu$, and the shortest visible violet rays are about $380 \mu \mu$ 


\section{THE WORLD BEYOND OUR SENSES}

- that is, about one-half as long as the red. It is not possible as yet to go very far into the ultraviolet; when it is we shall get very close to the ultimate structure of matter. But even now it is possible to detect invisible rays that have only a quarter the length of the shortest visible raythat is, about $100 \mu \mu$.

Far out in the spaces beyond this beyond-theviolet, in regions yet unexplored, lie probably the Röntgen rays and yet others of which experiment may disclose the effect even though it may not as yet apprehend them directly. Far beyond the confines of what we call matter, there seem to be minute particles, the tiny grains of which the relatively huge atoms of matter are made. These particles are thrown off from all highly heated or highly electrified bodies, such as the sun, the electric light, etc. They are the absurdly misnamed cathode "rays" which Sir William Crookes, and latterly Professor J. J. Thomson, of Cambridge, in England, have studied so deeply. These, bombarding space and all it holds with terrific speed (fifty to a hundred thousand miles per second), give rise to all sorts of perturbations of the ether, and of these the $\mathrm{X}$-rays are one. The cathode rays are made to impinge upon certain chemical substances, and through this impact we have that peculiar fluorescence which shows through solid things. No 
means has yet been found to measure the wavelength of this new kind of light.

Beyond the other end of the spectrum the measuring hand has gone much farther. The longest light-wave is but 810 micro-microns; the longest heat-wave is 70,000 . Here are the materials for a scale. This will give you an idea of the compass of the rays upon which we depend for the most of our knowledge of things outside us:
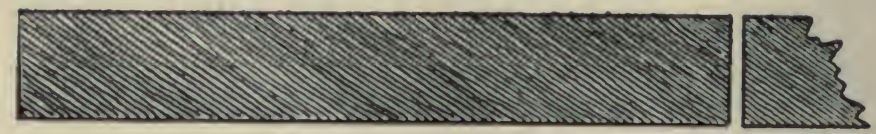

a

The visible part of the spectrum is shown by the unshaded space, $a$-all the rest is invisıble, and known to us only by mechanical means.

It is only through the little gap marked $a$ that we get a glimpse of the real world. In order that we might make use of all this wide range of etherwaves, it would be needful that we have a temperature sense as acute as our sense of sight, and eyes as sensitive as a photographer's plate. We have neither. A comparison may help to make this clearer. The naked eye, in clear skies, might count in all the heavens perhaps two to four thousand stars; the number would vary greatly with individuals and climes. Aided by the finest telescopes, this number rises to tens of hundreds of 48 
THE WORLD BEYOND OUR SENSES

thousands. Calling in the mechanical aid of the photographic plate, an international star - map is now being made which will definitely locate the position of twenty to thirty million suns. That is the difference between the eye and the camera. In some part, these twenty-odd million stars are fixed by means of the invisible rays of the ultra-violet, to which the eye is wholly insensible.

Again, it is with difficulty that we realize a change in temperature until that change amounts to several degrees on the thermometer. In order to detect and map the invisible rays of heat, the infrared rays, it was needful to construct instruments about one million times as sensitive. The most delicate of these devices is the bolometer, which was the invention of Professor S. P. Langley, secretary of the Smithsonian Institution at Washington. It will accurately register a change in temperature of one-millionth of a degree centigrade. It will register the heat of a candle a mile and a half distant.

Lest any one surmise that there is some guesswork about this, it may be noted that there are several heat measurers, of almost equal sensibility, whose results accord perfectly with Professor Langley's extraordinary machine.

From the longest heat-rays, measuring $70,000 \mu \mu$, to the shortest known rays of the ultra-violet, but roo $\mu \mu$ in length, we have an unbroken series of 
ether-waves. This series covers the first faint tremblings sent out, let us say, by a bar of iron that we have begun to raise in temperature, up through the red glow which first makes the bar visible in the dark, to the dazzling light it sends forth when it has become white-hot. What we call light and heat, then, are but purely personal, or subjective, sensations, aroused by the same medium, and differing only in the rapidity of motion in this medium.

Have we reached nature's limits, or may we farther go? At the moment exploration of the ultra-violet seems blocked, but at the opposite end subtle experiment is reaching out to link yet another great field of science to this long chain. That is the field-one might almost say empire-of electricity. I have elsewhere ${ }^{1}$ given account of recent endeavors to ascribe electrical phenomena to the movement of extremely minute particles of matter, a thousandfold smaller than the smallest atom known, called corpuscles, or electrons. However this may turn out, it is certain that some forms of electricity and heat and light are very close of kin, apparently merely varieties of ether-motion.

This identity was predicted by Clerk-Maxwell in a purely mathematical calculation more than forty years ago, long before any experimental evidence

${ }^{1}$ See "Progress towards an Explanation of Electricity," p. г 3 r. 


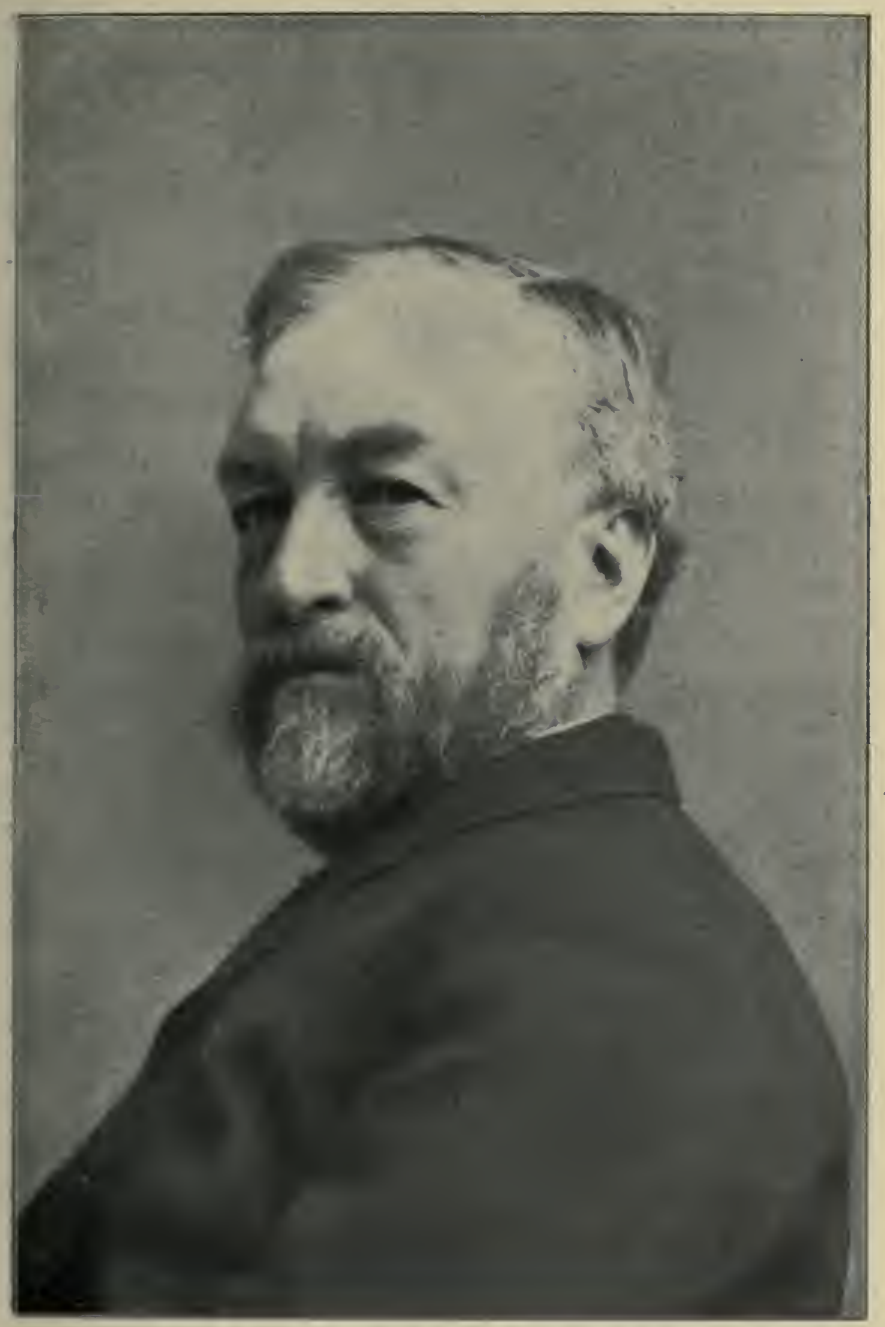

PROFESSOK SAMLEL PIERREPONT LANGLEV

Serretary of the Smithsonian Institution at Washington, inventor of the bolometer. 

existed. Its verification, in the hands of Heinrich Hertz, a quarter of a century after, was the strongest support the ether-wave theory has yet received.

If Maxwell's ideas were sound, a discharge of electricity across a gap would set up vibrations in the ether round about, just as a stone dropped in a pond will set up waves that go travelling outward in every direction. And Hertz found that this is exactly what happens. It was this discovery which made wireless telegraphy possible. These ethervibrations are called, in honor of their discoverer, Hertz-waves.

Hertz found that his electric-waves measured about one hundred and fifty feet from node to node - that is, from the top of one wave to the top of the next. The waves used by Marconi, in telegraphing across the Atlantic, are considerably longer than this-six hundred feet or more. These waves travel at the same speed as light-that is, at the incredible rate of 184,000 miles per second. Apparently they go straight through walls and mountains, and are only arrested by metal. Hence the employment of a net-work of metal wires at the receiving-stations in wireless telegraphy.

From an electric-wave one hundred and fifty feet long to a light-wave measuring a few millionths of an inch is a far cry. The gap is wide. Nevertheless, the scientific imagination bridged that gap 
and accepted Hertz's discovery as proof of the identity of the two. Since then the Calcutta physicist, Jagadis Chunder Bose, who was the first to send a signal by wireless telegraphy, has succeeded in producing electric-waves but two or three millimetres (about a tenth of an inch) long. The waves sent out by these delicate little machines are much nearer to the longest heat-rays than to the longest electric-waves. The actual gap is only from three millimetres to seventy micro-millimetres. Filling this gap is really a mere mechanical detail.

Thus is one great chapter in the physical account of this world practically complete.

Need it be added that as for the longer waves of heat our senses grow dim and uncertain, for the electric-waves we have no sense at all. They lie outside our sensual world, and until science had devised new senses, as it were, we had not so much as a suspicion of their existence. Suppose that we could be dowered with such an electric sense. The spark-gap of the oscillator, or sender, answers to a source of light, the receiver to a mechanical eye. If, like this mechanical eye, our eyes were sensitive to these electrical waves, then we might watch the progress of a play in Buenos Ayres or have witnessed the struggles at Peking. Of what we might learn of the unseen world about us only years of patient and toilsome research will afford us so much as a hint. 
Shut out from our apprehension of what is going on around us by all but a narrow peep-hole, as it were, we find, as we turn, that we are equally limited in every other direction. Particularly notable is this when we consider the phenomena due to that especial mode of motion we call heat.

Water at freezing gives us the sensation of intense cold; at boiling, of intense warmth. To measure the gradation of warmth, or cold, between, we find a substance which expands evenly, like mercury, and, taking a tube, mark the point at which the mercury stands when placed in freezing water as zero, and the point to which it rises in boiling water as roo degrees. We have then the centigrade, or "hundred degree," scale. This scale is in universal use throughout the world, save in two backward countries called England and the United States. Within the limits of the centigrade scale by far the greater part of terrestrial events take place. For example, above or below this scale, life, in any active sense, is impossible. But artificial resources enable us to go far below the freezing-point of water, and the gas-flame, the grate fire, or the electric arc supply temperatures far above boiling. And we know that space is far colder, and the interior of the sun far hotter, than anything we can attain here.

Under sufficient pressure, when we reach about 
r 40 degrees below zero, centigrade scale, the impalpable air we breathe becomes a liquid; a little lower, it turns to snow-it is solid air. At yet colder cold, or at about 240 degrees below, the lightest and most volatile of known substances, the gas hydrogen, likewise turns to a liquid, and a few degrees lower still to a solid.

The temperature of space is thirteen to fifteen degrees lower still. Of course, it can only be calculated, for there seems no human means of attaining it. Various methods indicate space temperature at -273 degrees centigrade $(-460$ degrees Fahrenheit). This is what present-day science regards as "absolute zero," the coldest cold, the point at which all motion of the atoms has ceased. But this may be a delusion; there may be no such point.

Measured, then, from the temperature which this populous earth will one day, dead and lifeless, attain, our little living world lies within the narrow limits of about 280 degrees to $35^{\circ}$ degrees of the "absolute" scale. When we turn to known temperatures above this, we find a far greater reach. The interior of a good grate fire reaches several hundred degrees above boiling water; a gas-flame to 600 or 700 degrees centigrade. The "lime-light" used in the theatres and magic-lantern shows reaches 2200 degrees or 2500 degrees centigrade, 
THE WORLD BEYOND OUR SENSES

while the centre of the electric-light arc is generally estimated at 3000 degrees or even 3500 degrees; these latter measurements cannot be very precise.

By the same methods, the temperature of the interior of the sun has been computed at 6000 degrees centigrade, though the figure may be much higher-10,000 degrees even; nobody knows. The estimate for 6000 degrees has some degree of probability, and it is fairly certain that the temperature of the sun is not much lower. This is 6000 centigrade degrees above freezing water; and what is called "absolute zero" is 273 centigrade degrees below this point.

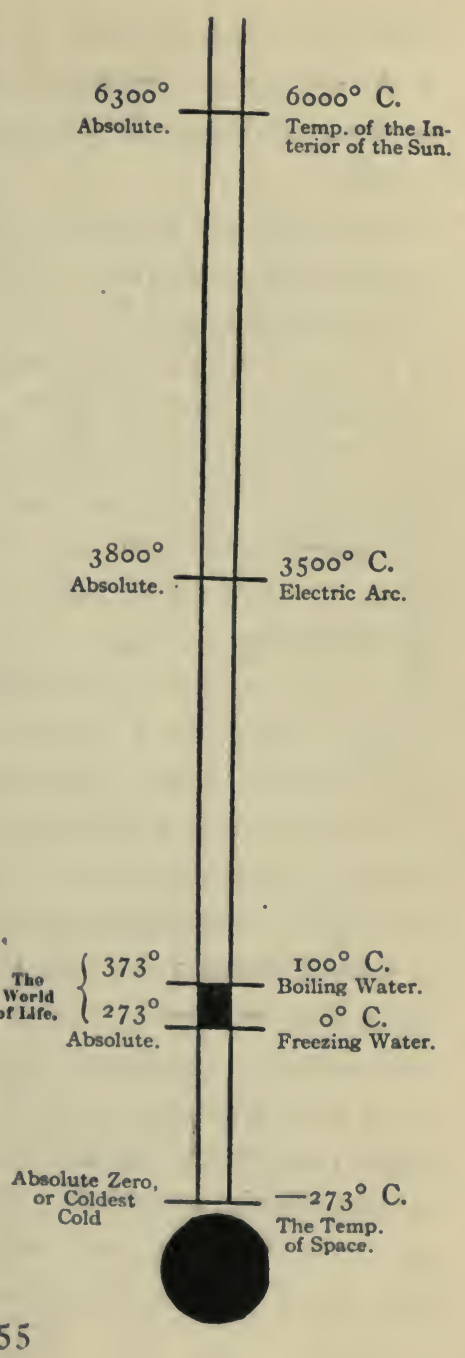


From the coldest cold to the intensest heat, then, is about 6300 centigrade degrees. The diagram on the page preceding shows where we live in such a scale.

So dominant a factor is heat in the universe, as we know it, that not merely life, but all physical phenomena, might be described as a heat reaction. It is heat which determines the point at which all chemical change shall take place, and therefore the whole march of life as well. It is heat, and heat alone, which converts the acorn into the oak, the inert egg into the chicken, that turns the barren earth to living green in the spring, that stirs the lifeless air to breeze or tempest, that lifts the surface of the water into the sky, and brings cloud and rain to the earth it has parched. It is merely failing heat that turns the woods to November brown and drear December; change and seasons are its work.

Could we exist in extreme cold or extreme heat, it would seem to us as if our familiar world had been turned upside down. In the regions of coldest cold, all chemical action would cease; dynamite could scarce by any power be made to explode; sulphuric acid, if it had not long before been frozen solid, would be mild as water; we might wash our hands in it; the vitriol-throwers would be without weapons. Long before this, as we descend- 
THE WORLD BEYOND OUR SENSES

ed in the scale, we should find liquids, like liquid air, which would boil violently in a trough of solid ice; mercury - our slippery, unstable mercurywould be so hard it might be used for a trip-hammer; bodies of every sort would acquire an astonishing elasticity, so that a bullet or a billiardball dropped upon a hard surface would rebound as if it were india-rubber.

In a recent address, Professor Dewar, of the Royal Institution in London, pictured the aspect of the earth could it be cooled to - 200 degrees centigrade (as no doubt it will in time). First we should have solid oceans of ice, and, covering these, the atmosphere would condense to an ocean of liquid air, covering the entire earth's surface thirty-five feet deep. It would mean an unending winter, three times more intense than the bitter cold of the poles.

In such a world, matter would take on properties that seem to us rare and curious now. For one thing, most substances would be phosphorescentor, better still, luminescent-and glow at night, after being illumined in the day, with many-colored lights. Milk, solid of course, would send out pale-blue rays; eggs would shine like globes of light, and the white of the egg, in particular, when properly treated, would give out enough light to read the newspaper. There would be no need of lamps, for the walls and 
ceilings might be covered with luminescent substances, so as to make them bright as day.

Outside, the nights would seem hardly less strange. The atmosphere would be composed chiefly of hydrogen and other light gases-argon, krypton, neon, helium, and others-whose infinitesimal presence in the air we breathe has only recently been detected. Could we step out into such an air, we should have a strange feeling, it would offer so little resistance. And as the brilliant auroras, or northern lights, seem to be associated with the presence of large quantities of hydrogen in the upper strata of the atmosphere, it is not improbable that in this land of coldest cold the heavens would be almost constantly aglow with these beautiful apparitions.

In such a cold it would be almost impossible to take a photograph, for at the temperature of liquid air light loses eighty per cent. of its chemical power. The forces of cohesion are enormously augmented, so that most substances would become as hard almost as quartz or diamond. And they would be proportionally strong. A slender thread of wire, scarce able to bear more than a few ounces at ordinary temperatures, would sustain the weight of a couple of pounds. A stout wire, able now to support some pounds, will, when dipped in liquid air, hold up a ton. 
So, too, we might make magnets out of the oxygen of the air, then solid like ice, and it is possible that could helium and other of the newly discovered gases be likewise solidified, we should have substances so transparent to the light that they could not be seen.

Incidentally it may be noted that these extremes of cold have given new weapons alike to the chemist and the physicist. With solid air, and still more with solid hydrogen, it is possible to produce almost instantly the highest vacuum attainable by mechanical means. A tube, exhausted with an ordinary air-pump and subjected to this degree of cold, condenses the remaining air or gas to a solid, leaving a vacuum of scarce one-millionth of an atmosphere. Through such an emptiness, sound, which is the vibration of the air, cannot penetrate, and through it a current of electricity, always bound up, so it seems, with an actual transport of matter, can be forced only with extraordinary efforts. There is so little "matter" left, even of tenuous gas, that a minute gap is an almost perfect insulator.

On the other hand, the metals, at these low stages, lose almost entirely their resistance to the passage of electricity, and become almost perfect conductors. In other words, it seems as if electrical resistance was due solely to the mechanical vibra- 
tions we call heat. So, too, spectrum analysis, the investigation of the properties of substances by means of light passed through a prism, has received a powerful aid, and it has been possible to isolate and analyze several new elements which had previously baffled inquiry.

Such are the fruits of the last ten years; for into this world of cold beyond our senses we have but just set foot.

Were we to turn about, and from regions of utter cold seek those of extremest heat, it would be an equally topsy-turvy world we should enter. Nothing seems more certain in our every-day life than that if things get hot enough they will burnthat is to say, combine with oxygen and sublimate in smoke or invisible gas. But at the temperature of the electric arc coal, even, does not burn. It becomes incandescent, and disappears slowly in invisible vapor; but it does not unite with oxygen ; this most familiar of chemical reactions refuses to take place. Even the compound carbonic acid, formed in the burning of coal, or in the body and given off by the lungs, is dissociated, the atoms torn apart by the fierce heat, and made to repel rather than attract.

The flame of the electric arc is the extreme of heat, as yet known. At this temperature, about 
3500 degrees hotter than boiling water, and about twice as hot as iron at a white glow, almost all the familiar reactions, alike of nature, the laboratory, or the furnace, are simply reversed.

Raised to this point, the moving seas would, of course, be vaporized, and more - the very atoms of vapor would be split in twain, and exist as free hydrogen and free oxygen. These two gases, at ordinary temperatures, combine with explosive energy. Burned in the oxy-hydrogen lime-light, they produce almost the intensest heat known outside the arc. A mixture of the two, exploded with an electric spark, detonates with a roar like dynamite. At 3500 degrees centigrade, they are inert; they cannot be made to combine.

Water, turned to steam at ordinary atmospheric pressure, occupies about one thousand seven hundred times its volume in the liquid state; and the vapor at 3500 degrees centigrade would have ten times the volume it possesses at the point of conversion-i.e., 100 degrees centigrade. Counting that oceans and arctic ice cover the earth to an average depth of between one and two miles, such heat would roll upward a mass of incandescent gas, glowing like the sun, almost, and covering the earth with a blanket thousands of miles thick.

Swept by such a blast, every trace of the agency of living things would disappear in smoke; every- 
NEW CONCEPTIONS IN SCIENCE

thing of metal-our great steel buildings, bridges, steamships - would melt and run like wax; the whole crust of the earth would shrivel, and in part return to the atmosphere as heated gas. Observers on another planet would behold a new star flash in their skies, which would appear to them more than double the present size of the earth.

It hardly need be said that at this temperature practically every known compound would be decomposed into its elemental atoms. There is, as yet, no evidence that the atoms themselves can be sundered in the arc. Of these primal atoms, there are some eighty odd forms, the so-called "elements" of the chemist; and these, variously compounded, make up all earthly things, our bodies, brains, and souls included. These elementary substances must have come into existence before the earth had ceased to be a fire-mist.

But when we rise to the temperature of the sun, 6000 degrees centigrade, at least, and possibly far higher, we should enter a far stranger world. There, it seems likely, the atoms have been reduced to a few primitive varieties; there, probably, but one state of matter is known-the gaseous. It is not likely that even the colossal pressures induced by the vast bulk of the sun are sufficient to liquefy gases at such fierce heat. 


\section{THE WORLD BEYOND OUR SENSES}

Could we, by some magic, exist corporeally in realms like this, we should probably find it a singularly uninteresting world. Four-fifths of the variety and interest of life we get via our eyes, and in a world of fire-mist there would be nothing to see, nothing solid whereon to stand, no difference as we turned right or left, no change anywhere. It would be much the same sensation, perhaps, as that which comes when you are shut in by a London fog.

Could our senses reach out to the stars, we should, no doubt, find other suns hotter still. Our sun is a little yellowish, and there are others, like Orion, which give a reddish light, while great Sirius, vaster far in bulk than our sun, glows with an intense and brilliant white. Red, yellow, and white stand, in the heating of metals - iron, for example - for increasing degrees of heat. This has suggested the idea that Orion and its like are rather cooler, Sirius and its like far hotter, than our luminary. The breaking-up of most chemical compounds by heating has suggested, too, that if the "elements" are really decomposable in the hotter stars, we should find fewer of them. This is just what happens.

In the spectrum, every "element" gives a perfectly distinct set of "lines," or bands, so that the spectroscopist may take any substance, and, heat- 
ing it to incandescence, know from the characteristic lines exactly what elements it contains. Using this means of identification, we find in the sun many of our terrestrial elements, while many more are lacking. Assuming that the course of nature does not vary throughout the known universe, the inference is that in the sun many "elements" have been decomposed.

In the white stars, like Sirius, the simplification seems to have gone much further. Very few of our elements may be identified in the spectrum they give. There are some stars that appear to be made up chiefly of hydrogen, the simplest and lightest element known. This has led to the conjecture that at a sufficiently high temperature all the elements would be broken up, and that we should have a single primal form of matter. Our "elements," then, in this view, represent merely the condensation and combination, in various ways, of this primal matter. In another essay, ${ }^{1} \mathrm{I}$ have recounted the efforts of Professor J. J. Thomson and others to find out just what this primal matter may be.

Sir Norman Lockyer and others have endeavored to give this fascinating hypothesis of Atomic Evolution a solid support. The experimental evi-

'See "The Search for Primal Matter," p. 145 . 
THE WORLD BEYOND OUR SENSES

dence thus far offered, however, has not seemed convincing. Scientific men, therefore, find themselves in the curious position of believing that such an evolution of the elements has taken place, and no doubt is still going on in distant suns, while they doubt the sufficiency of the evidencerthat has thus far been put forward as a demonstration.

The spectroscope has afforded a yet further dip into the world beyond our senses. That is, in the detection of dark suns, invisible through even the finest telescopes. A very early discovery in the history of the instrument was that if the source of light in spectral analysis is moving towards or receding from the prism, the characteristic lines of the spectrum shift slightly, up or down. By means of this curious circumstance, it has been possible to calculate the speed of some of the stars, and to know whether they are running away from or approaching our solar system. Even their orbits have been mapped, and this, too, has led to the recognition of many new double-stars, suns which are revolving about one another, and appear sometimes as one, sometimes as two. In some cases, the twin-star never appears, but the form of the orbit is so clearly defined as to make it certain that a twin exists.

In brief, it has been possible to detect, locate, 
map, measure, and even weigh vast objects that affect no human sense. Of all the triumphs of the scientific method, there is none more striking.

It is clear from all this that, even if we could count all the visible stars of space, we should still have little idea of the total number of heavenly bodies-in a word, of the aggregate mass of the universe. That has not hindered curious man from attempting the count, and very ingenious is the method employed.

Early in the last century, Sir William Herschel attempted to classify the stars according to their brightness. They were divided up into stars of "the first magnitude," the second, and so on, according to their ability to shine through a screen (later, according to extremely delicate photometric methods). A French astronomer, the late M. 1'Hermite, observed that the number of stars from one "magnitude" to another in this classification increased in steady progression. Measuring very carefully the amount of light given out by each order of stars, he was able to calculate the total number of stars that would be required to supply the total light we get from the stars now. His estimate was something like sixty billion suns (60,000 millions) larger than our own.

From this a captivating suggestion. So far as we know, the light of the stars is absolutely un- 
absorbed by space. We know of stars so distant that, though light travels six hundred million miles per hour, they might have been blotted out before Christ was born and they would still be shining for us in the sky. Yet distant as they may be, there is no reason to suppose that their light reaches us in the least dimmed. If this be true, then M. l'Hermite has measured, crudely it may be, the limits of the universe. Here we touch a fascinating field of inquiry which will be more fully dealt with in a succeeding chapter.

Need it be remarked that these limits, if they exist, lie far outside all human sense. But so, for that matter, does the larger part of all physical phenomena. This is true alike as to the macrocosm and the microcosm. So far as our native senses go, the motion of the sun and of the moon seems the same. Both appear to revolve about the earth, and so the Middle Ages believed. One guess turned out right, the other wrong. The earth turns round at such a rate that a man on the equator is travelling a thousand miles an hour, seventeen miles a minute. At the same time, we are plunging through space, in a circle round the sun, at the rate of nineteen miles per second. The whole solar system in turn, bag and baggage, the sun and all its planets, from Venus to Jupiter and Neptune, appears to be shooting towards the pole- 
star at the same tremendous speed. On the other hand, various facts lead us to believe that the particles of air in a quiet room, or of a motionless drop of water, are in a state of intense activity, moving with more than cannon-ball speed. Of all of these motions our senses give but the vaguest reports.

What is true here is true universally. The flash of the earth through the sky is directly known to us only through the change from summer to winter and back again. Had we eyes as delicate as the spectroscope, to the world of color would be added hundreds of tints and shades to which we are now insensible; could they see with microscopic vision, we should be terrified with the teeming populations of the air we breathe, the water we drink, the things we eat. Were the sense of touch as fine as that of some micrometers, the smoothest billiard-ball - a razor's edge, even-would seem rough and jagged as a flint knife of the Stone Age. Were our ears attuned to all the gradations of sound producible by a siren, we should step into a new world of harmony; were they as delicate as the microphone, the utmost stillness of the night would come like the clang and clatter of Broadway.

In a later chapter the possible bearing of all this on some of the fads of the day, like telepathy and its kindred, will be briefly suggested. Meanwhile, 
THE WORLD BEYOND OUR SENSES

what is worth observing now is that the vast extension of human knowledge since the days of Galileo and Newton, grouped broadly under the name of science, has been chiefly the exploration of the world that lies beyond our primitive senses. 

THE FINITE UNIVERSE

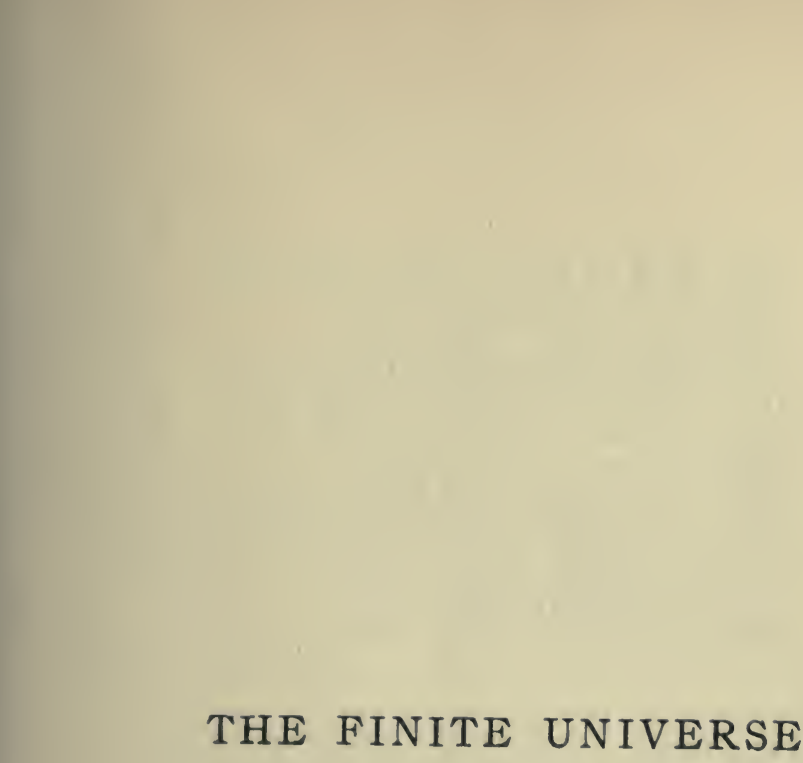


The wings of Time are black and white, Pied with morning and with night.

Mountain tall and ocean deep

Trembling balance duly keep.

In changing moon, in tidal-wave,

Glows the feud of Want and Have.

Gauge of more and less through space.

Electric star and pencil plays.

The lonely Earth amid the balls

That hurry through the eternal halls,

A make-weight flying to the void,

Supplemental asteroid,

Or compensatory spark,

Shoots across the neutral Dark.

EMERSON.

An intelligence which should be acquainted with all the forces by which nature is animated, and with the several positions at any given instant of all the parts thereof; if, further, its intellect were vast enough to submit these data to analysis, would include in one and the same formula the movements of the largest bodies in the universe and those of the lightest atoms. Nothing would be uncertain for it, the future as well as the past would be present to its eyes. The human mind, in the perfection it has been able to give to astronomy, affords a feeble outline of such an intelligence. Its discoveries in mechanics and in geometry, joined to that of universal gravitation, have brought it within the reach of comprehending in the same analytical expressions the past and future states of the systems of the world.

LAPLACE, quoted by Pearson, The Grammar of Science. 


\section{THE FINITE UNIVERSE}

THE first steps towards a rational conception of the world were taken by the astronomers, and all their work tended towards the idea of a universe whose extent could only be expressed by the vague notion of infinity. From Galileo to the Herschels and our own time the steady improvement of the telescope has meant the steady recession of meets and bounds, until the distances of space have become unthinkably vast. The result is reflected in popular speech, and in much popular writing. The idea of a universe infinite in extent, infinitely varied in character, is a commonplace.

Yet, if we consider it closely, there has been very little to justify this belief. On the contrary, perhaps the most remarkable thing in the advancement of knowledge has been the fixing of limits in natural phenomena. There is, in fact, much to suggest that there are in nature boundaries beyond which there is nothing, ultimate units of matter which cannot be subdivided, speeds which cannot be exceeded. All this is in direct contradiction to 
the nature of the mind. We are unable to conceive bounds to space; nor can we picture an object so small that it cannot be again divided; nor can we think of anything going so fast that nothing could go faster. Nevertheless, limits do seem to exist. The bounds and speeds and units of the universe all seem measurable quantities. They are, therefore, finite and not infinite. I shall try to give, in the briefest way, the evidence on which this view is based.

There are two reasons, at least, for believing that the stellar universe is not boundless. The first of these is grounded on the theory of light. We are aware of the existence of the stars only through their ability to affect the retina or the photographic plate. The light they send us is mainly white, that is to say, compound. It is a mixture of all the colors of the rainbow, and each of these colors represents a different wave-length. In passing through ordinary substances, like glass or water, the different colors are differently impeded or absorbed. If the light from the pole-star passed through an absorbing medium on its way to the earth, it is likely that the absorption would be, in some degree, selective. One color would be more absorbed than another. The light from the stars would not be white; it would be tinted. There are, of course, red stars, like Orion, yellow stars, like Arc- 
turus, but there are other stars indefinitely more distant whose light is pure white. The inference, then, is that light is not absorbed or diminished as it traverses space.

If light is not absorbed, and the number of stars were infinite, then the sky would be ablaze night and day, and we could distinguish the sun only as a rather yellowish disk. The sky is not so lighted; the inference, then, is that the stars are countable. In another place ${ }^{1} \mathrm{I}$ have reviewed the facts which indicate that the actual number is comprised between sixty millions and sixty thousand millions. These are rather wide limits, and they will probably be reduced to a much narrower range as astronomical science advances. In fact, it is possible that the upper limit is at least ten times too high, so that the number of stars probably lies between sixty millions and six thousand millions. This figure has nothing to do, of course, with planets or "dark" suns.

The second line of reasoning which would indicate a finite universe is this: So far as we now know, the law of gravitation, found by Newton, holds throughout space. The observed action of the socalled double suns, two stars revolving about each

'See "The World Beyond Our Senses," p. 4r. 
other, can be perfectly explained on this theory. If the number of stars was indefinitely great, the combined pull they would exert would probably be such that some of the stars would be flashing through space at inconceivable speeds. If this were true it could probably be observed. It has not. The velocity of a number of stars has been calculated, and, as this can be done by independent methods, the results may be taken as fairly reliable. It is true that when the so-called "runaway stars," like 1830 Groombridge, were first observed, it was thought that the attractive force of the whole stellar system was insufficient to hold such stars in leash, and that they would dash into the depths of space and be lost forever. Such a view now appears untenable. The speed of these stars merely indicates a stellar system vastly more extensive than the one hundred million suns which was the assumed figure when the runaway stars got their name. There is no decisive reason to believe, however, that the number is without end.

The distance of most of the stars is so great, and the angle which the earth's revolution subtends so small, that it may take centuries of delicate observation before we shall have any definite idea of the real size of the universe or of its shape or contents. It is fairly certain we shall some day, for 
it seems to be finite, and if it is finite it can be measured and weighed. Moreover, the disclosures of the telescope are only three centuries old, those of the spectroscope and camera but half a century. Set this in imagination against five or ten thousand years of invention, investigation, and discovery like to that of the last three or four generations, and who shall set bounds to what man may know then?

For one thing, it is coming slowly into view that space is not nearly so empty as used to be imagined. If the wave theory of light is true, and it seems well founded, then space is filled with a substance as tangible and no doubt as tractable as the waters of the sea. Again, gravitation is the weakest of known forces. Compared with the energy we must conceive as binding together the molecules, or in action when a pinch of salt is dissolved in a glass of water, gravity is almost inconceivably feeble. These colossal electrical and molecular forces, whose very existence has but recently been revealed, we may one day utilize and control. If, as Professor Dolbear picturesquely remarks, we could some way get a "kick" on the ether, space navigation would be easy. It does not seem impossible that we shall be able to do this within another hundred or two hundred years. There is the gleam of such a 


\section{NEW CONCEPTIONS IN SCIENCE}

possibility in the fact that negative and positive electricity seem to move at different speeds. The chief difficulty would lie in the fact that space is simply teeming with meteors and meteoric stones; the earth sweeps up a hundred or two hundred tons of them a day. They might make a voyage round the moon rather perilous.

As the space-filling ether is purely an inference, it is hard to get any precise ideas of its nature or its qualities. For the present it is simply a working hypothesis that may have its day. Indeed, in its full development, it is a collection of suppositions that war most unkindly one with the other. Nevertheless, the ether may be a fact, whatever be the fate of present imaginings about its properties. If space be filled with a uniform material, like air, then waves or vibrations set up would travel always at the same rate of speed, just as sound travels always at the same rate in air of uniform density. That is exactly what seems to occur. Light appears to be a form of wave-motion, and so does radiant heat, and likewise the form of energy discovered by Hertz, and so marvellously employed by Marconi, which we call electric-waves. Light-waves range in length from 60,000 to 30,000 to the inch; heat-waves from this to only about 350 to the inch; electric-waves may vary from a few tenths of an inch to a thousand 
feet or more. ${ }^{1}$ One might readily think that waves so different in length, some of them a thousand million times as long as others, would move with different speeds. They do not. Light-waves, heatwaves, electric - waves - in brief, all the motions attributed to the ether - clip through space at I 84,000 miles per second. If we could observe a flash of light from Mars, and at the same time hear signals from the Martians by wireless telegraphy, as Marconi heard his signals from across the Atlantic, the two would reach us at the same instant.

The discovery of electric-waves was made by Hertz, at Carlsruhe, in Germany, in 1888 . They not only proved the identity of electricity and light, but went a long way towards making the ether seem something tangible and real. They seemed a sort of demonstration, and to show, too, that this ether, no longer merely lumini-ferous, but electri-ferous as well, is a perfectly uniform substance.

Then, in 1895 , just seven years after, came Professor Röntgen's disturbing discovery of the X-rays. The Hertz-waves had had a sort of Messianic history. They had been foretold. Professor James Clerk-Maxwell had worked out the electromagnetic theory of light mathematically twenty-three years before. Hertz's discovery was sim-

'See "The World Beyond Our Senses," p. 4r. 
ply the brilliant fulfilment of Maxwell's predictions. The Röntgen rays were, so to speak, a flash from a blue sky. Their discovery would undoubtedly have been made in a year or two at least, for there were several workers-Lenard, Perrin, and othersdelving in the same field. Nevertheless, their detection was pure chance.

The Röntgen rays produce light. But, unlike light, they can neither be reflected nor bent. They go straight through things. There was no way to measure their speed, nor find out what they were. They did not seem to be a form of wave-motion at all. This gave rise to all sorts of suspicions. In nature there are no isolated phenomena; that is the sure lesson which all the advance from Galileo and Descartes has taught. If the Röntgen rays were a wholly new mode of action in nature, there might be no end of such; we might have to imagine other ethers, and velocities swifter than light.

We need not go to the trouble. The Röntgen rays are undoubtedly a form of light, for they travel at exactly the same speed. Professor Blondlot, in Paris, has just succeeded in effecting their measurement and he finds it identical. The especial figure of 184,000 miles per second is not one likely to be hit on by two different kinds of motion. We already knew of invisible light-waves only a quarter as long as the short- 


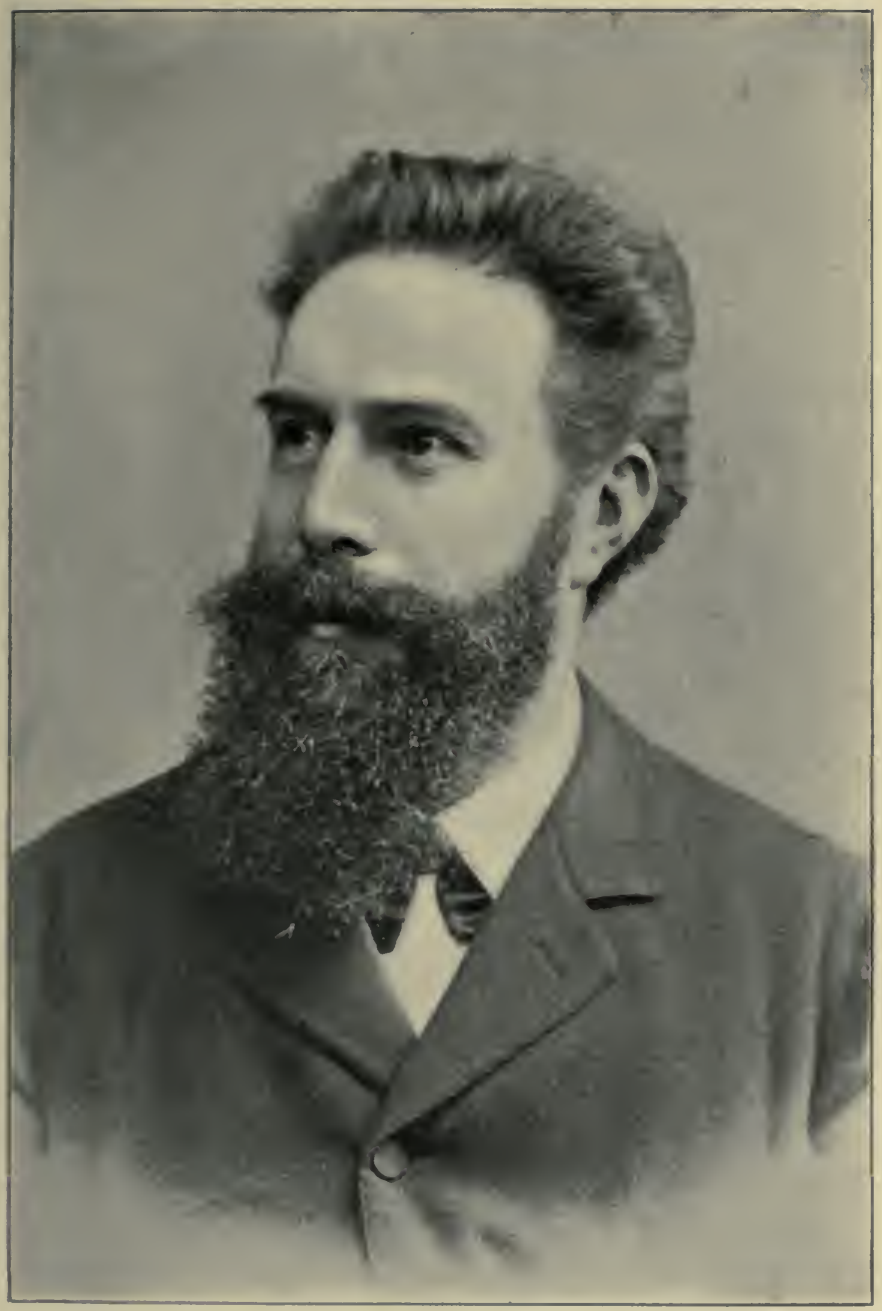

JROFESSOR W. C. RÖNTGEN

University of Munich, discoverer of the X-ray's 

est visible rays. The Röntgen rays probably lie out beyond these invisible ultra-violet waves. Likely it will not be very long before some ingenious way will be found to measure their period or frequency, and then we shall know their wavelength or lengths; for the Röntgen light might be compounded of a variety of waves, just as white light is. It may turn out a whole new "octave" of light.

But what is most interesting in all this is that this unexpected apparition in the field of physics fits in with the ether theory, just as did the Hertzwaves, whose arrival was expected. In order to account for the known actions of light, the founders of the wave theory, Young and Fresnel, were led to assume the existence of this highly tenuous medium filling all space. It was not long before it was found that heat radiations also have a wave form and travel at the same unthinkable pace. Likewise the action of a magnet, and also of an electric "field," is very easily accounted on the supposition of a disturbance in this same medium. It may be noted that the remarkable discovery in 1892 by a young Hollander, Zeeman, as to the effect of a magnet on light, tends to confirm this view. It was, like the Hertz discovery, the result of a prediction from the inferred properties of the ether.

When these and a number of minor results are 6 8 I 
grouped together with the discoveries of Hertz and Röntgen and the recent measurements of Professor Blondlot, it will be seen that the hypothesis of a space-filling substance rests upon a solid body of observation. Hazarded as an economical mode of thought a century ago, the evidence in its favor has steadily accumulated, so that in the minds of most physical investigators it is now considered as well-grounded a theory as, let us say, the Darwinian theory of natural selection. The comparison is chosen advisedly.

Taking up some mathematical calculations of von Helmholtz, Lord Kelvin has suggested that what we call matter might turn out to be inconceivably minute whirls or "vortex-rings" in this universal fluid. These rings would be similar to the smoke-rings which are formed by puffing smoke from the mouth, or those a locomotive often sends into the air. The action of these rings has been studied attentively by Professor J. J. Thomson and others; some of their performances are curious in the extreme. Two smoke-rings attract each other, just as if they were little worlds like the earth and the moon, and if in travelling across a room they are stopped by an obstacle, they will move on again when this obstacle is taken away.

On the other hand, without indulging in theory at all, a Norwegian physicist, Professor Bjerknes, 
has shown that the so-called actions-at-a-distance, which are the stumbling-block of all physical inquiry, could be very simply explained by supposing that we are afloat in the depths of an etherocean. He has made some very interesting models from objects floating in water to illustrate and clinch his ideas.

If these speculative notions should prove well founded, then we should have to accept the ether as the natural substratum of all existing things. It would be the stuff of which the universe is made. Without going so far now, we may hold fast to the proved fact that all the various forms of energylight, electricity, heat, X-rays, and probably magnetism as well - move at an identical rate of speed, and that this, though inconceivably swift, is measurable. Before delicate instruments had been devised to effect the measure of such velocities, it was thought that the passage of light was instantaneous, that its speed was infinitely great.

To the conception of a finite and one day measurable universe, we may then add that of a cosmos whose interchanges of energy are effected at a finite and measurable speed. It has the fixity and certitude of a perfect machine. It is assuredly a curious thing that the light of a fire-fly and the dazzling radiance of the distant stars, the warmth 
of a candle and the consuming heat of the sun, the invisible rays from the Crookes tube which lend a pale phosphorescence to a screen, and the huge electric-waves which transmit signals from Cornwall to Cape Cod, should all reach the same distance in the same flash of time. The speed of light and its kindred is at present the swiftest thing known. It may be there is nothing swifter, and can be nothing.

The only speck on the horizon that seems at the moment to contain possibilities which might upset this conclusion is the question of gravity. As to the rate of action of gravity we have no notion whatever. Its effects are not screened by any substance, and if, therefore, it is a mode of motion, we have no way of measuring it. When the moon comes between the earth and sun, the pull of the sun is simply added to the pull of the moon. The one in nowise influences the other. Gravity has more of the allure of something infinite than anything we know of. Yet the strength of its action is expressible in the simplest of equations. Newton's law of inverse squares was, indeed, the first found of the great physical constants of nature. So far as we know this force is universal. Trusting implicitly in the truth of this, astronomers weigh the sun, the planets; they even calculate the mass of dark stars whose existence is but an inference from the observed motion of others. It was by the 
same means that Adams and Leverrier were able to predict the discovery of a new planet and to fix at a given moment its exact place in the heavens. Thither the telescopes were turned, and there Neptune was found. That was, no doubt, the highest triumph the Newtonian theory had yet received. The prediction that Sirius was a doublestar, and the finding of its dark companion, was hardly less striking. It now seems doubtful if any change will ever have to be made in Newton's law. It will stand.

We may add, then, a third constant to our conception, and say that all matter whatsoever has the same attractive force. It would puzzle an enlightened savage if he were told that a given mass of impalpable air exerts the same power of attraction as a like mass of iron or lead. There are plenty of folk who are not savage to whom this fact and all its implications have never been clear. I have known many who never had heard of Galileo's famous experiment of dropping a one and a ten pound weight from the Ieaning Tower of Pisa, and proving that they reach the earth in the same time. Generally they do not believe it is true. No argument in the world could convince them that in a vacuum a feather falls at the same rate as a cannon-ball.

Moreover, nothing at first sight seems more con85 
tradictory to every-day experience than this law of equal attraction. There is nothing in nature to lead us, a priori, to believe that a ton of air and a ton of gold pull each other with the same force. Yet it is precisely because of this that the blanket of air we call the atmosphere presses down upon the earth with a force, everywhere, of fifteen pounds to every square inch. The earth is ploughing through space at the rate of nineteen miles per second; the reason the earth's atmosphere has not disappeared in the depths of space long ago is because of the Newtonian attraction between the earth and the farthest particles of the air. This attraction still subsists, even when the air is millions of times more rarefied than at the earth's surface, and where single particles may have a free path of miles, instead of thousandths of an inch, as at ordinary pressures.

We are accustomed to think of the sun as a molten mass, implying a fiery liquid. It is more likely a ball of incandescent gas, so that the force which holds the earth to its customary revolution is exerted by the particles of a gas, like the air. The same is probably true of all the stars; they are balls of gas. Some of them are moving at the rate of three or four hundred miles $a$ second. This speed is generated by the pull of one gas-ball, or set of them, on another. Some of these flaming 86 
worlds appear to have a mass thousands of times that of our sun, which has in turn three hundred thousand times the mass of our earth. The calculated speed of Arcturus, the great star near the Bear, is three hundred and seventy-five miles per second, and its estimated light about eight thousand times that of the sun. Yet this, as all other known bodies, seems to obey Newton's law. We may, therefore, infer that we live in a universe all of whose particles or masses, be they atoms or Arcturian suns, draw to each other, mass for mass, with even force.

These particles and masses show another curious relationship. If the atomic weight of the elementary substances be multiplied by the specific heat, the result is a constant quantity. It seems not unlikely that the amount of heat that can be taken up is also fixed. Several considerations suggest such an upper limit to temperature. The stars we know are very hot, far hotter, probably, than any temperature producible by terrestrial means. On the other hand, as we climb high mountains, or men go up in balloons, it grows very cold. The inference is that space must be extremely cold. Space is either empty or contains a substance which does not seem to absorb the radiant heat of the stars. One might think, therefore, that the temperature of space is the coldest possible 
cold. That is highly probable. Men's minds have varied in their notions as to what heat is. It used to be thought a substance. But briskly rubbing together two pieces of ice produces heat enough to melt both. If mere friction can produce heat, it is evidently a form of motion and not a material thing. That is the way it is now regarded. If space is not warmed by the heat of the sun and the stars, then heat is the motion of something else than the material of space, if there be such.

We know of heat only as it is associated with what we call matter, and since all bodies, when made hot enough, turn to vapor and fly away in the air, heat is thought to be the motion of these very small particles. To send out the measured waves of heat and light, these particles would have to vibrate at a rapidity beyond anything we can conceive.

Waves of light reach the eye at the rate of $45^{\circ}$ to 750 million millions per second. The particles of matter would have to vibrate the same number of times to send these waves out. The number is so unthinkable that one might get the notion that there is no limit. That may be, but, in view of the finite nature of observed phenomena, it is quite possible there is a limit. There is reason for believing that heat is the motion of the individual atoms, 
and not of the molecule as a whole. For example, when hydrogen and oxygen are exploded, to form water, the molecules of the two gases are supposed to be broken up in order that by their recombination they may form a water-molecule. The heat produced by this reaction is intense, so much so as to give the impression that the attraction between molecules is very small compared with the attraction between the atoms. This attractive force is no doubt finite and measurable; it is quite probably due to the electrical charges the atoms are known to carry. If there is an upper limit of heat, it would be the extreme amount of motion these electrical attractions are able to generate. It is worthy of note that ordinary aluminum, when ignited, seems to produce about the same temperature as the electric arc. These two sources supply us with the most intense heat we know. The heat of the sun, and even of the hotter suns, like Sirius, may not be greatly beyond this. The subject is still obscure, and until some inventive genius devises more delicate mechanical appliances, we must be content with our ignorance.

To the divisibility of matter the mind sets no limits; but nature does, at least so far as our knowledge goes. In fancy we can think of nothing so minute that we cannot conceive half of it; but half 
a molecule of water or sugar or cotton or salt is no longer any of these familiar substances, but an utterly different thing-oxygen, hydrogen, carbon, chlorine, sodium. We may convert ice into water, and water into steam; it is the same chemical substance. But make the steam hot enough and it will be dissociated into its constituent atoms. These may be in turn brought back to a liquid; we can now even solidify both oxygen and hydrogen. They are no longer water or ice; they behave just as differently, for example, as do water and sulphuric acid, or ice and lunar caustic. Every substance is made of molecules, and these are nature's physical units. They are finite, measurable facts. ${ }^{1}$ Matter is not infinitely divisible, but granular in structure. These grains of matter can be measured as accurately as the distance of the earth from the sun.

Chemistry has taken one step further. The most elementary facts of chemical combination force the idea that the molecules are usually compound. We know that the molecules of water and salt and sugar are, for they may be broken up. The molecules of the elements ${ }^{2}$ are supposed generally to contain at least two atoms. That is the simplest way to account for the facts. There are other facts, however, which make other and more

'See "What this World Is Made of," p. Io3.

"See "The Search for Primal Matter," p. 145. 
difficult suppositions about the atoms necessary, so that for many the atomic theory is something of a double cross. The question of valency - that is, the ability of some atoms to hook on to two or more of other kinds, is an especial stumblingblock.

In the mind of the writer the evidence for the objective existence of the atom has recently gained a very solid support. Thin solutions of glue or jelly, which do not ordinarily solidify, may be precipitated by adding small quantities of various substances. Barus took note that the precipitants are always the substances which, dissolved in water, are able to convey electricity. Sixty years' puzzling over these electric solutions has finally obliged the puzzlers to assume that the substances dissolved in the water are torn apart by the tremendous molecular forces at work therein. Thus, if ordinary salt is so dissolved, it is supposed to be separated into its elements, sodium and chlorine, and that these exist in a free state in the water. If the water is evaporated, they are said to recombine gradually, so that when all the water is gone there is dry salt again. The particles of sodium and chlorine are supposed to bear electric charges very great in comparison with their mass. If a ball of pith could be so highly charged as these particles, it would act with an explosive energy like dyna- 
mite, either attracting or repelling bodies with smashing force.

If the precipitation of the gluelike solutions be an electrical effect, and if the theory of electric solutions be true, one might expect to find one of the constituents of the salt-that is, either the sodium or the chlorine, carried down with the glue or the jelly. This is exactly what happens. The electric theory was built up with infinite toil, and the chain of reasoning upon which it rested was beautiful to follow; but it is simple facts like this which clinch it and make it tangible to the mind.

These highly electrified particles seem to be the atoms of the chemist. Behind the physical unit of matter-the molecule-we have, therefore, the unit of chemical combination-the atom. The necessity of such an assumption has so steadily increased since the first crude conjectures of Dalton that today it has become an integral part of all chemical investigation. This is especially true of the chemistry of the products of life. Modern organic chemistry rests not merely upon the belief in the material atom, but conceives for some of them a definite shape. The atom of carbon, which is the nucleus from which all living things and the products of all vital activity are formed, is pictured as an asymetrical tetrahedron - that is, simply, a minute pyramid with unequal sides. If this seems 
going far, it may be observed that in following this conception the distinguished German chemist Emil Fischer has been able to fabricate forty different kinds of sugar where nature knows not onequarter so many. The triumphs of the atomic theory have been so signal and so unbroken that it may be regarded as the most practically fruitful hypothesis now in the service of the investigators of the properties of matter. All chemical syntheses, and all hopes for the laboratory manufacture of food-stuffs, and of life, rest thereon.

The millions of different substances known upon the earth and in the stars are all reducible to seventy or eighty varieties of atoms. These are the elements. The inquiring mind of man will not stop here. Instinctively it will go on and reduce all these elements to the varied combination of a single primal substance. Within twenty years from the time Lavoisier had laid the foundations of the quantitative analysis of matter this suggestion had been put forth by Prout. It has hung before the minds of workers in this field like an ignis fatuus for a century. At last there appears on the horizon the possibility of its experimental demonstration.

Studying deeply the puzzling phenomena of the Crookes tube, the same which produces the X-rays, Professor J. J. Thomson has reached some strik- 
ing results. The exquisite glow which appears in the Crookes tubes when a current of electricity is passed through them seems to be due to minute particles shot by repulsion from one of the poles. These particles are heated to incandescence, and travel with a third of the velocity of light-fifty thousand miles per second. Professor Thomson and his co-workers have found a way to measure their mass, and the charge of electricity they bear. The charge is the same as that of the particles which ferry electricity through a liquid. But their mass is but a thousandth part of that of the lightest atom known. What is more striking than all is that they seem all alike. No matter what may be their source, they have the same mass, the same charge, act exactly the same. The cathode - the pole from which they spring-may be of gold or lead, of copper or silver; it makes no difference. Moreover, it seems as if these cathode particles, as they are called, are streaming from everywherefrom the sun, from the tips of the leaves of a tree. Space appears to be swarming with them. It seems as if the quest of primal matter was attained. These particles are primal matter.

They are certainly the smallest things known. It is conceivable that they are the ultimate units from which the whole universe is made. As the chemical elements, by their combination, form the 
substances of familiar and daily experience, so these cathode particles, variously grouped, make up the seventy or eighty different kinds of elemental atoms. It is all so new that one gasps a little, trying to realize the full import of this discovery. If it is confirmed by future experiments, there are not many events in the history of science which may compare with it-perhaps Newton's demonstration of the law of gravitation and one or two others. Newton's achievement is described in this fashion because a good many people have an idea that Newton discovered gravity. The latter was, in some sense, as well known to Plato and to Archimedes and Aristarchus as it was to Newton. So there have been millions of addled heads filled with vague ideas of a primal substance. What Professor J. J. Thomson has done is to bring forward experimental proof. That is all that counts.

Whether the cathode particles turn out to be urstoff or not, Professor Thomson's researches appear to have added a new physical constant of a rather unexpected sort-that is the natural unit of electricity. The charged atoms in an electrically conducting liquid all carry the same quantity of electricity, or a simple multiple of that-two or three or four charges. In a word, a chain of reasoning quite similar to that which leads to the idea 
of a chemical atom introduces the notion of an electrical atom. The word atom, however, is so definitely associated with particles of matter that another name has been found for this electric unit of nature. It is called an electron.

Even before anything smaller than the chemic atom was known, this idea of electrons was thought to be full of large possibilities. It acquired a vital significance when Professor Thomson showed that the cathode particles are a thousand times smaller than the smallest known atom-that of hydrogen -and yet that they carry the same charge. They carry the same charge as an atom of silver which has more than one hundred thousand times their mass. To our vague conceptions of what is electricity we must add the idea that it is a finite quantity, countable in units, like, let us say, grains of sand.

Perhaps this new notion is hardly so foreign to our habits of thinking as it seems at first blush. We know absolutely nothing of electricity save as it is associated with ponderable matter. The converse of this idea seems now taking possession of the field-no matter without electricity. Electricity seems everywhere. It seems an invariable property of matter.

Supposing, then, that the cathode particles are, in truth, the stuff of which the atoms are made, we might consider these particles in a state of intense 96 
whirl; this whirl of the particle might produce in the surrounding ether the effects which we call electrical. This is the simplest supposition that can be made, and towards its demonstration many a mind is now turned. For the present, at least, there is no account of how these charged particles, mutually repellent, are bound together in atoms so rigidly coherent as to appear absolutely indestructible. Neither is it clear how atomic aggregates of particles will cohere to form the molecule. Chemic affinity, the theory of matter, the nature of electricity, are still unsolved problems. We must await more light. But when the solution comes it will probably be of all three together.

"The first principle with investigators of nature," said von Helmholtz, "must be that nature is intelligible for us; otherwise it would be folly to try to study it." If the cosmos, of which we are a part, is infinite, it is not intelligible, for the infinite is beyond our understanding. If it is infinite in extent, infinite in bulk, it would contain infinite forces, attracting over infinite spaces, and moving objects with infinite speeds. If its parts are infinitely divisible, the combinations of these parts would be infinite in variety and action. So far as we know, there is nothing in natural phenomena to suggest such conclusions. 
Nature is simple, and therefore understandable. That the universe is unthinkably vast does not imply that it is without limit. That it is composed of an unthinkably great number of suns does not imply that this number is uncountable. If it is limited in extent and in bulk, the mind of man will find a way to measure and weigh it. That its parts are unthinkably small does not imply that the process of division may be carried on indefinitely. There is probably a material substratum, either granular or continuous, and, if such an underlying material exists, all of its properties and actions will one day be known.

These conclusions are not now current, and the writer is not aware that they have been stated in these terms before. They are implicitly assumed in every effort to further natural knowledge, and their recognition will be necessitated unless the course of physical investigation undergoes a radical and unexpected change. At the present time there is not very much to indicate that an infinite universe exists. If it does not, if cosmos is finite, we might some day know all about it that there is to be known.

NOTE ON MAN'S PLACE IN THE UNIVERSE

Something of the same point of view was embodied in a recent address by Simon Newcomb, called " The Universe as an Organism," to which the writer's attention has been drawn. 
But this reference should not be taken to imply that Professor Newcomb stands for the especial conclusions here developed. Some of the same material has been employed, too, by Dr. Alfred Russel Wallace in a curious article on "Man's Place in the Universe," which appeared as these pages were being put in type. It should not be needful to suggest that the peculiar views of Dr. Wallace are not shared by the present writer. The deep study of spiritualism and its kindred which has occupied the later portions of the distinguished naturalist's life find a not unnatural culmination in the discovery that our tiny globe is the centre of the stellar system, and that the object of creation is the development, on this earth, of man's immortal soul. It did not require the subtlety of a theologian to point out that even supposing, what is in no wise probable, that the earth is now the centre of the stellar system, it appears to be drifting away from that centre at the rate of a million miles a day. It was not, then, at the centre yesterday, nor will it be to-morrow. The idea is simply absurd. Equally so seems the suggestion that life on this earth, and "man's immortal soul," have any special significance for the universe at large. Even supposing the other planets of our solar system now uninhabited, they probably have been or will be some day. Moreover, the evidence of the spectroscope seems fairly conclusive that the $m a$ terial of the universe is the same, and this material seems dominated by the same forces and the same laws. If, therefore, the stellar universe consists of several hundred or several thousand million suns, it is possible there are millions of other planets upon which life exists. It is conceivable, even, that hundreds of thousands are undergoing an evolution identical with that of our earth, both in character and time; in a word, that in far-away places other worlds like ours are just emerging from an animal existence, from infantile superstitions, and vulgar aims, and beginning the study of natural phenomena. So far as we can see, life is simply a stage of planetary evolution. Planets, suns, and systems come and go, wax and wane, 


\section{NEW CONCEPTIONS IN SCIENCE}

even as kingdoms and peoples. Our little earth and its companion "wanderers," and the central body to whose fate they are bound, are hardly unique. Journeying through an apparent eternity of space and time, we know not whence they have come nor whither they go, and it seems doubtful, now, if we ever shall. 
WHAT THIS WORLD IS MADE OF 
The rounded world is fair to see, Nine times folded in mystery;

Though baffled seers cannot impart

The secret of its laboring heart, Throb thine with nature's throbbing breast, And all is clear from east to west. Spirit that lurks each form within Beckons to spirit of its kin; Self-kindled every atom glows, And hints the future which it owes.

EMERSON.

Natural causes, as we know, are at work, which tend to modify, if they do not destroy, all the arrangements and dimensions of the earth and the whole solar system. But though in the course of ages catastrophes have occurred and may yet occur in the heavens, though ancient systems may be dissolved and new systems evolved out of their ruins, the molecules out of which these systems are built-the foundationstones of the material universe-remain unbroken and unworn.

Clerk-Maxwell, Bradford Address. 


\section{WHAT THIS WORLD IS MADE OF}

In the wide days of old Greece, philosophers seemed to grow under every tree. They speculated on everything betwixt heaven and earth, and it was a matter of course that they puzzled deeply over what this world is made of.

Some of their guesses were fantastic in the extreme. That of Aristotle, who was long accounted the wisest man of antiquity, may be cited as an example. Aristotle taught that everything is compounded of hot and cold, wet and dry. Hot+dry made fire, hot + wet formed the air, cold +dry the earth, and cold + wet, water - the four elements. Fuddle-duddle like this served men's minds for food through more than two thousand years, and down even to the days of Shakespeare and Bacon.

There were in the ancient days a few, like Democritus and Lucretius, who, reasoning closely on the things they saw, conceived the world as made up of the helter-skelter play of minute particlesthe atoms. The facts they had to go on were scant, and their ideas, if ingenious, amounted to little 
more than a guess. Still, they guessed wonderfully well. In this paper I wish to sketch the steps which, in our modern day, have led by very different and diverse paths to the same conception.

Usually, in any reference to atoms, there are bewildering computations as to how many million billion there are, say, in a drop of water. There seems a mania for making out these ultimate particles unimaginably small, and hence of incredible number. They are not. Beginning with some of the familiar things of every-day life, I hope to show that the atom is not so far beyond the visible as one might suppose, and that it is something quite tangible, and thinkable, and real.

Some painsful genius once figured out that it would take only an ounce of the spider's web, spun into one long thread, to stretch across the Atlantic-three thousand miles. In former days, this was often cited as an example of the extremely tenuous state which solid matter may assume and still be perfectly continuous.

But we know now of threads of substance perhaps a thousand times thinner. If, for example, a drop of the white of an egg, or one of the white corpuscles of the blood, or, better still, the microscopic cell of protoplasm from which we all spring, be slightly stained, so as to reveal its structure, it 
will be found full of threads so delicate as to be scarcely visible under high magnifying powers.

The limits of visibility with the microscope have been very carefully measured, and are from $\frac{1}{100,000}$ to the $\frac{1}{200,000}$ of an inch, about. So that the chromatic threads in the protoplasm are somewhat less than a hundred-thousandth part of an inch thick. This is a very clumsy way to express it; it is like saying that a lead-pencil, for example, is about a hundred and fifty thousandth of a mile in diameter; so more convenient units have been chosen. The shortest wave-lengths of light might be employed as a standard; this is about one sixtythousandth of an inch. ${ }^{1}$ The chromatic threads of protoplasm, then, would be somewhere around half a wave-length thick.

But for scientific measurements the metric system is in universal use, and the wave-lengths of light happen to be fractional parts of any decimal division of a metre. So the even millionth of a metre has been agreed upon for microscopic measuring. It is called a micron, from the Greek word for small, and is written with the Greek letter $\mu$. It is about a millionth of a yard, or the twenty-five thousandth of an inch. For still smaller spaces, as we have seen, this is again divided by one thou-

'See "The World Beyond Our Senses," p. 4 r.

$$
\text { I05 }
$$


sand, and called a micro-micron (written with two Greek $\mu$ 's, $\mu \mu$ ). The shortest light-waves, then, are $0.4 \mu$, or $400 \mu \mu$. The chromatic threads are about $1 / 4 \mu$, or $250 \mu \mu$, thick.

This is smaller than any piece of wire can be drawn. With infinite pains Wollaston, a hundred years ago, drew out a platinum wire to $75^{\circ} \mu \mu$. It still remains the most delicate wire ever drawn. But some of the metals may be hammered out into leaves thinner yet. Gold-leaf is a classic instance. A single grain of gold has been pounded out so as to have a surface of seventy-five square inches. This, it is easy to calculate, makes it not more than $36 \% 000$ of an inch through, or about $\frac{1}{15} \mu$, or $66 \mu \mu$. It would take about a thousand such sheets of gold, each pressed down solidly on the other, to equal the thickness of this sheet of paper.

By treating such sheets chemically, Faraday was able to produce gold-leaf that, he says, would require fifty or one hundred thicknesses to equal one wave-length of light. That would have been only four to eight micro-microns ( $4 \mu \mu$ to $8 \mu \mu$.) Faraday's way of measuring was rather vague, and I do not know if his estimate has ever been verified. He did not care much for mathematics, and the bewildering equations of mathematical physics puzzled him as sorely as they do common folk.

At any rate, Faraday's sheets of gold were so 106 
thin that they were transparent, and shone with a pale green. Heated a little, they lost all color and became entirely transparent. The light came through this gold as it does common glass. Yet so far as the microscope could reveal, it was perfectly continuous; there were no holes in it. This is probably the thinnest solid metal possible to produce. Nevertheless, by dissolving gold and then depositing it in a thin layer on glass, Faraday was able to go ten times further. Such layers, he says, were probably not continuous, "yet they acted like plates towards the light." According to his estimate, there would be five hundred or a thousand such layers to a wave-length. Thus they would have been only from one to one-half a micro-micron thick ( I $\mu \mu$ to $0.5 \mu \mu$ ).

If Faraday was right, then with his chemically treated gold-leaf he surpassed what was long supposed to be the thinnest continuous substance known. This was the wall of a soap-bubble. People who left off blowing soap-bubbles with their childhood may be interested to know that these childish playthings have engaged some of the greatest of scientific minds. Newton was one. Everybody has observed that, just as the soapbubble is about to break, little black spots appear, and if the bursting of the bubble were not so quickly done we should see that it is at these 
black spots that the break in the wall actually occurs.

These spots are black only by contrast. Seen in a strong light, they present a series of ring-like colorations, and it was this part of the soap-bubble that Newton studied most deeply. These rainbows are known as Newton's rings.

Old Sir Isaac was an indefatigably curious man. Reading the Queries that he puzzled over, and then wrote down, makes one think there were few things in this world his wonderful brain did not find time to ponder. Some of the guesses he made, at things beyond the reach of experiment in his day, came so close to the truth that they seem almost like previsions. Of course, they were not; it was simply that he "intended his mind upon things," as he says, more than other folk are wont to do.

Searching for the extreme limits of continuous or solid matter (as opposed to liquids or gases), the black spots or rings in a soap-bubble were the thinnest things Newton could find. So far as accurate measurement goes, they remain so to the present day. These black spots are at most not more than I $2 \mu \mu$ or I $4 \mu \mu$ thick. It would take about ten thousand such thicknesses together to equal one sheet of this paper. And there are parts of the black spots, the centre, only half as thick as this-that is, only about seven micro-microns $(7 \mu \mu)$. 
This goes far beyond even the infinitesimal waves in the ether that make what we call light; and these waves were long thought of as the smallest things directly measurable in this world. It was only by knowing the wave-lengths of light that it was possible, at first, to measure the thickness of the soap-bubble's wall. More recently electrical means have been employed also, and the results of the two are in entire accord. With the longest lightwaves, those of the red, ${ }^{1}$ it is about $800 \mu \mu$ from the top of one wave to the next, and even with the shortest visible rays - the violet-it is nearly $400 \mu \mu$ -from fifty to one hundred times the thickness of the soap-bubble's black spot.

As all this means little to the imagination, we may make a comparison. The huge ocean-waves encountered in a storm are rarely more than five or six hundred feet from crest to crest-much less, for example, than the length of the Deutschland. Cast upon a beating sea of light, a boat the size of a soap-bubble's thickness would mean, in comparison to the waves in an ocean storm, a cockle-shell four or five feet long.

This is going very far. But we may have perfectly continuous layers of a liquid thinner even than this. An interesting instance was found by Lord

'See "The World Beyond Our Senses," p. 4I. 
Rayleigh, the English physicist, who presents the noteworthy paradox of a great man of science and a nobleman to the peerage born, not raised. If you will take dry camphor and powder it, and drop it in pure water, the particles will begin to scurry about in every direction. Under a microscope it is very gay. But a trace of oil spread over the surface of the water suffices to bring all the particles to a stand-still. Lord Rayleigh had the curiosity to measure accurately the thickness of the thinnest layer of oil that would do this. Knowing the size or volume of the drop of oil needful, and knowing the surface over which it spread, he could readily calculate its thickness. He found it could not be more than $\mathrm{r} .6 \mu \mu$.

Professor Röntgen, famous as the discoverer of the $\mathrm{X}$-rays, has gone still further. Using another test for continuity, he produced a layer of oil not more than half a micro-micron thick $(0.56 \mu \mu)$. A step more was taken by Professor Warburg, of Berlin, when he succeeded in weighing the invisible layer of water vapor which condenses on a very dry glass plate in moderately moist air. From its weight it took but a moment to compute that the layers could not be more than $0.2 \mu \mu$ thick-that is, about half a million times thinner than thin writing-paper.

Whether this layer of water is continuous or not, 
it is impossible to say, for the limits of the microscope are reached with objects at least five hundred times as large. And any experimental evidence seems lacking. But Lord Rayleigh was able to show that his oil-layer is continuous, because if it had not been it would have arrested the movements of some of the camphor particles, but not of all. It stopped them all, so that either his or Professor Röntgen's oil-layers may be taken as the extreme limit of continuity at present attainable.

So far we have been dealing only with substances which give an apparently continuous surface. But this is far from representing the extreme divisibility of matter. The exploding soap-bubble disappears in the air, and in the air vapors of oil or of water exist in so finely divided a state that they cease to sink under the force of gravity. They are drawn up, or rather dissolved, in the air under the molecular attraction of the air-particles.

This process of dissolution, or breaking-up of matter, is illustrated when we put sugar in the coffee or the housewife adds bluing to the tub. It is carried much further when we first dissolve a little indigo in sulphuric acid, and then put this in water. Thus treated, a single grain of indigo, the weight, say, of a small pin, gives a distinct coloration to a ton of water. In order to produce this reaction, the indigo must have been divided up 
into enough parts to be present, in large numbers, in every drop of the water; it must have been broken up into millions of millions of parts.

The subtle substance known as fluorescein, dissolved in water, makes the water fluorescentmakes it shine with a pale light after it has been illuminated. A gram of this substance will produce fluorescence in a hundred tons of waterthat is, in a hundred million cubic centimetres. The substance must be evenly distributed through every minute fraction of a cubic millimetre; it must have been split into billions of pieces.

This same process of molecular division is taking place constantly under our eyes, as, for example, in all things which burn, when solids like coal, liquids like kerosene, go off in more or less invisible gases; or when water and other liquids evaporate or go off as steam. One might easily think that this convarsion of a solid or a liquid into a gas carries the process of division much further than in the examples I have cited, but this is not always so. Water going over into steam occupies, at ordinary atmospheric pressure, only about seventeen hundred times its volume as water. Liquid air evaporating into common air gives only about eight hundred volumes. This is very small in comparison with one volume of fluorescein dissolved in a hundred million parts of water. 
WHAT THIS WORLD IS MADE OF

Of course, this does not represent the limits of divisibility for the air or the water, nor even the fluorescein. It is very easy nowadays to produce a vacuum of a millionth of an atmosphere-that is, containing only a millionth part of the air or other gas that was there when the process of exhaustion was begun. And the vacuum tube will still be "full" of air. There will not be a space equal to the millionth part of a hair's-breadth that will not be occupied by whizzing molecules. What is true of air is true of any substance. This extreme divisibility may be paralleled with common salt. It is well known that perfectly pure water is a nonconductor of electricity. A single gram of salt dissolved in water suffices to carry electricity through fifteen hundred tons of it. The theory of conduction in liquids is that the electricity is ferried across from one pole to the other by the individual atoms; each atom carries its own little charge. We must suppose, in this case, that the gram of salt is evenly distributed through every one of fifteen thousand million cubic centimetres. In each cubic centimetre there would have to be millions and millions of ferrying atoms.

An experiment with this same substance, or rather one of its two constituents - sodiumthrown into a flame, is equally amazing. A gram is the weight of a thimbleful of water; a milligram, 
the weight of a drop about the thickness of a penknife's blade. A millionth of a milligram of sodium in a lamp-flame suffices to reveal distinctly the characteristic sodium coloration in the rainbow-like spectrum of the flame. To do this, this millionth of a milligram must have been vaporized into a gas containing millions of distinct particles.

Another striking example might be drawn from the phenomena of smell; a grain of musk will scent a room for years. All this time, if the present theory of smell is correct, it must have been raining its small particles in every direction, incessantly. Yet it seems to lose little or nothing in weight.

There would be very little point in cataloguing these instances of extreme divisibility by themselves if they did not afford some clew to the structure of matter. From the days of the old Greeks, and, doubtless, tens of thousands of forgotten and unstoried years before, curious-minded man has puzzled over the problem of whether this divisibility has any limit or not. The old Greeks could only guess; they had no tools for the brain to work with. The whole progress of science, and, for that matter, of the human mind, is conditioned on mechanical appliances. The only difference between a savage and a Lord Kelvin is that the savage must depend on his unaided hands, his 
primal senses. There is probably not a great deal of native difference in the mental capacity of a fine type of a savage and that of a Spencer or a Descartes.

Clerk-Maxwell, the great physicist of Cambridge, was wont to say that progress was symbolized in the clock, the balance, and the foot-rule. It is because we know accurately how to weigh, to measure, and to time that we know more than the ancients, and the fact that some few of their random guesses have turned out to be true speaks rather for the simplicity of nature than for their intelligence. It is because this later day has contrived subtle ways of counting and measuring that we have come to know something of the way our familiar world is constructed.

It seems to be made up of very small particles, perfectly definite in size and weight, and, curiously enough, not varying greatly in their dimensions one kind from another. These ultimate particles, or molecules, as the physicist calls them, may be measured in a variety of ways, and as the result of these measurements it seems probable that Newton with his soap-bubble rings, Faraday with his gold-plates, Professor Röntgen with his thin layers of oil, have approached very closely the actual dimensions of a molecule; in other words, that present-day science has reached the borders of 
the invisible molecular world, the chaos from which all things come.

Half a dozen distinct lines of investigation lead to the calculation that these ultimate particles cannot be larger than a very few micro-microns, nor less than a twentieth or a thirtieth of a micromicron. These are the widest limits; there is good reason for believing that the size of the molecules varies only between a single micro-micron and one-tenth of that. This is Lord Kelvin's estimate. If Professor Röntgen's oil-films were, as he believes, continuous, then the upper limit for oil molecules would be half a micro-micron, for that was the estimated thickness of his films. Professor O. E. Meyer, who has written an exhaustive work on the subject, passes in review all the various methods of computing the size of the molecule, and concludes that their average diameter is not far from two-tenths of a micro-micron $(0.2 \mu \mu)$.

Accepting Professor Meyer's estimate, the thinnest part of the soap-bubble is about thirty molecules thick, Faraday's layers of gold-leaf about twenty, and Professor Röntgen's oil-films two or three. Of all the conquests of the human mind, I know of none more beautiful than this, wherein it has reached out into the invisible world, and, so to speak, put upon the scale-pan the units of creation, the stuff of which worlds are moulded. 
It would pass the limits of this essay to attempt to describe in detail how this amazing result has been reached. Lord Kelvin in his famous lecture on "Atoms" recounts four separate methods of calculating the size of these particles; and there are two or three more which have been developed since that lecture was delivered, twenty years ago.

One of the first grew out of the curious bending which a ray of light undergoes as it passes through glass. The wave-lengths of light may be measured with extraordinary accuracy, and, in order to account for this bending, Cauchy tried to calculate how large the particles of glass would have to be. It is now known that his estimate was far too high, but the method, perfected by later investigators, has served to set an upper limit at least.

Another path lies in the familiar fact that two metals, like zinc and copper, merely placed in contact, develop a very small quantity of electricity. This, too, can be accurately measured, and the amount of heat it would produce, were it used, say, for electric cooking, may be quickly calculated. Lord Kelvin conceived a way of estimating how far apart the molecules of the metals would have to be in order that the electricity they generate, by contact, should not melt them. Knowing the weight of metal he used, he could calculate that they must be more than a 
thirtieth of a micro-micron. This fixed a lower limit.

Then there was the familiar attraction between water and glass, illustrated in the every-day fact that we can fill a glass higher than the brim, or that when a tube of very small diameter is dipped in water the water will rise several inches in the tube, in apparent violation of the law of gravity. This is capillary (hairlike) attraction. Close of kin is the force (the so-called surface tension) which makes water and all other liquids form in drops. This is what holds a soap-bubble together. It is possible to measure this force very definitely, slight as it is, and from this to calculate the distance at which its effect would be inappreciable. This is reckoned at $0.2 \mu \mu$. By a quite independent method Lord Kelvin reached the conclusion that there could not be several molecules in half this thickness - a most striking agreement. It was exactly as if two geometers, employing entirely different means, should compute the distance from, say, Cape Nome in Alaska to Cape Horn in far Patagonia, and that their estimates should agree within a fraction of a mile.

By far the most accurate method, however, lies in the behavior of gases, like the air. When, for example, some ill-smelling gas is set free in a room, it takes a definite time for the smell to penetrate to II 8 


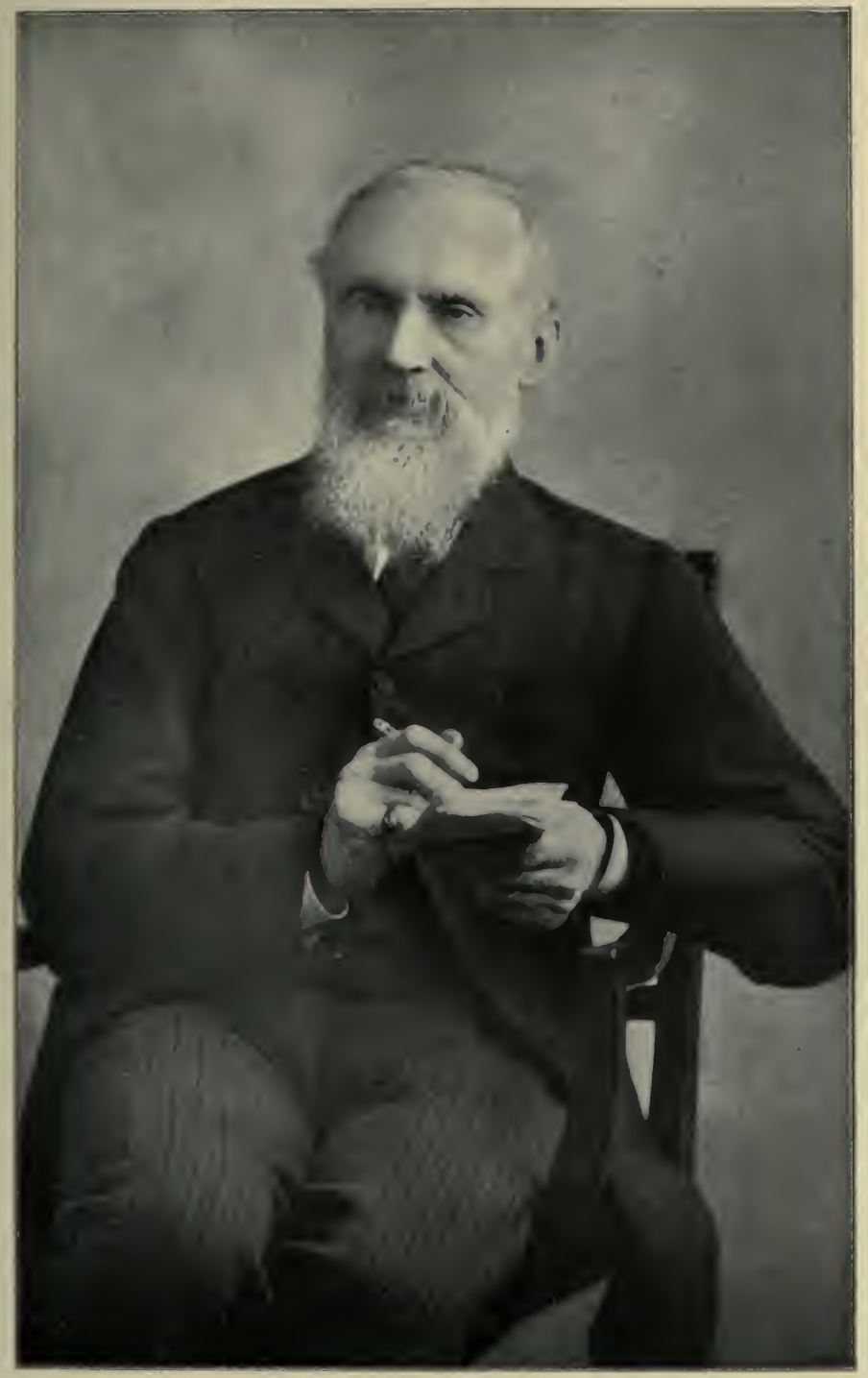

I.ORI) KELVIN (SIR WILI.IAM TIIOMSON)

Pamous for his researches in electricity and the constitution of matter. 

every part. From this, and similar facts, it is possible to get an idea of the rate at which the particles of the gas travel. So, too, the rate at which heat is diffused supplies further information, for the theory is that the heat is transmitted from one particle to the other, and that to effect the transfer the molecules must collide. A perfect vacuum is a perfect insulator to ordinary heat. From this, the distance traversed between the collisions may be computed. Finally, it takes less power to run an electric fan, say, in one kind of gas than in another. One offers less friction than another. From these and other observations the mathematician finds no trouble in telling you the number of molecules in a quart of air, how fast they fly, and how often they smash into each other; and he will tell you, too, that the molecules cannot be above nor below a certain size in order to account for the observed facts.

So one might go on. Ordinary air is a very bad conductor of electricity. As you exhaust it, thin it, it gets better and better, so that when you have such a vacuum as in the little Crookes tube which produces the Röntgen rays, it is a very good conductor. There is a simple relation between the number of molecules and the conductibility. This, and the behavior of light also, agrees perfectly with the values found in other ways. So, without going any further, it will be seen that the measurement 
of the molecules rests upon wide and solid foundations. We may regard it as so well established that if we could take apart the objects of every-day use-books, plates, furniture, not less than foods, water, air-we should find them all made up of particles from one to ten millionths of a hair's-breadth in diameter, reckoning two hundred and fifty hairs to the inch; that is, from $\mathrm{I} \mu \mu$ to o.I $\mu \mu$. Our microscopes will show microbes from $I_{50} \mu \mu$ to $250 \mu \mu$ in thickness; so that to be able to see the inorganic bacteria, the molecules, we should have to have microscopes from one to two thousand times as powerful as we have now ; in other words, an instrument which would do the same for the present microscope as that has done for the naked eye. The microscope has been improved to very near its theoretical limits, so that if ever we actually behold a molecule we shall need a new light to see with, less gross than common light, or else find new optical methods not now dreamed of. ${ }^{2}$

${ }^{1}$ Even as this is written, Herrn Siedentopf and Zsigmondy have shown a method by which some of the larger molecules, such as those of the colloids, actually may be seen. The method resembles very much that of darkening a room so that only a single ray of sunshine streams in. In this way, the dancing particles of dust become visible. By the new method, particles from 4 to $7 \mu \mu$ in diameter should be seeable, under some conditions. This is probably below the size of the ultimate units of living matter, so that we have here yet another step into the invisible and the unknown. 
But could our eyes open on this molecular world, we should have the laugh on the old-time theologians and their quaint ideas of "dead" matter. We should find the molecules of the quiet air speeding about with the velocity of a cannon-ball; a drop of water would resemble a thick swarm of bees, pounding against each other in their flight with tremendous force. Even the crystalline diamond would seem like pyramids of billiard-balls, hung wide apart by invisible springs and gyrating intensely.

Probably, too, the molecules are whirling round and round on their axes, like the earth; and to account for their ability to send out light and heat waves, we must suppose them to have vibrating motion in and out - as, for example, when you flatten a rubber ball and then let it go. If you put such a ball in water, you will see that the rebound of the ball makes but a single ripple; our sensations of light are produced by ether-ripples beating on the eye at the rate of from $45^{\circ}$ to $75^{\circ}$ million millions per second. If we keep to our mechanical ideas, then, we must imagine the molecule as a body able to flatten and elongate itself with that same rapidity. It is confessedly a puzzle, though, to imagine just how these minute molecules, which are probably not more than $0.2 \mu \mu$ in diameter, can set up the relatively huge wave-motions we call 
light, still less the vastly larger waves we call heat. The smallest of the light-waves are about $400 \mu \mu$ in length, the larger ones $800 \mu \mu$, two to four thousand times the diameter of the molecule; while the heatwaves range from this to $70,000 \mu \mu-$ or, say, a quarter of a million times the pulsating source. This is beyond anything of which we have experience. In order to get a working picture of molecular actions, we have to imagine for the light- and heatbearing ether qualities so contradictory as to make the entire subject unthinkable. You will find many writers, scientific and other, talking glibly of the ether as something which we can actually comprehend. It is not, and the confused and fuddled thinking one finds about it, in high sources, is often astonishing.

Besides its free-path motion, and its heat and light vibrations, every molecule is a magnet and is electrified. Some are feeble, some are powerful, and it is altogether probable that their magnetic and electrical properties constitute what is called chemical affinity. At any rate, the late Professor Mayer, of the Stevens Institute, conceived, by means of his floating magnets, some extremely ingenious imitations of molecular or atomic arrangement. Very small steel needles were stuck through thin bits of cork. When these were placed in the water, underneath a large magnet, they 
spontaneously arranged themselves into symmetrical groups, most interesting to watch. If this experiment had been made so that these little magnets were suspended in the water instead of being held to a plane surface, so as to employ all three dimensions of space, we might have a very good model of the finer structure of matter.

If shape, structure, chemic behavior, lie still in obscurity, it is at least clear that the molecules are endowed with tremendous energy. For example, no known pressure can liquefy air at ordinary temperatures. Its heat-motion must first be reduced very near to nothing. Again, in order that particles of water may hold together-in a drop, in a glass, in the ocean, everywhere-they must be attracting each other with great force; one estimate sets it as equal to three hundred thousand pounds per square inch-twenty thousand times ordinary atmospheric pressure.

Thus far we have kept within the domain of physics, and in saying that the molecules seem to vary but little in size, the reader might infer that they vary little in kind. But here the chemist steps in with other methods to demonstrate the existence of seventy or eighty distinct varieties of molecules - elements, he calls them. These vary widely in 
weight, in combining powers, in every sort of way. Some seem to have three, four, and five arms with which to hold other atoms, while some have but two, some one, and some none at all.

Moreover, the chemist makes a distinction between the atom, that which is irreducible, and the molecule, which may contain two or two hundred or two thousand atoms. And by methods of exceeding refinement he will fix this number for each molecule. For water there will be three, for salt two, for sulphuric acid seven, for sugar forty-five, and so on. The molecules of water, salt, acid, sugar, are the ultimate particles of their substances; divide them further, and they cease to be water, salt, etc. They are resolved into their primitive atoms.

By a very simple experiment the chemist shows that, at ordinary temperatures, molecules usually contain at least two atoms. Here are two bulbs containing two different gases, say, hydrogen and chlorine. Mix them and explode them, and the resultant gas occupies the same space as did the two before. But the result is no longer a simple substance, but a compound-hydrochloric acid in the state of a gas. Following Avogadro's hypothesis, it is supposed that equal volumes of all gases, at equal temperature and pressure, contain the same number of molecules. The chemist reasons, therefore, that the molecules of the hydrogen and 
chlorine must have been split in two. They must, therefore, have contained two atoms. If the average diameter of a molecule is about two-tenths of a micro-micron, then the atom cannot be more than half as big. It is likely much smaller. This, though, is hardly more than guess-work. The very existence of an atom is simply an inference, a deduction. The molecule we may regard as something tangible and real; the atom is a kind of working hypothesis.

But even of the molecules, we know, as yet, very little; and when we come to picture them, there is difficulty enough. For example, water is practically incompressible. We might infer, then, that its molecules touch each other. Evidently, though, they do not occupy all the space, for you may fill a glass brimming full, and then empty into it a considerable quantity of salt or other dissolvable substance without making the water run over. Did the salt slip in between, or inside the molecules? We have no mortal idea.

Moreover, if there are two atoms in the molecule, one would be tempted to think of the molecule as longer one way than another. And there is some reason to think that this is true. Again, it is hard to understand why water freezing in a pitcher overnight should burst it. Most things contract with the cold; water changing to ice expands. There 
are a great many such puzzles, some of them suggested by the most familiar things.

In the molecular world, science still gropes. It is just like exploring a great cavern without even a candle. We have reached down to the physical units of the world as we know it; these are the molecules, and we have learned how to count, weigh, measure, and time them, and calculate, after a fashion, their force and power. But this is not the end. The molecules in turn seem made up of smaller units, the atoms. What are these made of?

For a long time men of science-some of them, at least-looked upon the atom with a little of the old superstitious awe. It seemed to bear "the stamp of the manufactured article," to quote a famous phrase. ${ }^{1}$ It was as if with the atom creation began; and there were seventy-odd kinds. It was a relic of man's waking dreams.

The more philosophically minded took another view. If the millions of different things in this world are all compounded out of seventy-odd elements, and are all reducible to these, probably these seventy elements may themselves be resolved to a single primitive stuff-urstoff, as the Germans say.

'Sir John Herschel.

I 26 
WHAT THIS WORLD IS MADE OF

Hardly yesterday this was but a speculation; to-day we may have the proof. It is very new and most unexpected, for it comes out of the little vacuum tubes which produce the X-rays. The story of how it has come will take another chapter. 

PROGRESS TOWARDS AN EXPLANATION OF ELECTRICITY 
Chagrined a little that we have hitherto been able to produce nothing in the way of ufe to mankind; and the hot weather coming on, when electrical experiments are not fo agreeable, it is propofed to put an end to them for this feafon, fomewhat humoroufly, in a party of pleafure on the banks of Skuylkil. Spirits, at the fame time, are to be fired by a fpark fent from fide to fide through the river, without any other conductor than the water; an experiment which we fome time fince performed, to the amazement of many. A turkey is to be killed for our dinner by the electrical fhock, and roafted by the electrical jack, before a fire kindled by the electrified bottle; when the healths of all the famous electricians in England, Holland, France, and Germany are to be drank in electrified bumpers, under difcharge of guns from the electrical battery.

Benjamin Franklin, Letter to Peter Collinson, London, A pril 29, 1749. 


\section{PROGRESS TOWARDS AN EXPLA- NATION OF ELECTRICITY}

PROBABLy the world had begun to wonder vaguely what was this new thing called electricity long before Benjamin Franklin's famous experiments. But it was when Franklin showed that the lightning drawn from the clouds, and the sparks one gets from rubbing a cat's fur briskly, are one and the same, that interest became acute.

Franklin was not merely the first of the great electricians, but a thinker as well. It is surprising to follow all his ingenious researches and realize how far he actually got. It was he, for example, who was the first electrocutionist-though his victims were hens rather than murderers-and it was he who first employed electricity for cooking.

Over the true nature of the thing whose properties he did so much to unravel, Franklin pondered long and hard. When, said he, I take a glass rod and rub it with a piece of flannel, I find that it will attract or repel certain substances- 
pith-balls, for instance. Under a convenient arrangement, I can make this property pass, so it appears, through a wire, and produce the same effects at a considerable distance. What has happened?

There were two alternatives. The particles of the glass rod might have been thrown into an especial form of motion, and this motion might produce attraction or repulsion, as it ran in one direction or the other. Electricity, passing through a wire, might in such a case be compared to a wave that travels across a pond. On the other hand, electricity might be a sort of fluid, a real substance, invisible, imponderable, subtle beyond any other known force.

Franklin's mind was of the concrete sort, and the last explanation seemed to him to cover the known facts in the most satisfactory way. His conjecture was that all bodies are normally electrified at all times. Under certain circumstances the quantity of electricity contained in a given body could be increased; it would then display the properties of what is called positive electrification. If the normal quantity of the fluid was decreased, it would become negative. This subtle fluid must possess a sort of inertia; it seems to flow from a higher to a lower level, like water. Hence, for example, the appearance of the electric spark. The 
latter was the passage of a quantity of electricity from a positive or negative to a more nearly neutral stage.

Then other discoveries intervened. The matter hardly seemed so simple. First came Volta's invention of the voltaic pile, as it came to be called - that from an alternate arrangement of different metals, like copper and zinc, with bits of moist paper in between, an electric current would arise. From this came the modern battery, such as runs our telephones and fans and electric-bells, and it was with this that Davy produced such marvellous effects, dissolving substances hitherto thought to be elements, and showing the intimate relations of electricity and chemical affinity. And after this, Faraday, revealing how the armature of a magnet, swung round mechanically in the magnetic field, would give rise to a new kind of current, one that seemed to pulsate backward and forward with extraordinary rapidity-what used to be called, to distinguish it from the voltaic current, faradic electricity, as the first was called, quite wrongfully, galvanic electricity, after Galvani, the predecessor of Volta. Nowadays the latter is regarded simply as a continuous current, the former the alternating current.

Finally came the measurement of the speed at which electricity travels. It was found to be the 
same as that of light, one hundred and eighty-four thousand miles per second.

If the ideas of Franklin seemed to fit in fairly well with the discoveries of Volta and his immediate successors, it was not the same with the amazing performances of Faraday. Davy and Arago had shown that an ordinary voltaic current, passing in a coil about a soft iron bar, converts the bar into a magnet so long as the current lasts. Faraday reversed this, and found that simply by pushing a bar of iron towards or away from a magnet generates a current. The latter was so small that though the great experimenter had his finest instruments trained to detect any effect, if there was one, it was days before he discovered that the thing he sought was actually there. But it was the seed of the oak. The modern development of Faraday's device is represented in the giant generators at Niagara Falls, where a line of ten massive dynamos converts the equivalent of fifty thousand horse-power into a current of electricity, and sends it waving through the cables to Buffalo.

No better example could be chosen to stimulate the imagination and make it ask questions. Throw off the "load" of these Niagara generators - that is to say, destroy the magnetic field, and at the same time shut the water from the penstocks which supply the power which turns them, and they will 
go on spinning for hours, so perfectly are they poised. But throw on the "load," and a power of fifty thousand horse is consumed in keeping them going. Yet to the eye there has been no visible change; simply a shunt current has been sent through the coils of the dynamos and made of these inert masses of steel powerful magnets. To whirl the armatures in this magnetic "field" now requires tremendous power. What, then, are the armatures doing? They touch nothing. They are simply cutting the invisible "lines of force" which radiate through the field, and it is doing this work which constitutes the so-called "load." They are cutting paths through an invisible something which lies beyond human ken, but which is nevertheless as real as the waters through which the Deutschland ploughs its way; and some of its properties are measurable.

It was clear enough that any theory of electricity must take into account all these relations between the "fluid" and magnetism; and here Franklin's notions seemed rather crude. Moreover, the curious fact that light and electricity travel at the same unthinkable speed readily suggested that there might be intimate relations between these two sets of phenomena as well. Meanwhile, in the domain of optics, some novel conceptions had surged. 
Sir Isaac Newton was among the first to go very deeply into the nature of light; it was he who first split up the sunbeam into the rainbow-like spectrum, and it was his discoveries in this field that gave him his fame, and made the world listen when, later on, he proposed to reduce the universe to a mathematical equation. Like all great men of science, Newton was endowed with a lively and a very vivid imagination, and it was needful for him, as it was for Franklin and Faraday, to make pictures about the matters of his thought. Regarding light, as regarding electricity, two conceptions in particular were open. Light might be, like sound in air, merely the rapid vibration of an invisible and imponderable something; or it might be pictured as an incessant hail of bodies so minute as equally to escape all means of direct investigation.

Newton reflected deeply, then chose the latter. He called the minute bodies his fancy had created "corpuscles," and in terms of these he built up the Newtonian theory of light. It did not stand very long, and by the time the last century had got fairly on its feet the scientific world had given its suffrage to the rival undulatory theory of Newton's contemporary, Huygens. The latter, in the hands of Young and Fresnel, imagined light simply as a peculiar wave, or wobble-and-wave, in the un- 
ending ether which fills up the blue outside the sky.

Later, to the mind of Clerk-Maxwell, the English physicist who died so young, came the thought that electricity and light are, at bottom, identical - light, short ether-waves; electricity, long ones. Maxwell never lived to see his brilliant guess verified. Heinrich Hertz, of Karlsruhe, did that, ten or fifteen years after Maxwell was gone.

Naturally, then, scientific workers came to think of electricity in the same terms as those of light. Franklin's "fluid" theory was discarded, along with Newton's corpuscles, and dismissed.

Recently the distinguished successor of ClerkMaxwell in the chair of physics at Cambridge, England, Professor J. J. Thomson, took these relics from their hiding-place, and found them singularly alive. The result is what has come to be known as the electron, or corpuscular theory of electricity, and, by inference, since the two can no longer be kept separate, of light as well. And there is hot talk now between the adherents of the newly old and the oldly new.

Readers whose memories run back twenty years may recall something of the flutter aroused when Sir William Crookes sought to demonstrate the existence of a fourth state of matter. Studying the peculiar actions which go on in that same Crookes 
tube which has become so familiar as the source of the Röntgen rays, Professor Crookes was led to the belief that the beautiful, velvety, greenish glow inside the vacuum tube which comes when an electric discharge passes, is due to the incandescence of tiny fragments of matter travelling at an incredible speed. But many doubted.

Professor J. J. Thomson has found a way to measure the speed of these particles, their weight, or mass, as well -in a word, to demonstrate that they are real. They seem quite wonderful, too, for they are the smallest things known to man, and it may be that out of them the universe is made. Following Newton's phraseology, Professor Thomson calls them corpuscles. It is rather bewildering to be told that these corpuscles may turn out to be electricity, matter, light, the aurora borealis, magnetism, chemical affinity, and various other trifles, all at once.

These corpuscles have introduced an utterly new conception into the domain of electricity-that the latter is atomic in character, or, according to the new ideas, atomic in structure. In order to get at some sort of a working model of the processes which go on in his laboratory, the chemist was obliged to resort to the notion of ultimate units of matter, atoms-literally, that which cannot be cut. Choosing the lightest of the atoms - that of hydrogen-as 


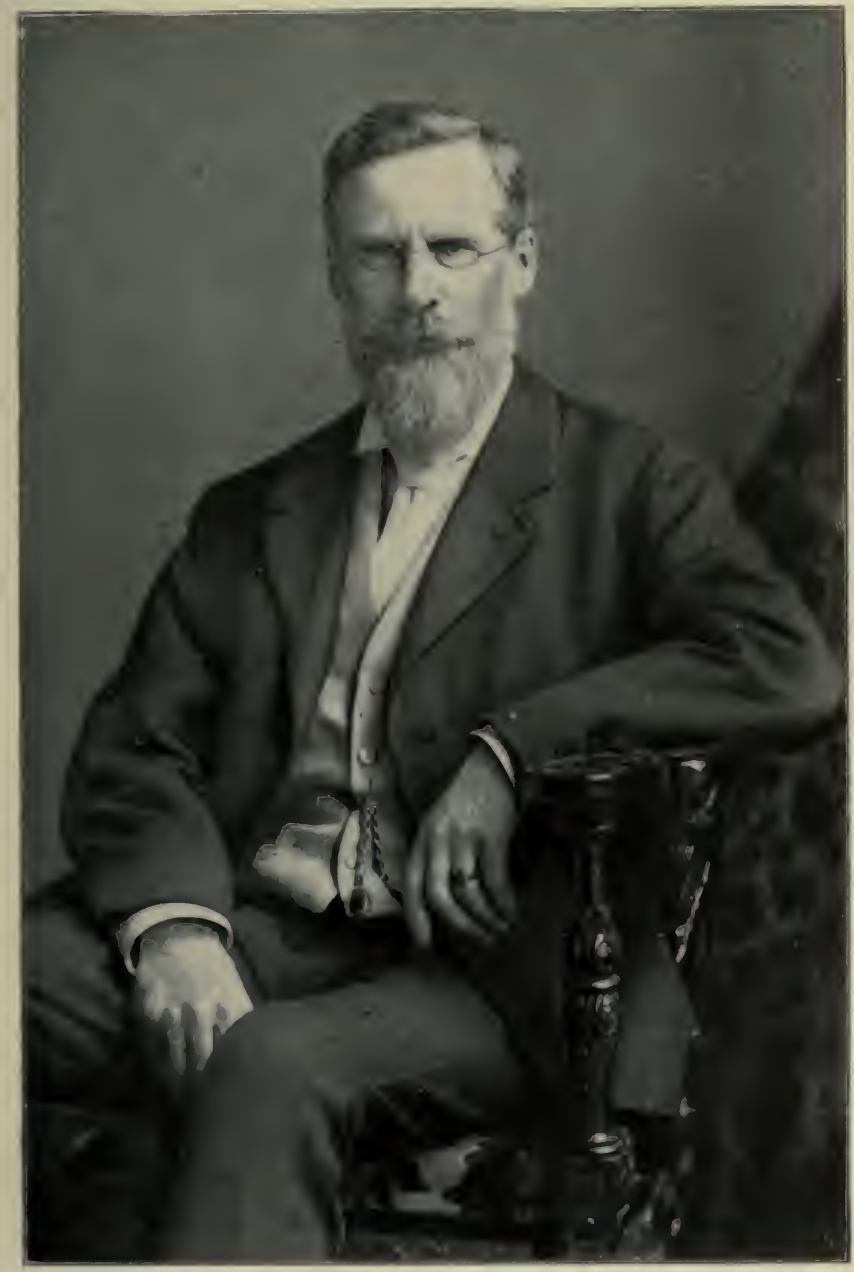

SIR WH,I.IAM CROOKES

Chemist and philosopher, distinguished for his work in the field of molec ular physics. 

a basis, the chemist weighs and measures his atoms of gold or sulphur or iron as if they were so much sugar or salt in his scale pans. A few years ago the notion that there exists a similar natural unit of electricity would have been deemed bizarre enough. But the researches of Professor Thomson and others have shown that the bits of flying matter in the nearly absolute vacuum of a Crookes tube bear a high electrical charge; a stream of them may be bent and deflected by a magnet as if it were a piece of iron. Having found an extremely ingenious way actually to count the number of corpuscles within a tube, and knowing the total amount of electricity they bore, it was merely a problem in very long division to calculate the charge on each corpuscle. No matter what the origin of the corpuscles, or the substances employed, this charge is always the same. It is nature's electrical unit; obviously it needed a label, and Professor Stoney called it an electron.

Now the initiate are endeavoring to determine what is the relationship of the electrical charge, the electron, to the bit of matter, the corpuscle, which carries it. Strange as it may seem, this may be but a school-man's riddle. .The electron is known only as it is associated with a something which has mass, or weight-that is, matter-brief, the corpuscles. In turn, the corpuscles are unknown save 
as possessing the properties of an electrified body; brief, surrounded by or charged with an electron. Then are what we, in our ignorance, term matter and electricity, so indissolubly bound up together that they are to all intents one and the same?

That is how it looks now. The chemist's atom, in the new view, becomes but an aggregation of electrified corpuscles. The mass of the latter is but a thousandth part of that of the lightest of atomsthat of hydrogen; but a hundred-thousandth part of that of an atom of silver or gold. Clusters of these corpuscles, varying in number and arrangement, but absolutely identical among themselves, build up the different kinds of matter-the eighty or ninety "elements" known to the chemist. The corpuscles, in a word, constitute primal matter; they are the stuff of which all existing things-a starfish or a planet, a music-box or a mummyare made.

On the other hand, the electrician is invited to see in the passage of a ten-thousand-kilowatt current but a drift, or rather a rush, at incredible speeds, of these corpuscles-or, if you prefer, electrons-along a wire. It is rather staggering, but the drift may be swift. Professor Thomson calculates the speed of the corpuscles in a Crookes tube at rather more than fifty thousand miles per second 
-about one-third the speed of light. Professor Becquerel figures that the peculiar uranium radiations, called after him the Becquerel rays, travel at twice this rate. It is but a step to imagine others partaking of space with the voracity of light, and, what is the same, of electricity itself.

But this is merely a restatement, in slightly altered terms, of Franklin's old idea. A fluid need not be so grossly sensible as molasses, for example, to be a something which flows. So, in the present view, as water is a fluid made up of particles which, in the form of vapor in the air, may be so delicate as to escape our senses, so electricity is but a fluid made up of particles - electrons or corpuscles - of so extremely subtle a nature as to be sensible only under conditions of extreme condensation, just as the water vapor must condense to drops before we become clearly aware of its presence. Such, in very crude fashion, is the new view.

Those who were reared to the ideas of ClerkMaxwell, regarding electricity as a wave-and-wobble in the highly hypothetical ether, have not failed to implant upon the new theory their collective feet. The matter, however, seems hardly to demand such vigorous discussion. For one may ask, in turn, what is this electrically charged corpuscle, this electron? Perhaps the ether still exists, filling the wavy ways, and the electron may be a sort of ether- 
strain or whirl - even the vortex-ring imagined long ago by Lord Kelvin.

Here available evidence stops and fancy may have freest rein. So, if we like, we may imagine light to be just what old Sir Isaac imagined it long ago-just a bombardment of the retina by a hail of flying corpuscles, given off by every incandescent body. If this be a little difficult of belief, seeing how sensitive is the active part of the eye, we may reflect that the corpuscle is amazingly small. We lack appropriate units of measurement, for to compute them in fractions of an inch would be like measuring the thickness of a hair, say, in fractions of a mile. Lord Kelvin figures out an average atom at less than one twenty-five-millionth of an inch in diameter. A corpuscle is certainly not more than a tenth part of that, and it may be a great deal smaller.

The subject is a little complex, and mayhap a trifle heavy. So I have preferred to retain this slight sketch as a sort of introduction to a more detailed account in the next chapter. 
THE SEARCH FOR PRIMAI, MATTER 
It seems probable to me that God in the beginning formed matter in solid, massy, hard, impenetrable. movable particles, of such sizes and figures, and with such other properties and in such proportion to space as most to conduce to the end for which $\mathrm{He}$ formed them; and that these primitive particles being solids are incomparably harder than any porous bodies compounded of them; even so very hard as never to wear or break in pieces; no ordinary power being able to divide what God himself made one in the first creation.

Sir Isaac Newton, Optiks. 


\section{THE SEARCH FOR PRIMAL}

MATTER

Some account has already been given of how Sir Isaac Newton thought of light as a perfect hail of minute atoms - corpuscles, he called them. Whether from a white-hot body like the sun or a mild affair like an ordinary candle, he saw these little flying chips of matter shooting off in every direction at an incredible speed. It was Sir Isaac Newton who, in fact, laid the foundations of what is called the science of optics, and his ideas, and the mental pictures he drew of these processes in nature which go on beyond the reach of our senses, remained dominant until well along in the last century.

But theories, like plants and people, grow old, and by-and-by Newton's theories were decently put in the ground and a head-stone put up over them. They seemed of no more use to science or to man. Upon the foundation laid by an astonishingly versatile Englishman, Dr. Thomas Young, and the later work of a French physicist, Fresnel, has been reared a wonderful fabric called 
the luminiferous-i.e., light-bearing ether. Nowadays the heavy heads that bother themselves with such matters see in a ray of light merely the pulsation or vibration of an intangible substance which acts like a solid, but which lets ordinary matterbricks and bread and people-go through it just as if it, or they, were a sieve.

No one could ever count up what an amount of time and trouble, of experiment and mathematical calculation, has been spent to make this pure inference turn out to be real and true. The idea has been singularly fertile, and by its aid many simple explanations are possible. It will give an easily understood picture of the action of Signor Marconi's wireless telegraph, of the Röntgen rays, the invisible rays of heat, which Professor Langley, of the Smithsonian Institution at Washington, has studied so thoroughly, and much more. One of the very latest books on physics opens with the remark that all the actions and the phenomena which are grouped under the name of energy, as light, heat, electricity, and magnetism, have come to be simply questions of the mechanics of this inexplicable and contradictory substance, the ether.

So at least matters stood when the late century passed out. But now there is just a suggestion that the present theory of the ether, gigantic alike in conception and result, may likewise go the way of the 146 
world. The germ of such a possibility has certainly crossed the mind of more than one worker in this field, and it may even be surmised that there are many who would not be sorry to pen its obituary. Be that as it may, within the last two or three years Sir Isaac Newton's corpuscles have been showing signs of life.

Brief reference has already been made to this in a former chapter, but the story is worth telling in detail, even at the risk of some repetition.

Most folk who are interested in curious bits of mechanism have seen and noticed the little glass bulbs, with a tiny windmill inside them, which often stand in a watch-seller's window. Under the action of a strong light, or sufficient heat, the little vanes inside this vacuum bulb begin to whirl gayly. The instrument, called a radiometer-i.e., a measurer of radiations, such as heat and lightwas the invention of Sir William Crookes, about thirty years ago, and has been the basis of some very interesting investigations in the domain of molecular physics.

When he had gone a long way in his researches, Sir William Crookes was led to try the effects of electricity on this same little machine. He found that it would run just as well. Then he went further. Some time before-that is, in $1869-a$ 
German named Hittorf had observed some curious actions which took place when the vacuum in the well-known Geissler tubes was carried to a very high degree. Most every one who likes to dabble in scientific matters has seen the beautiful displays which take place when various chemical substances, salts and minerals, are put into these glass tubes of high vacuum and attached to an electrical machine. Gorgeous colors result when the tube is shot through with the electrical current. Hittorf noticed that the same sort of an exquisite glow, something like that which phosphorus gives off in the dark, occurred when a current was put through a tube containing no salts or other substances at all. The colors changed with the kind of glass used, while the glow itself acted very differently, according to how far the exhaustion of the tube was carried.

Men of science were immensely puzzled at this unexpected apparition; it was as if a kind of scientific ghost had stepped out from the wall. . No end of experimenting was carried on, but no great headway was made until Sir William Crookes turned his ingenuity as an experimenter to unravel the matter.

Crookes' first attack was to produce a vacuum such as had never been dreamed of before. How the earth's atmosphere weighs down upon its crust I 48 
with a pressure of fifteen pounds to the square inch, that its weight will balance the weight of a column of a heavy substance like mercury to a height of about thirty inches, is known to every one. It is easy to imagine that there is not much air left in a tube, say, that will only support such a column a thousandth of an inch high. Professor Crookes made such improvements in the Sprengel airpump that the measure of the vacuum he could obtain was represented by a little column only a few hundred-thousandths of an inch high. $\mathrm{He}$ could exhaust a bulb so far that it contained less than a millionth part of its original quantity of air, or, for that matter, of oxygen or hydrogen, or any other kind of gas with which it might have been filled to start with.

This was, and remains to this day, the highest possible vacuum that can be got with an air-pump. Still, measured by the delicate work that is done nowadays in the laboratory, there was yet a comparatively large quantity of air, or gas, left. Professor Crookes conceived the idea of making little bulbs, shaped like dumb-bells, and sealing up in the one end some substance like phosphorus or sodium, which grabs very eagerly at water vapor and different kinds of gases. This absorbing power increases very rapidly with heat, so that, by slightly warming the one end of the bulb in which the 
phosphorus was contained, he could push his vacuum as far as the one-twenty-millionth of an atmosphere. This was a capital advance.

Armed with his new weapon, Professor Crookes attacked the study of this peculiar glow which Hittorf had discovered a few years before. One of the first things he came to see was that these radiations-for under his high vacuum the glow took on more and more the character of a ray of lightalways move in perfectly straight lines, and at right angles exactly, to the end of the piece of metal which served to bring the electrical current to one of the ends of the tube. This was always the end of the tube at the opposite side from which the current entered. Faraday named it the cathode - that is, the negative pole, the pole from which positively electrified particles would be pushed away rather than attracted. Hence grew up the name of cathode rays, as applied to Hittorf's glow, a name which has become so familiar with Professor Röntgen's discovery of the X-rays.

With this notable observation, that the rays moved in straight lines, it is easy to see that when Professor Crookes took for a cathode a little piece of metal curved like a concave mirror, he could concentrate the rays in a point. At this point everything became tremendously hot. Glass melted. Even the most obstinate of metals, like gold and 
platinum, burned and boiled and spluttered away, as if in a fierce caldron. They evaporated like boiling water, and the glass on the opposite side became coated with a thin film. This has often been used since to make delicate little metal mirrors, for scientific use. This "electrical evaporation" was decidedly another step in this puzzling study, and seems destined to play a considerable rôle in what one may largely describe as the ultimate explanation of what is matter. It is possible by this means to split up the solidest of bodies in parts of an almost indescribable fineness, not merely into atoms, but, as we shall see, perhaps into the very primal basis of matter, the stuff of which all known things are composed.

Next Professor Crookes took a magnet, and, bringing it near his exhausted bulb, streaming with cathode rays, saw the rays bent and twisted as if they had been taken hold of and pulled down. Then, by rigging up two little cathodes side by side, and thus bringing into existence two parallel streams of cathode rays, he saw these rays mutually push each other away. They repelled one another just as do the like poles of a pair of magnets. So he said these rays must in some way carry an electrical charge. But the means to measure this charge were lacking then.

Professor Crookes observed another curious fact: 
the higher the degree of exhaustion in his tubes, called now Crookes tubes the world over, the less was the electrical force required to bridge the empty space which lay between the two ends of the wires at the opposite ends of the tubes. The first inference was, then, that an absolute vacuum would be a perfect conductor of electricity. But even before Crookes' time it had been found that a degree of exhaustion could be reached where the conductivity began to grow less again. Professor Crookes was able to make bulbs emptied so far that it took a very high electrical charge to jump a gap of even moderate length. The inference from this was that if the vacuum were carried still further, a bulb could be made which would not conduct electricity at all. A perfect vacuum would be an absolute bar.

If this be true, said Professor Crookes, then it is not the hypothetical ether which carries these " rays," but a very tenuous form of matter. He pictured the particles of the tiny residue of gas in the tube as becoming electrified by contact with the cathode end of the electrical circuit and shot away at a frightful speed by virtue of the repulsion of like kinds of electricity. So he was led to sum up all these curious phenomena under the name of radiant matter.

The tea-kettle of science knows storms quite as violent as those which can arise from differences of 
similar importance in every-day affairs. Ideas like this met with the same opposition that new ideas always do, and a violent controversy ensued, which has only very recently come to an end. Heinrich Hertz, to whom is due the discovery of the Hertz waves, which have done so good a turn to mankind in giving us wireless telegraphy, took up the study and showed that the cathode rays were not, as had previously been supposed, stopped by solid bodies. He was able to drive the cathode rays through goldleaf and produce a phosphorescent glow behind this thin screen. This discovery was, in some sense, the precursor of that of Professor Röntgen.

A little later another young German, Philip Lenard, devised what amounted to a little window in the tube, a window made of thin aluminum foil. By means of this, Lenard was enabled to give the cathode rays a means of exit, and, as Professor Thomson remarks, was thus the first physicist to cross the Rubicon between the inside and outside of a Crookes tube. Then, by way of keeping up the balance of pride between nations, a young Frenchman, Jean Perrin, showed by an ingenious device that the rays do, as Professor Crookes had supposed, carry an electrical charge.

It is here that the work of Professor J. J. Thomson began. By repeating and so elaborating $M$. Perrin's experiment as to set the question of a 
charge beyond all doubt, he was able to go further, and by means of an ordinary electroscope actually measure the amount of this charge.

Here, at last, was solid ground. Professor Thomson was able to measure so accurately the charge that he could prove that a certain space shot through with cathode rays always contained a definite amount of electricity. In other words, he could measure the relationship or ratio between a given mass or bulk of matter, as he conceived the cathode rays indubitably to be, and the charge they bore. This he expressed in his mathematical

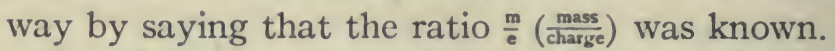

It will be remembered that Professor Crookes had observed that the cathode rays were bent in any desired direction by means of a magnet. But that the same bending would take place when an outside charge of electricity was brought up to the rays long eluded demonstration. This latter Professor Thomson succeeded in bringing out clearly by another of the clever experiments with which the whole history of this investigation has been filled.

By means of parallel plates bearing an electrostatic charge, Professor Thomson proved that electricity could bend the rays equally with a magnet. And this enabled him to measure the speed of the "rays." He found that, varying with the degree 
of vacuum in the tube, the little particles which constitute the rays go whirling through space at a tremendous rate. The slow ones flash by at about a thousand miles a second. A rifle bullet, for example, goes only a few thousand feet a second. The swifter rays attain a velocity of above fifty thousand miles a second, while latterly it has been found that some other rays of an almost identical character-those discovered by Professor Becquerel, and others by Madame Curie, in Paris-reach half the speed of light itself. The velocity of light is about one hundred and eighty-four thousand miles per second. Even a slow imagination leaps instantly to the thought that yet other travellers will be found which go as fast as light-ay, which are light itself.

Knowing the velocity, and knowing the constant relation between a given mass of the cathode rays and the charge of electricity they transport from one end of the tube to the other, would it now be possible to measure the mass and charge of each individual particle? It was a daring thought. But here, as so often happens, a curious discovery in quite another field came to Professor Thomson's aid.

In the laboratory at Cambridge, Mr. R. T. C. Wilson had been working on some odd performances of the Röntgen rays. He took a chamber, or 
cylinder, filled simply with dust-free but not waterfree air; when this was suddenly expanded, by means of a piston being pulled out, so that the air would occupy twenty or thirty times its original volume, no effect was to be observed; but if the chamber was flooded by Röntgen rays, the expansion produced a fog. If this fog was allowed to settle and another expansion was produced there often came another fog, and sometimes it took two or three expansions before the fog failed to appear. There could be no possible doubt that in some way the fog was due directly and solely to the Röntgen radiations. Not merely that, but there was a direct relation between the time and the intensity of the radiation and the amount of fog produced, so that, for example, it was possible to permit a certain radiation and produce a certain degree of fog.

All this brought remembrance of a fact noted by the veteran Sir George Stokes, likewise of Cambridge, that in the case of a fog there was a certain definite relation between the size of the little drops of water of which it is composed and the time it takes a fog to settle. Knowing the rate of settling, you may readily calculate the size of the drops. Knowing the size of the drops, you may afterwards collect the water deposited, weigh it, and then calculate the number of the drops.

The only possible explanation of the fog proI 56 
THE SEARCH FOR PRIMAL MATTER

duced by the Röntgen rays was that the rays acted as a nucleus upon which the water might condense. Without such a nucleus there would be no fog. There were control experiments which. showed that the rays of ultra-violet light-the rays of light so short that our retina will not respond to them-have the same power to produce such a fog as I have described. Other observations, which it would take one too far afield to consider here, indicate that the particles produced by the ultra-violet rays and the cathode rays are, perhaps, identical.

There was further ground for belief that each separate particle, and only a single particle, could act as a nucleus for Mr. Wilson's fascinating fogs. If each drop, then, contained a single particle, here was a means of actually counting the number of particles concerned in a given amount of cathode radiation. It would likewise supply the measure of the mass of each particle. But this was simply the value of $m$ in Professor Thomson's equation.

The mass of each particle known, the charge of electricity it bears is equally known. The problem is solved.

It was solved, but the result was so astonishing, so utterly upsetting of all existing theories, that it is only since Professor Thomson's experiments have been repeated and verified in all the lands of the earth - and, happily, confirmed by other experi- 
ments, arriving at the identical result by quite different means - that men of science have been willing to acknowledge their value. They were revolutionary, for they indicate the existence of particles of matter-countable, weighable, measurable quantities of matter - a thousand times smaller than the smallest known atom.

At first sight this seemed incredible. The mighty atom, if one may borrow a phrase, is the present basis of the whole science of chemistry, and in part of physics as well, both sciences of a marvellous development. An immense amount of indirect evidence has been dug out and built up in the long toil of the century, which can only be neatly joined or vividly pictured by the supposition that the atom is an ultimate reality. There is, indeed, no other explanation in the field. So many and such different kinds of researches have tended to confirm the idea of the atom as the smallest existing particle of matter, that the notion of chopping up this atom, in turn, was a little too much for many.

I have here spoken of the atom as though there were only one kind; but, as we have seen, modern chemistry has been built up on the notion that there are as many different kinds of atoms as there are different elements or kinds of matter. They range in weight from that of hydrogen, the lightest, $15^{8}$ 
to that of uranium, around two hundred times as heavy.

Yet the atoms of the different elements, varying so widely in their weights, their reactions to light, heat, and so forth, seem curiously alike when it comes to carrying electricity through water. Each one carries the same charge, or just twice or thrice it. It was this fact which proved such a stumblingblock to the acceptance of Professor Thomson's results.

What the latter found was that the ratio between the amount of electricity carried by an atom in a water solution and the mass of that atom was a thousand times less than the ratio between the mass and charge of the particles of a cathode ray. It might have been inferred from this that the charge carried by a cathode ray was a thousand times that carried ordinarily by an atom, and, therefore, that the atom and the particle of the cathode rays were one and the same. But Professor Thomson was able to show that the charge of electricity in the two cases was identical. It follows, then, that the cathode-ray particle is a thousand times smaller than the smallest of chemical atoms.

It was clear, therefore, that these minute bodies needed a name, and, taking a leaf from Newton's note-book, Professor Thomson called them cor- 
puscles. But they seem destined to play a far more important rôle than the flying streams which Sir Isaac Newton imagined two centuries ago.

Where the chemical atoms offer an engaging variety, with the corpuscles there is none at all. Whatever be the source from which they spring, whether they come from ordinary air, or from hydrogen or carbonic acid, or from metals, from dull lead or gleaming gold, they seem, one and all, the same.

Has the physicist reached at last the primal matter, the ultimate basis of all existing things? This, it would appear, is Professor Thomson's own view, for already, as I have indicated, he has begun to utilize his corpuscles to explain the composition of matter, and even the nature of electricity, while yet others, coming to his aid, have seen a variety of ways in which the corpuscles may serve to widen our horizons and solve many a mystery.

First, what is the conception that we may make of the atom itself? Compared with the corpuscles, the atom must be something gigantic, a huge composite made up, perhaps, of the corpuscles themselves. And all our present-day conceptions run to notions of matter in motion. Nothing is at rest. The atom might be conceived, therefore, as a great swarm or cluster of corpuscles, revolving about a mutual centre much as our planets whirl about the sun. 
Suppose that by any force-say that of an electric charge or impact against some solid bodythese corpuscles are split off, and either get entangled with other aggregates of matter or go shooting through space at an almost incredible speed; we have then the phenomena of the cathode rays.

But the most remarkable fact is their sameness. It would seem as if the variety and chemical differences of the atoms were due simply to the number, the motions, and positions of bits of primal matter, identical among themselves. In this way we should have an explanation of chemical phenomena of something the same character as that which is used to explain the otherwise inexplicable composition of organic substances. As we now have a stereochemistry, a chemistry of the position of atoms in space, so we should have some day, perhaps, a stereo-physics, a science of the grouping of the corpuscles within the atom.

It is interesting to note that already the young Frenchman who demonstrated the electric charge of the corpuscles, M. Perrin, has calculated that the time of revolution of the corpuscles in certain substances like aluminum, about a suppositional atomic centre, would give very nearly the identical wave-length that is shown by these substances when their light is sent through a prism and displayed upon the screen of the spectrum. It is in 
this manner that theories reveal their value. They are to be judged largely by their fruit, and already the corpuscular theory has proven fruitful.

Professor Thomson draws attention likewise to the application that Arrhenius, the Swedish physicist, has already made to some very familiar happenings. As Professor Thomson has been at pains to show, all incandescent bodies give off corpuscles. The sun we conceive as incandescent. Is the sun, therefore, a gigantic cathode, negatively charged, sending off into space in every direction myriads of millions of millions of these little carriers? So it appears. Some of these would strike the upper regions of the earth's atmosphere, and thus come under the influence of the earth's magnetism. The corpuscles would describe a kind of a spiral, and these would travel along the line of the earth's magnetic force. As they pass northward or southward to the poles they would be bent down following the magnetic dip, and we should have then a simple explanation of the aurora borealis.

In a similar way the luminous character of comets might be explained, and Arrhenius has even gone so far as to calculate the enormous pressure which these cathode rays would exert in a space around the sun. Here we should have an explanation of the reason why comets, when shooting round the sun, turn their tails away from the sun instead of 162 
having them drawn towards it, as one would naturally think they would.

Again, the other workers in this field see in the corpuscles a possible explanation of the extraordinary properties discovered by Professor Becquerel and Madame Curie in uranium and radium, matter which has the capacity to go on glowing with a pale phosphorescent light, apparently forever. It has been shown that these substances each and all emit cathode rays-that is to say, corpuscles. They are all of them of a very high atomic weight, and we might conceive, therefore, that the corpuscles which are thrown off represent something like the Neptunes of the system. They may be supposed to be very far from the centre of attraction, and the least cause may break them off. IVe may even conceive of substances like uranium, whose bulk must be hundreds of thousands of times that of the corpuscles, shooting off the latter spontaneously, and the puzzling action of these radio-active substances would be explained.

One is curious to know what further might lie on the edge of the future. Professor Thomson has tried some calculations as to what would happen if these corpuscles were supposed to be whirling about on their own axes, like the earth, and would thus establish a magnetic field in their vicinity. But nothing he has been able to work out so far 163 
would come anywhere near to explaining the enormous magnetic force of the earth.

On the other hand, perhaps, we have here a clew which will tell us something of why the atoms, as they increase in weight, seem to show a periodic character, a kind of rise and fall in their properties, just as, for example, the notes in each octave, though different, sound in unison. It is one of the problems of the future.

Finally, one may ask what possible practical bearing this brilliant discovery might possess; whether, for example, we should ever be able to utilize the corpuscles for the transport of force and motive power at long distances, without the aid of wires. Professor Thomson's view is that, conceivably, in the upper regions of the atmosphere an incandescent body, like that of an ordinary carbon filament, might be employed to drive off cathode rays which might be collected at some distant point. It is to be observed that it is perfectly easy to direct the rays, since they always travel in straight lines, as we have seen. On the other hand, Professor Thomson has made an interesting calculation to the effect that with an ordinary Crookes tube the amount of matter actually shot off as cathode rays would not amount to more than a few millionths of a gram per twenty-four hours. Professor Becquerel has gone a little further and made a calculation that a thouI64 


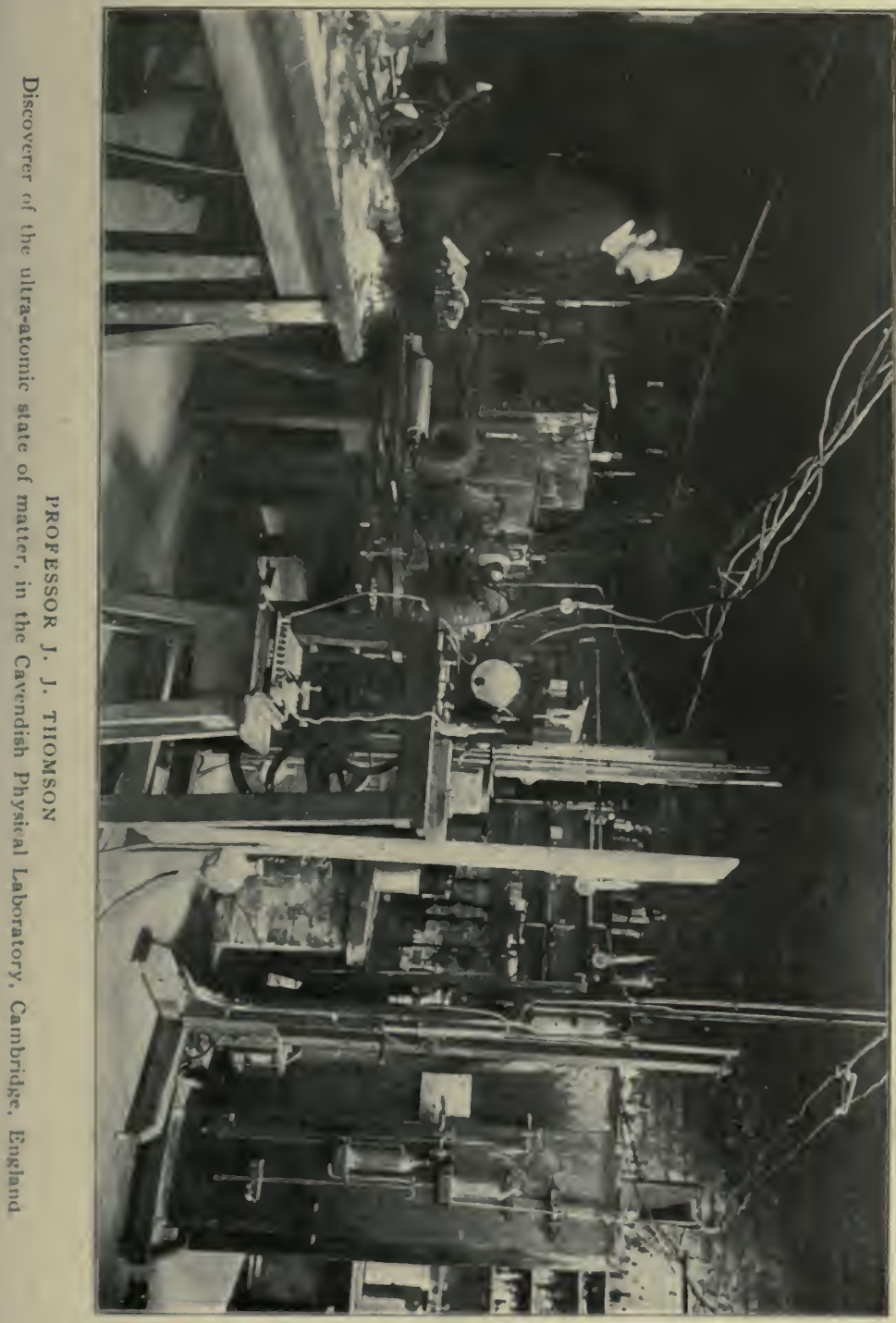



sandth of a gram of his spontaneously active substances might go on radiating for a million years before it would be possible to detect a difference in its weight; though more recent experiments of Heydweiler and Landoldt make this doubtful. The German investigators believe they are able to measure the loss per twenty-four hours. If their results are correct, then the radio-active substances no longer present an apparent contradiction of the law of the conservation of energy.

Such, in broad outline, is the far-reaching rôle which these chips of atoms appear to play. When it is remembered that their existence even was hardly suspected a year or so ago, it will be seen that the unexplored fields of science are not yet exhausted, and that the work of the new century has not unworthily begun. 

THE RISE OF SYNTHETIC CHEMISTRY AND ITS FOUNDER 
Knowing how contented, free, and joyful is life in realms of science, one fervently wishes that many would enter its portals. On this account many pages of this treatise are unwittingly stamped with the earnest desire that the habits of chemical contemplation which I have endeavored to instil into the minds of my readers will incite them to its further study.

Mendeleer, Principles of Chemistry. 


\section{THE RISE OF SYNTHETIC CHEMISTRY AND ITS FOUNDER}

From endeavors to pick to pieces the atoms, we may turn to the more fruitful efforts to pile them up, or group them together into familiar thingsdyes, drugs, oils, foods - in a word, the rise of synthetic chemistry. I shall build the story, as it belongs, around the distinguished career of its founder.

It was in the wide halls of the Sorbonne, to which the genius of Puvis de Chavannes has lent so large a measure of distinction and charm.

First came the President of the Republic, after him the vice-president and the president of the Chamber of Deputies, the prime-minister and his cabinet, the general-in-chief of the army, the chief functionaries of state.

Then there were the representatives of the academies and learned societies, bringing addresses, a hundred and more, from every part of the earth, the tribute of the scientific world. 
The scene was imposing. It was a national fête - to a chemist. It was the French Republic celebrating the half-centenary of her most eminent living man of science. Once before, when the nation paid its debt to Pasteur, had the like been seen in France; not many times in any country or any age.

Fifty years before, M. Berthelot had gained a modest place as preparateur at the Collège de France, long one of the strongholds of French science. Foregathering with his books in a high garret, he became aware of the existence, next door, of a reflective, serious - minded young man, just fled from the priestly seminary of St. Sulpice. The friendship they formed, following their strangely parallel lives, ended five or six years ago with the death of M. Renan.

The unfrocked young seminarist held closely still to his vocation; the study of religions remained his life-work. M. Berthelot chose the mysteries of matter. For a time philosophy allured; but something of a prescience of his genius for experiment must have stirred, and in the laboratory his career began.

In the years that have gone, the face of the world, and our ideas about it, have changed much. Then the "vital forces" were as much of a reality as the spirits which, for Kepler, pushed the planets round in their course. Rather abashed by the mathe- 
matical formulæ of Newton, they retired from astronomy to preside, under a slightly altered garb, at the chemistry of living matter. It is singular how wide-spread was this obsession even among the hardest heads.

Lavoisier had been at some pains to show that this interesting world is made up of a rather small number of substances put together in a rather simple way. He had a notion that water might be broken up into simpler elements; he was rich, and he spent a matter of fifty thousand livres to prove it. A multitude of other familiar bodies showed him their skeletons, or rather the pieces of which their skeletons are made. He created the science of analysis. A little while before the Terror struck off his splendid head, Lavoisier wrote:

"Chemistry, in submitting to experiment the different bodies of nature, has for its object the decomposition of these bodies so that we may study separately the different substances that thus enter into combination. . . Chemistry, then, marches towards its end and its perfection in dividing, subdividing, and re-subdividing still."

These ideas were fecund, and by the time Berthelot took up his work, some sixty or seventy elements, or indivisible substances, had come to be recognized. A few, of rare occurrence, have been added since; but it is worthy of note that none have been taken away. An immense amount of 
pains have been spent in the hope of reducing these simple bodies to others simpler still, but after half a century of effort they remain intact. Chemically, no element has ever been quartered and drawn.

But by the time Balard's new preparateur took up his work the elements and the substances compounded of them had been marked off in two distinct worlds. The one was inorganic, lifeless; the other organic, living. From these two worlds two chemistries sprang.

Long before Liebig a distinction had been noted between the substances of the mineral world-the earth we tread, the tools we use, and those of the living world, the things we eat and the stuff we are. The mineral compounds are simple; they are easy to take apart, to analyze, but they are made up from a wide number of elements; indeed, many of the minerals we know-copper, mercury, iron, gold, silver, lead-are elements themselves. And they are rather easy to put together to make the familiar things we know and use. A metal, sodium, with oxygen makes soda, with chlorine, table-salt. The oxygen, exploded with hydrogen, forms water; the chlorine with hydrogen gives hydrochloric acid. Inorganic synthesis is not difficult.

With the living world it is different. Even its simpler products-sugar, starch, butter, oils-are 
hard to break up. The work was long and painful. Even to this day some of the more complex bodies - the ferments, and the substances which form the physical basis of life, the various kinds of protoplasm-are known only in an approximate way. But this is known, that the whole realm of organic things contains practically only four substances: carbon, such as we find in coal-that is the base of them all; the elements of water, oxygen and hydrogen; and the nitrogen of the air.

The myriad and bewildering variety of organic products, the substances of our bodies, the odor of the rose, the leaves of the forest, the appeasing delicacy of fruits, seem no more than these four substances put together in differing ways. Nay, analysis shows that the most astonishing variety of things can be made up of identically the same number of atoms of each element.

Starch and cotton, to take a striking example, are made up of the same proportions of the four organic elements. So with fruit-sugar and the acid which makes milk sour - the one is sweet, the other bitter; one a liquid, the other a solid; one forms beautiful crystals, the other none. Yet here again the same number of little particles of the same simple substances unite to form the sugar or the acid; the only difference is the way they come together, how they are grouped. 
When Berthelot began his work, chemists despaired of ever unravelling such a tangle. Here was a mystery; it needed a name, and the phrase "vital forces" cloaked handsomely their ignorance. Berzelius, the great Swedish chemist, who dominated the science in the first half of the century, saw in his art only an art of destruction. To rebuild was a chimera. "Even," he wrote, "if we should succeed in producing, with inorganic bodies, substances of a composition similar to those of organic products, this mere imitation would give us no hope that we could ever produce the actual things themselves, as we succeed, in the most of cases, in confirming the analysis of the mineral bodies in effecting their synthesis in turn."

Even Gerhardt, the reformer of chemistry, a thinker and a genius, grew dogmatic here. With a taste for good phrases, he declared that "the chemist does precisely the opposite of living nature; he burns, destroys, operates by analysis, while the vital force alone may synthesize; it rebuilds the edifice that the chemical forces have torn down."

All this was in the face of the fact that two or three very notable syntheses of organic bodies had already been made. A quarter of a century had gone since Wöhler had produced artificial urea, and it is worthy of note that both he and his fellowworker Liebig understood fully the import of his 
discovery. Kolbe had done as much for the acid of vinegar in 1845 . But the time was not ripe.

One of the first exploits of the young Berthelot was to analyze glycerine, then study its combinations. With a rapidity that is still a marvel, a crowd of discoveries followed. Alcohol appeared from its elements; with the gas ethylene he made formic acid, which comes from distilling ants. The fatty substances yielded their secrets, the problem of the sugars was attacked. In five years he had created a new science-synthetic chemistry.

A little later came the synthesis of acetylene, now so common as an illuminating gas. It was the point of departure for a prodigious work. Condensed, simply by heating, acetylene became benzine, the base of innumerable compounds; adding yet more hydrogen, the new compound became ethylene, and ethylene with water gives the alcohol of our whiskeys and wines. Merely to enumerate the results of this incessant activity would form a catalogue.

M. Berthelot had dissipated the phantoms of a vital force and revealed a chemistry, as he himself has phrased it, "more powerful, more varied, more ingenious than nature itself." He had reproduced the natural substances; he had fabricated an immense number of others, their cousins and near relatives. To-day a German dictionary of organic 
chemistry enumerates and defines fifty thousand distinct compounds. The most of these are known to the laboratory alone. But even this is but a beginning. Setting out from the fifteen or twenty of the elementary fats found in nature, to take but one example, it would be possible to create from these some millions of others, of which the principal properties might be announced in advance.

M. Berthelot's work was the beginning of a new form of industry. Already it has destroyed several profitable occupations-for instance, the raising of madder-root and indigo for dyes, now' replaced by others cheaper and more brilliant by far. Already, following in the French chemist's track, Fischer, of Berlin, has realized the synthesis of all the sugars, and, if his processes are not yet commercial, the time does not seem distant when artificial sugar will compete in the market with that fabricated with the sunlight and the soil. Under the same impulsion, too, has come the manufacture of a variety of new anæsthetics and anodynes. From the same coal-tar which supplies the brilliant new dyes, come also phenacetine, antipyrine, and a long line of other stops for wearied nerves.

The Organic Chemistry Founded on Synthesis appeared in 1860. The Origin of Species came a year before; Pasteur's work on the microbes, Claude I 76 
Bernard's on the mechanism of sensation, the year following. It was a pregnant time.

For his fruitful researches, M. Berthelot had been rewarded with a professorship at that same College of Pharmacy where, some years later, M. Moissan was to win a like brilliant reputation for his artificial production of diamonds. This was at thirty-two. At thirty-four came the Joecker prize. Four years after, under the lead of his former chief, M. Balard, the Collège de France created for M. Berthelot the chair of organic chemistry, which he has continued to hold to this day.

Meanwhile, his restless spirit was reaching into new fields. He had shown that this mysterious vital force of his predecessors does not exist. The line dividing the domains of organic and mineral chemism is a figment of the mind. The self-same forces rule in each. It was time to show another mystery the door. For these chemical forces, these "affinities of the atoms"- what are they? For the force of gravity we have the balance, for electricity the electroscope and the galvanometer, for light the photometer. A chemometer, a measure of chemical actions, was lacking. For a science of chemical mechanics, not so much as a corner-stone had been laid. This was M. Berthelot's new task.

Doctrines of energy were abroad in the world. The kinetic theory of gases had been worked out 
into a picture which explains the properties of gases in the bewildering flight and whirl and rebound of their smallest particles, the molecules. The mechanical theory of heat, that heat is simply the clash of the particles, had been built on the same foundations. A kinetic theory of matter was emerging. In the new view, all is motion; there is no "rest." Some experiments of M. Berthelot, made with Pean de St. Giles, revealed a new factor in chemical action, the factor of time. This implied motion; it ought to be measurable.

These two investigators studied the rate of formation of some compound ethers in the reaction of alcohol with acids. The experiments threw a new light upon the subject, for they showed that the velocity of the reaction was not merely measurable in time, but conditioned by a variety of physical factors, among others, that of the quantity or mass of the substances present. The formation of the ethers proceeds more and more slowly as the process goes on, until finally all action comes to an end, .even though both alcohol and acid remain in the liquid. This influence of mass, as it is called, has since been disclosed in all chemical processes, and has been developed into a wide theory of chemical equilibrium, which has thrown a new light upon the atomic world. The working out of the theory has fallen to other hands than those of M. Berthelot- 
to the Norwegians Guldberg and Waage, who had taken up the subject before him, and, among others, to the 1ate Professor Willard Gibbs, of Yale.

Meanwhile, in this play of the atoms, what dominating force presides? The old chemistry had assimilated the varying attractions between different substances to the human passions. The atoms hate and love, seek or reject, their fellows. They, too, have their "affinities." Of this antique idea we catch an echo in Goethe's well-known tale. For M. Berthelot's iconoclastic spirit, the affinities were but princely phantoms like the "vital forces" themselves. The real agent here is heat. With this conception, the new science of thermo-chemistry was born, and its godfather was the founder of chemical synthesis.

Not that the close relations of chemism and heat were unknown before his time. Before M. Berthelot were Thomsen and Andrews, and Favre and Silbermann, and the Russian chemist Hermann Hess. And long before these a famous memoir from Lavoisier and Laplace. But when, in 1864 , M. Berthelot penetrated this new field, the marks of his predecessors were faint and few. His experiments, almost unexampled in their number and extent in the whole realm of experimental science, which provided the foundations, and his co-ordinating genius raised the imposing structure of to-day. 
His ideas were simple, his methods rigorous and direct.

When a chemical combination takes place, when, for example, the two gases, hydrogen and oxygen, are exploded to form water, there is an evolution of heat. A few singular and perplexing exceptions require explanation; they seem to be due to changes of the physical state, to condensation, for example, where the amount of heat absorbed outvalues the heat evolved by the purely chemical effect. This, at least, is M. Berthelot's idea, and it is to be said that unless some such view be accepted, these curious anomalies would bowl over all our mechanical conceptions of the material world. This deviation remarked, the rule holds good.

The quantity of heat generated can be measured. For this the calorimeter was invented. M. Berthelot's calorimetric bomb has been a device of great value. There have been other workers in this field, but their labors seem slight beside the thirty years of uninterrupted toil of this indefatigable man. His work was summed up in two massive volumes which appeared in 1879 , bearing the title of Chemical Mechanics, Based on Thermochemistry. A year or so ago, a second two volumes of yet more monumental proportions saw the day. It is an encyclopredia of the subject. 
For M. Berthelot there are three principles which cover all. The first of these is that the amount of heat developed is a measure of the molecular work done-that is to say, of the chemical affinities. Whether the values so obtained afford a clear basis for comparison, free from all confusion, or whether, perhaps, an electrical method may not yield more serviceable results, is still an open question. If chemical affinity turns out to be simply electrostatic attraction, as seems not improbable, then the thermo-chemical system will probably undergo modification. Until then, M. Berthelot's principle must hold.

The second law is that the amount of heat evolved in a given reaction depends solely upon the final state reached, no matter by what route that be attained. If carbon be first burned to carbonic oxide, $\mathrm{CO}$, then to carbon dioxide, $\mathrm{CO}_{2}$, the result is the same as if the complete combustion had been reached directly, as in the case of an ordinary wood-fire. This is the principle of Hess, and is useful in calculating the heat reaction where that cannot be done by direct measurement.

The third principle seems innocent and looks beguiling enough, but it has caused no end of trouble and dispute. It affirms simply that every chemical change tends towards the production of such compounds as evolve the most heat. If this were 
strictly true, it would, of course, explain very simply why one substance is able to displace another in a given compound; in the language of the older chemistry, why, for example, the metals have a greater "affinity" for chlorine than for bromine. A long list of combinations might be compiled which strictly follows this law. Unfortunately, another list might be made of those which seem exceptions, and M. Berthelot's celebrated "principle of maximum work" seems to be exact only at absolute zero. It is an ideal rather than an actual law.

Closely connected with these questions, as M. Berthelot has shown, is the curious problem of the allotropes. Red phosphorus and white phosphorus are both "elements," and the same element at that. One is a poison, the other harmless; one may be changed into the other merely by heating. One kind of sulphur forms crystals, another will not; a third forms a different kind of crystals. Here, again, heat will effect a transformation. Ozone and common oxygen smell and act differently, yet an electric current of high tension will convert the one into the other. Charcoal, graphite, and the diamond are all forms of the same element, carbon. Here was one of the paradoxes of chemical philosophy. It was not easy to see how an element, supposed irreducible, indestructible, and unchangeable, could exist in more than one guise. 


\section{SYNTHETIC CHEMISTRY}

M. Berthelot was able to show that the difference lies simply in the varying amount of energy bound up in the one "form" and the other; hence that the heat evolved by combustion is not the same. A grate-fire of diamonds would be less economical in point of heat effect than a fire of wood-charcoal. Here again was the utility of science made plain!

A companion puzzle to the allotropes was that of contact, or "catalytic," action. At ordinary temperatures, oxygen and hydrogen may remain in contact for years; a trace of platinum sponge thrown into the mixture, and there is an explosion violent enough to shatter everything in sight. Oxygen and hydrochloric acid may be heated to a high degree, yet they will not combine. A trace of copper oxide starts a vigorous reaction. Chlorine is avid of metals, yet if both be perfectly dry they may remain in contact for years. A trace of moisture brings an instant change. It all seems as if the catalytic agent, as the third substance is termed, pulls a trigger and sets free the forces of combination, until then locked up. But how this is possible was not in the least clear.

M. Berthelot took up the problem, and by an ingenious series of experiments disclosed the fact that, for example, in the case of the "catalytic" action of platinum sponge, there was, first, a com183 
bination of the platinum with the hydrogen gas, then immediately a reaction between this new compound and the oxygen. The first of these combinations had escaped notice, for it is destroyed at the moment it takes place. Other cases of this mysterious force of "catalysis" were explained in the same way. But new and simple mechanical conceptions have to fight their way in the courts of chemistry as elsewhere, and it is curious to note that in many an English text-book the mysteries still find a handsome place.

These are rather special problems. The researches of M. Berthelot on the relations of heat and chemical change found quickly a very practical application, for they led him inevitably to the theory of explosives. The sole distinction between the action of dynamite and that, say, of a candle or a grate-fire is just the same distinction as between a flame and rusting iron. It is simply the speed of the reaction. All these cases are combustions. The oxygen of the air combines with the iron slowly; it is an affair of days, or even weeks. The union of coal and oxygen in the hearth or stove is quicker - an affair of minutes. In the case of powder or nitroglycerine it is a matter of the fraction of a second. With a courage that few chemists possess, M. Berthelot undertook to measure the rate of all explosions. He was able to go 184 
further, and show that an explosion always proceeds in the form of a wave. It is instantaneous to us only because our sense-perceptions are limited in such a way that a series of impressions, following very quickly, as in the kinematograph, seem continuous.

These researches reduced the vague and rather incoherent notions of explosives, which were regnant when M. Berthelot took up the study, to clear and precise deductions, which enabled the chemist to foresee and foretell the effects of any given reaction. They explained why many explosions are incomplete; in the old days often only a part of the powder was burned, the rest was blown away intact; this was the origin of the so-called "powder wounds." The new methods provided a means to control the time of the explosion, so that it is easy enough now to make a powder which will burn like an ordinary match. They made it possible to augment enormously the shattering force of explosive compounds.

When M. Berthelot began, the old black powder, improved slowly since the sixteenth century, was still in universal use. Gun-cotton, it is true, had been discovered as far back as $18_{3} 8$, but the rapidity of its action and the danger from its use were a bar to its general employment. A long series of researches, rivalling in fertility and number those 185 
upon chemical synthesis and thermo-chemistry pure, enabled M. Berthelot first to predict, then in the years that followed to realize, explosives of double the force of anything hitherto known; further, to make these so docile to control that they may be applied in the utmost variety of ways. One of the first results was the beautiful discovery by his collaborator in these researches, M. Vieille, of smokeless powder. From these beginnings a vast industry has grown, for the industrial use of explosives in blasting, railway construction, and other arts of peace now far exceeds their employment in the dwindling game of war.

In the struggle of the Franks and Prussians, and especially in the long siege of Paris, M. Berthelot displayed his tireless activity in devising new means of defence, and, when the ammunition ran low, of manufacturing more, in unheard-of waysin founding cannon, in building mines to explode under the enemy, and even in directing the artillery fire from the heights of Avron. When the disaster was complete, when from the débris of the empire's fragile fabric free and undaunted spirits began the rebuilding of a new republic and a new France, $M$. Berthelot proved a pillar. Apart from the high official positions he has held, he has, as the head of the commission on explosive substances since I873, done much to make France impregnable I 86 
against another invasion. Indeed, in augmenting the defensive powers of man, the influence of his fecund labors was felt even in the struggle in South Africa.

If science, industry, humanity, alike stand in his debt, to them must be added agriculture as well. The remarkable range of his interests found new vent in the purchase of a slender plot of ground on the outskirts of Paris for the laboratory of vegetable chemistry of Meudon. Here, a quarter of a century ago, he began yet another line of chemical investigation, which already seems likely to double or quadruple the fertility of the earth.

One of the four elements from which all living matter is built up is the inert nitrogen of the air we breathe. It seems not assimilated by animals; exact measures disclosed that in the nutrition of plants the atmospheric nitrogen does not intervene in the least. The nitrates and salts of ammonia, which are the condition and almost the chemical sign of life, seem borrowed from the soil. It is the presence of these which determine whether a soil is rich or poor. The carbonic acid in the air supplies the carbon; the rain, the hydrogen and oxygen; and the sunlight, the energy. That the plant manufactory of hydrocarbon compounds, the food of animals and man, may go on, the nitrates of the soil must be renewed. A banker paying out 
each year more than he receives soon closes his doors.

A line of delicate experiments revealed to $M$. Berthelot that the fixation of nitrogen is incontestably due to the presence of microbes. His work he summed up in an expressive phrase. "The soil," he said, "is in some sense living." This idea, taken up by some German experimenters, has led to the establishment of microbe cultures, for the breeding and sale of the especial family of germs which perform this useful work.

But M. Berthelot, not content, has gone further and shown that, under the influence of a silent discharge of electricity, many organic compounds may absorb the nitrogen of the air. So a series of lightning-rods leading to large metal plates buried in the ground markedly increase the yield of a field. The influence of the nitrates used directly as fertilizers is so evidently beneficial that with the development of the guano beds of Chili a great industry has grown up. Still, the nitrates are dear, the beds not extensive. Taking up an old experiment of Cavendish, M. Berthelot has shown that under the action of a high-tension current of electricity the nitrogen and oxygen of the air may be made to combine in large quantities. Much, indeed, of his chief work has been done with this puissant aid. He was the first to show the rôle I 88 
which electricity may play in chemical synthesis. The formation of acetylene from its elements was realized by means of the electric arc, a method which has since, in his own hands and those of M. Moissan and others, yielded such astonishing results.

Patents, looking to a commercial exploitation of this electrical process for fabricating nitrates, were recently taken out in this country. They were not from the French chemist. It is the pride of his countrymen that in all his career he has never turned one of all his long roll of brilliant discoveries to his own profit. Pasteur, Claude Bernard, Faraday, were men of the same stamp. In our Yankee land such an attitude seems a little in disaccord. Is it for this reason that America can produce no great figures like these? Does this intensity of self-interest explain why, spending a greater sum each year on its colleges and universities than any other nation, the United States cannot claim a single epoch-making discovery in the whole wide field of scientific work?

M. Berthelot has never had time to make money. With an inventive genius like his, fortunes needed only an outstretched hand. But there were too many interesting things to do, to know.

Yet these pages have quite failed to depict the man if they have left the impression that $M$. 
Berthelot is other than the most intensely practical of men. Was it not his prevision that gave us ten or twelve years ago a glimpse of that earth of the future when our farms will be turned into parks and the food of our tables will come no longer from the fields but from the laboratory, as the most delicate perfumes, the dazzling colors of dyes, the drugs that lull our nerves to sleep come now? The little phial or the pellets in which we are to carry about a vest-pocket dinner are $\mathrm{M}$. Berthelot's own. From this engaging fancy his bold imagination has looked forward to the day when, from the test-tube and its mixtures, life itself may come. Looking back over the fifty years of his scientific career, such a dream seems not more daring than was his proposal to fabricate in his laboratory the products of life, when he began.

The rude sketch of M. Berthelot's wholly scientific work, covering, though it does, more than is crowded ordinarily in several lives, yet reveals but a part of his amazing activity. It is almost unbelievable that this unwearied investigator in so many paths of research, who has performed with his own hands such a countless number of experiments, who has prepared six hundred memoirs of his work and published fifteen or twenty huge technical works, could find time amid all this, and his lectures, and the ordinary cares of family life, 
to be a historian, a politician, a writer of philosophical works, a minister of state, and quite as ready for a shindy with his favorite enemies, the clericals, as was ever Huxley himself.

M. Berthelot is a scholar as well as a savant. No one has delved so deeply in the lore of the old alchemists as he, and from his pen translations of texts from Greek, Arabic, Latin, have come; solid volumes of history, too. He is a radical of radicals; for him, science shall not merely "yield a deeper knowledge of the universe and a new conception of human destiny; to-day it claims the direction at once material, intellectual, and moral of society." Several volumes of essays bear witness to the intensity of his views. Altogether his literary production is prodigious, more than most lives devoted wholly to letters may show. And he possesses a style replete with all that suavity and limpid charm which is the pride of the French race. The lifelong friendship for Renan must have left its impress here.

And he has mingled in political life as wellmilitantly and aggressively. He has been a senator of France for twenty years, twice Minister of Public Instruction and Fine Arts, then Minister of Foreign Affairs. He has long been the perpetual Secretary of the Academy of Sciences, in some sense the official head of French science. He is an orator, and, 
moreover, as the volume of letters to and from Renan disclosed, an admirable writer of letters. His polemics with Pasteur, his antithesis in all save their common genius for experimentation and work, told that he wields a dexterous blade.

Some little points in his psychology are reported by the eminent physician who made M. Berthelot one of his studies of men of genius. The first is that the frontal lobes of his skull, which are separate in infancy, grew together much later than happens usually. Helmholtz was slightly hydrocephalic as a child. The receipt for genius would seem to be: Plenty of brain-space. The second, that the experiments leading to his discoveries have never been the result of carefully followed trains of thought, of pure ratiocination, but have just come of themsclves, so to speak, from a clear sky. A third, that he sleeps lightly, and all his life has been a persistent dreamer, so much so that at one time he studied his dreams with the thought of turning them to account in his work. Yet never have they given him a single hint or idea or suggestion of any value whatever. In his letters to Renan he remarks that his early predispositions to a gloomy view of the future, his constant apprehensions, and a rather pessimistic outlook on life, have never left him. Yet his family and private relations have been almost ideal, and his career one long series of un- 
interrupted success. His remark recalls that of Bismarck in his old age, that all the really happy moments of his life would fill but a few minutes.

Of the man as he appears: There is recollection of a gray morning in March, two years ago, when I took my way along the banks of the Seine, and up the sole boulevard of which the Latin Quarter may boast. In the subdued light the sombre pile of Notre Dame, a little shrunken and out of place under the usual brilliant skies of Paris, stirred, with its elusive beauty, those poignant emotions which a rare junction of mood and scene may sometimes bring. Even the rather aggressive columns of the new Sorbonne seemed softened, as I turned into a narrow street, where at their side stands the old Collège de France.

Across the court and up a dim, uncertain pair of stairs you fumble in the dark passage for an iron door, open, and find yourself in a small, bare amphitheatre, bare and gray as a cloister. A stray dozen students are there, one a girl. By-and-by the door of an underground passage opens, a little man with an enormous head enters, followed by his préparateur. He shuffles a few notes, scribbled on the backs of envelopes or chance pieces of paper, drops a lump of sugar into a tumbler of water, stirs it carefully with a glass rod, drinks of it gingerly, and in an abstracted, almost inaudible monotone 
begins. It is a large-featured, rather heavy face, with deep-set, grayish eyes from which the joy and sparkle have gone, if they were ever there. They are not dull eyes, but they are mournful, and something in them takes hold of you and grips. The small, slender body seems weighted with such a head, and stoops and rounds a little. The low, monologuing tone of the lecture never rises; occasionally there is a gleam of rather mordant humor, perhaps a passing reference to "some ideas très à la mode." You have in the easy tolerance, the slight disdain of the phrase, the key of a mind that has seen systems come and go, and through long years learned, no doubt, of the evanescence of ideas.

Thus, at seventy-five, M. Berthelot continues to deliver, twice a year, his course of lectures; it is a habit which, after half a century, is a little difficult to put aside. He is easily the foremost man of science in France, the first chemist of Europe. And a scant dozen of students and curious, like myself, make up his audience. The occupants of the other chairs in this same old institution lecture twice a week-some once. M. Berthelot gives three, "according to his custom," he observed. The day I was there he announced that the usual Thursday lecture would be omitted, " on account of duties elsewhere." These duties were the ceremony of his admission to a chair in the French Academy, where 
the learned world, the world of letters, the wit and the beauty, too, of the gay capital, came to do him honor. Perhaps it is something of this unobtrusive simplicity, this singular devotion to a task that will be laid down maybe with life itself, that you feel in those world-old eyes.

$\mathrm{He}$ answers to the fine conception he himself drew when, a few days later, he stood in the great hall of the Sorbonne. "It is not," he said, "for the egotistical satisfaction of our private vanities that the world to-day renders homage to the savant. No! It is because the savant worthy of the name consecrates a disinterested life to the grand work of our epoch: I mean the amelioration-too slow, alas, to our view - of the lot of all, from the rich and the happy to the humble, the poor, and the suffering. That was what was implied by the public powers nine years ago in this same hall, in honoring Pasteur. It is what my friend Chaplain has endeavored to express on the beautiful plaque which the President of the Republic is about to offer me. I do not know if I have completely filled the noble ideal which the artist has here delineated, but I have tried, at least, to make this the object and end, the directing purpose of my existence." 



\section{BORDERING THE MYSTERIES OF \\ LIFE AND MIND}


By a necessity engendered and justified by science, I cross the boundary of the experimental evidence, and discern in that Matter which we, in our ignorance of its latent powers, and notwithstanding our professed reverence for its Creator, have hitherto covered with opprobrium, the promise and potency of all terrestrial Life.

TyNDall, Belfast Address. 


\section{BORDERING THE MYSTERIES OP LIFE AND MIND}

THE morning journals of New Year's, I902, brought tidings from the meeting of American physiologists at Chicago that sent many a mind travelling back to the strange news which had come out of Germany just seven years before. Then, from the secluded University of Würzburg, came word of Professor Röntgen's discovery of his magic rays, that can lay bare the interior of our bodies, pierce solid metals, souls too, perhaps. Seldom had there been so dramatic a step into the invisible and unknown. The man of science marvelled not less than the man in the street.

The papers that were read at Chicago were equally of a sort to stir the imagination of laymen and the elect alike. One, by Dr. Jacques Loeb, bore on the preservation of living substance from decay. A second, from the same source, dealt with the more intimate nature of the life processes, and tended to show that vitality and electricity are possibly one and the same. A third, by Dr. A. P. Mathews, 
a younger colleague of Dr. Loeb, in the University of Chicago, endeavored to lay bare the secret of the nerves, the action of anæsthetics, to reach close to the nature of the mind.

All of these papers grew out of the work that has occupied, more or less, the entire career of this Chicago University professor, who, a year before, had been brought so strikingly to the public notice. Then Dr. Loeb showed that it was possible, in a sense, to produce living things artificially. Chemical agents might effect the fertilization of the eggs of some lower orders, notably the little sea-urchins which swarm on the shores of salt waters. These discoveries seemed to topple over all the ancient ideas of life. And that was their purpose.

No doubt, before many another eager mind dreams of thus controlling the life-processes have floated. The idea must be older than the legends of Faust or Prometheus. And the legends of Faust and Prometheus are very old. But in the present instance these conceptions had been reached by a natural course.

Dr. Loeb's earlier work had dealt with the theory of the instincts. For example, a moth flies straight for a flame. Sometimes of a morning about the light-houses the birds lie scattered and dead, seemingly drawn by the glare to strike against the heavy panes. A flower standing in a room turns its petals 
towards the light. To the birds we ascribe intelligence, to the flower no more than the attraction of light. Yet it seems as if the self-same forces rule over both.

This is what Dr. Loeb set himself to prove. And with it, to explain the origin of all the so-called instincts. When the new-born caterpillar climbs to the end of a branch where it may find the fresh bud on which it feeds, it seems as if some dim intelligence were at work. When it is satiated, it climbs down again. A fly will lay its eggs in meat, whereon its larvæ may feed, but not on fat. These and a thousand other marvels of a seeming shaping towards an end have filled physiology with a metaphysical fog.

In a series of interesting researches, Dr. Loeb showed how all these wonderful adaptations to an end could be explained in a very simple way. Young caterpillars, for example, will follow the light, so long as they are hungry. If they find no food they will keep climbing, conceivably until they die. When they are cold, they will not move. When the warm sun comes in the spring, they begin to crawl upward. They will do this anywhere and on any substance. When they come in contact with food, they begin to eat. When they are fed, they will crawl away from the light. All that is needful to assume is that in the hungry condition 
the light sets up certain chemical reactions which cause the animal to move, just as it sets up a reaction in a photographic plate, or explodes a mixture of hydrogen and chlorine gas. In larger phrase, it is merely a working of positive or negative heliotropism, an attraction or repulsion by the light.

So with the fly. Certain chemical stimuli from meat cause a fly to lay its eggs. In the fat these stimuli are lacking. They can be produced artificially. In the short-hand jargon of science, it is simply a chemical reaction between certain substances in the skin or sense organs of the fly and the meat, a case of chemo-tactism.

So some of the flower-like animals. The actinians, so much like vegetables that they may be distinguished hardly, will wind their slender tentacles round a bit of crab-meat, but reject a wad of paper, which, to us, tastes just the same. It seems like intelligence to watch it, and the older physiologists found no absurdity in saying that these vegetable forms "like" meat and "dislike" paper. Yet the actinian, like the fly, merely responds mechanically to a chemical stimulus.

And so through all the list. Heat may act as a repellent force; thus, for example, if a moth arrive in the neighborhood of a flame, so that the pushing effect of the heat just balances the pulling 


\section{MYSTERIES OF LIFE AND MIND}

effect of the light, the moth will go round and round as planets spin about the sun, or, in other cases, describe a curious zigzag motion, something like a comet. There is naught here but the play of physical forces.

More curious still is the effect of mere contact. If you turn over a starfish, it quickly rights itself. This seems a highly sensible thing to do. Still, as Dr. Loeb found, if you suspend the starfish in water, attaching its arms to bits of cork, it keeps turning over and over, with no seeming preference for which side is up. If a piece of wood or stone be offered, to which it may cling, no matter what be the position, it seems satisfied. Unless its feet have something solid to cling to, the nerves are apparently stimulated; hence the turning motions. Contact brings the animal to rest. This is what Dr. Loeb calls stereotropism. Long words like these seem merely like substituting one mystery for another, but they describe actions as simple as the words are hard.

Physiologists who had a bent for philosophy were not slow to see the drift of all this ingenious and disturbing work. (If the forces that shape the exquisite forms assumed by the crystals on a frosty window-pane, or the leaves and branches of a tree, are the same as those which guide a moth in its flight, there scems no good reason for stopping here. 
Between a moth and a tame crow is a difference of degree only. And a crow is a notably able and crafty bird. We commonly award him very human propensities, so that from a crow to a child is only another series of evenly spaced steps.

The logical issue of these experiments Dr. Loeb has developed in a book on brain physiology, which deals with some current ideas in a way to "make wiseacredom rub purblind eyes and stare." For him animals, like plants, are more or less complicated arrangements of proteid substances, responding in a very simple way to the ordinary physical forces that we know about us.

But more curious things were to follow. The unoffending reader who wends his way through the serried pages wherein Dr. Loeb's work is set down will recoil before the Oriental prodigality of large names. Yet the experiments are simple, the meaning unmistakable. If by his revelations of the rôle of the "trophisms" and "tactisms" Dr. Loeb drove boldly into the domain of mental phenomena, his next invasion struck at the dearest tenets of him who deals with the science of forms - the morphologist. The whole theory of the latter was bound up with the idea that the shape and looks and structure of an animal result from the complex arrangements in the germ from whence it springs. That these could be altered at pleasure, 204 


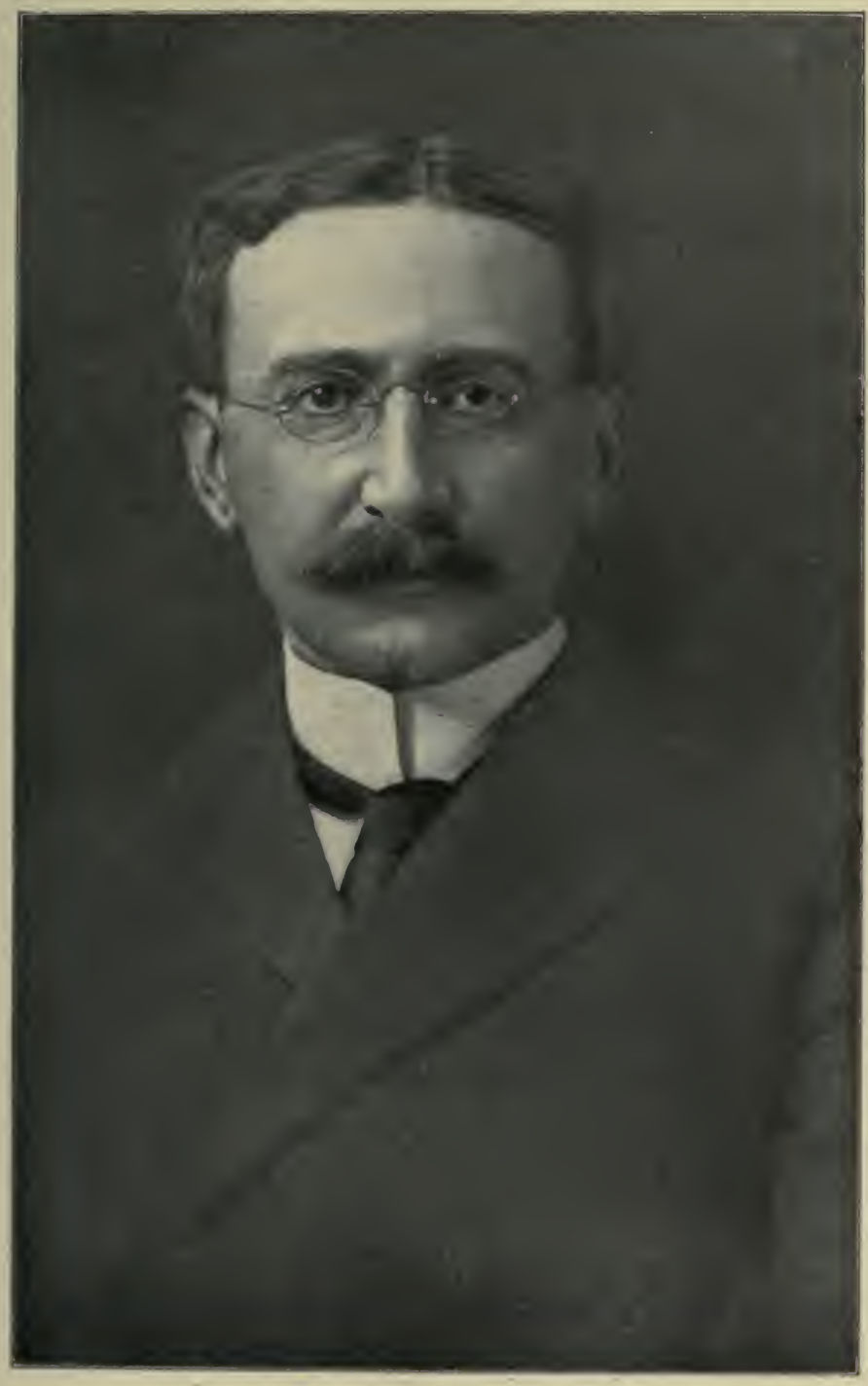

PROFESSOR IACQUES I.OER

Discoverer of artificial parthenokenests 
even in the lower forms, by the same simple reactions of light and heat, chemicals or gravity, was undreamed of.

Taking one of the lower animal forms, plantlike affairs called the hydroids, Dr. Loeb cut from its body a cube. Quite without regard to which side was uppermost, from the top grew the tentacles or branches which form the head, from underneath the roots. If, when growth was partly complete, the piece was inverted, or even if a naturally grown hydroid be turned upside down, from beside the upturned roots came a head, from beside the deposed head a growth of roots.

If, in the body of a little affair named, from its gracefully branching head, the cerianthus, an incision was made, any place, promptly came a new mouth, with its ring of tentacles. Sometimes, if the cut was small, only the tentacles grew. But these would grip food (rejecting wads of paper and things) and draw it in just as if a mouth was there. If the two mouths, the new and the old, were close enough together so as both to touch the same piece of food, a fight ensued. If the same sort of a contest be provoked between the tentacles of the natural mouth and those from an incision where no new mouth had been formed, sometimes the blind "mouth" gets the food, and the animal can thus be led to involuntary suicide. 
If a normal animal be cut in twain, in the middle, and a new mouth grown at the lower end of the upper half and then the animal laid on its side, both ends take in food. If fed in succession, one mouth would reject the food it had just swallowed when the other mouth took food.

Many other experiments, curious and fanciful, disconcerting too, followed. Mere contact with a solid substance could turn one organ into another. Organs were grown in the most absurd places, others were transplanted. This work was, of course, taken up by hundreds of other investigators all over the world, and as a purely fantastic instance, Ribbert has recently shown that a mammary gland transplanted to the ear of a guinea-pig would begin to secrete normally when a litter was born.

All this seemed to show that there is no complex structure in the germ-cells from which these lower forms spring, but that their varying shapes are simply a reaction between a specific kind of protoplasm and the physical forces of light, heat, contact, and chemism, which mould it this way or that. It is a fascinating field, and many would have counted it sufficient for a lifework. Not so this innovating spirit.

A new time was stirring in the stagnant provinces of chemistry. Under the lead of van't Hoff, 206 
Arrhenius, Ostwald, a mechanism of the atoms, or, as it has come to be called in Germany, a physical chemistry, was developing. Many of Dr. Loeb's experiments had been upon the effect of various chemical stimuli. The new theories, which had divided chemists into camps of friend and foe, seemed to offer new weapons to biology. One day he took up the problem of the rhythmical contractions of the jelly-fish, a subject dear to Romanes, the protege of Darwin. If the upper part of the animal be cut away, the contractions stop. Dr. Loeb tried placing the beheaded animal in a solution of common salt; the movements began again. A bit of potassium or calcium added, they stop again.

But if this be true of a lowly jelly-fish, perhaps it is equally true of the rhythmical beat of the heart. And this Dr. Loeb found to be the case. An excised heart could be kept beating for hours, stopped, started, quickened, or slowed, simply by changing slightly the chemical character of the solution in which it was placed. In the same way an ordinary muscle, that, for example, of a frog's leg, could be made to beat in rhythm. Surely this was coming very near to "playing with life." The whole literature of these astonishing researches reads like Faust-dreams come true. If a Newton could tremble before the proof that a mathematical 
formula, cherished through twenty years, expressed a truth, there can be slight wonder that a work so marvellously successful should breed large hopes.

It was clear now that the beat of the heart is not due to some mysterious influence of the still more mysterious nerves, as had so long been supposed. It comes from the presence or absence of a minute quantity of certain salts. The new chemistry stepped in to show precisely how these may act.

A lump of common salt dissolved in a vessel of water makes the water a conductor of electricity. Bits of metal joined to a copper wire dipped therein start an electric current. A lump of sugar so dissolved has no such effect. This was for more than half a century one of the deepest problems of chemical philosophy. It remained so until the distinguished Swedish physicist Arrhenius brought forward evidence to show that the molecules of the salts and acids are torn apart when they are dissolved, and apparently with tremendous force. We are but on the threshold of a knowledge of the actions which take place in the molecular world; in some instances, as in the case here under view, it seems as if these forces are so great that we have scarce any means of coping with them. The effect in dissolving the salts seems to be an enormous electrical charge on the individual atoms. In the tearing apart, one set is charged positively, the 208 
other negatively. In the case of ordinary salt, sodium chloride, the metal atoms of sodium take the positive charge, the chlorine atoms the negative. These electrically charged atoms, long before their nature was understood, Faraday named ions.

This simple conception has revolutionized modern chemistry. In the famous phrase of Arrhenius, "it is the ions which act." And it is the ions which may cause the heart or a muscle to contract. The negative charges set them going. The positive charges stop them. Such, in an extremely popular presentation, is the essence of this remarkable work. In the new view, the ultimate cause of muscular action, and, not improbably, of all life-processes, is electricity.

The applications of this conception are wide.

If the apparently simple question of solutions was the hardest problem of the chemists, that of the beginnings of life, the process of fertilization, was the burning question of biology. From the countless myriads of eggs produced by the female organism, and the equal hordes of the sperm-cells, a single egg, a single sperm, unite to form the single microscopic cell from which all forms of animal life originate. Unfertilized by the male cells, the eggs quickly degenerate and die.

All the problems of life, growth, heredity too, lie $x$ 209 
buried, then, within this bit of living matter, so small it is often invisible to the eye. The sperm and the egg must be the carriers of all that one being tansmits to its descendants. Exterior forces here seem to play but a minor rôle. After the union of the two cells, the influence of either parent seems as slight as that of a hen brooding over its nest of eggs. An incubator may replace it, a fact whose wide significance seems a little to have escaped the airy-headed folk who prattle of prenatal influence.

But before the astonishing results here considered, no one dreamed that an egg could grow and develop without the remotest aid of the sperms. Else, how explain the supposed "facts" of heredity? How can traits and characters of the male parent be transmitted to his offspring?

Yet under some conditions the male element seems not needful. Dr. Loeb succeeded in producing growth without the sperm. His disconcerting discovery was directly the result of the application of his chemical theories to these processes.

One of the lowly organisms which lend themselves so well to study and experiment are the little sea-urchins, so valued by biological workers. Taking the sea-urchins' eggs from the ovary, before there could be the slightest possibility of contact with the sperm cells, they were placed in the ordinary sea-water in which the animals live. 
Eight or nine years before, Dr. Loeb had observed that if the fertilized eggs were placed in seawater made a little more concentrated by adding some neutral salt, they do not begin to divide and grow as they do ordinarily. The process of celldivision seems inhibited. But if afterwards they were put back into normal sea-water, they at once broke up into a large number of cells, instead of dividing successively into two, four, eight, sixteen, thirty-two cells, etc., as they usually do. Several stages, so to speak, have been skipped over. In other words, the process of development of the animal had gone on, in a measure, without the fact being apparent.

While continuing his studies on the effects of salts upon life phenomena, he was led to the fact that the peculiar actions of the protoplasm are influenced to a great extent by the ions contained in the solutions which surround the cells. By changing the relative proportions of the ions, it is possible to vary the physiological properties of the protoplasm, and thus to impart to a tissue properties which it does not ordinarily possess. Pursuing this idea, he took unfertilized eggs, and after many trials succeeded in finding a solution of chloride of magnesium which caused the eggs to develop to the same stage that they do normally in an aquarium. Subsequently it was found that other salts and the 
eggs of other animals would do the same. These results, at first contested and even scouted, have been obtained by other workers in many lands. There is no longer a shadow of doubt that artificial parthenogenesis, as the process is technically termed, is an established fact.

In a strict sense, the unfertilized egg cannot be termed living matter. The first characteristic of living matter is that it can grow. In other words, here is an organic product, like sugar, or starch, or the fats, which, treated chemically, can be developed to a certain stage artificially. It was near to a realization of the dreams of Berthelot and Claude Bernard, ay, and of many anotherthe manufacture of life in the laboratory. Certainly it was one of the vital discoveries in the history of physiology.

A close study of all these novel and unheard-of reactions, the heart which may be started or stopped with a pinch of this salt or that; the muscles which may be made to beat like a heart; the egg which may be vivified by chemical means, revealed the common chain that seems to link them all. One of the riddles which faced the older chemists, those of half a century ago, was the curious fact that, when the atoms come to combine with others, some of them seem, so to speak, to have but a single arm with which to take hold, 
while others have two, some three, some four, and even five. So, for example, when wood or coal "burns," the four-armed atom of carbon can seize and hold two of the two-handed oxygen atoms, while in the molecule of water, each of the twohanded oxygen atoms will bind two of the singlehanded hydrogen atoms, and so on.

Chemists, with the old alchemists' love of highsounding names, called this valency, or atomicity.

Very early Faraday saw that each "valence," each arm, was able to carry a certain quantity of electricity. Its capacity is fixed. These electrically charged atoms, then, are not all alike. The two-armed atoms carry two charges, the threearmed three charges. If, as now seems dimly to be true, what we used to call the loves and hates of the chemical "affinities" was but a name for the action of these electrical charges, then chemistry, like light, will have been annexed to the wide domain of electricity.

Professor Loeb's latest work has done much to fix this impression. He has found, for example, that a pure solution of common salt will not keep the heart, or the muscle of the jelly-fish, going. A little calcium added sets things right, though too much will act like a poison. Some of the ions then are toxic, some are antitoxins. Will this turn out to be true of all poisons, that their action results 
from the positive or negative charge of electricity they bear? This is but a surmise as yet, but it seems a promising lead.

Meanwhile, it is clear that the "valence," or the number of electrical charges, plays an important part. The poisonous working of a single-charged negative ion may be offset by the addition of a small quantity of a double-charged positive ion, and, perhaps, of still less of one with a triple charge. So, too, a triple charge may destroy the harmful action of a double charge. It is just simply the number of charges which counts.

Here, then, are the most significant of the life processes-growth, reproduction, muscular action, the influence of poisons-brought back to the play of the electrical ions, negative and positive -one, two, or three valent. Almost involuntarily one turns round to ask what is the effect of the food we consume each day.

Apparently the chief rôle of food is not to be digested and "burned" in the muscles and organs, as present-day physiology assumes, but to supply ions. The heat developed is a by-product. The chief action is the production of electricity. The body may be likened to an electric battery. Food, then, is of value according to the amount and kind of electricity it affords. Many, no doubt, have entertained a suspicion of this for a long time. If it 
should turn out to be true, here is a large chapter of physiology that, it would seem, must now be rewritten.

It would be strange if before the eyes of such an investigator had not fluttered that will-o'-thewisp which has enchanted so many speculative minds, the problem of prolonging life. But Dr. Loeb's idea is, as one might easily suppose, original and new. His work in parthenogenesis had made it clear that while ordinarily the unfertilized eggs quickly die, simply by normal or chemical fertilization they live. Viewed in one light, it is as if there were two distinct processes going on. Death and disintegration are not a mere breaking down, a going to pieces, but a specific process, that is checked by the life process.

But if such a "mortiferous" action really exists, perhaps it could be checked chemically as well. That is what he tried to see. Potassium cyanide was tried, and it was found that if the unfertilized eggs were placed in a weak solution, they could be kept alive for days. If, then, the cyanide be allowed to evaporate, the eggs may be developed and grow in the normal way.

It seems paradoxical that life may be thus maintained by a powerful poison; but if we conceive of a specific mortal process which may be held in check, and regard the potassium cyanide as sub- 
stituting a condition of suspended action, the matter seems clear.

This reads like a very simple experiment; most great experiments are. It would be idle to suppose from this that the secret of long life has been found. But one would be more preoccupied still who disregarded the significance of this new line of investigation.

There remained one wide area of the life processes which Dr. Loeb had but bordered - the action of the nerves, the physical processes by which we feel and know, the avenues through which come the awe of Niagara, the tragedy of a Duse, the wonder of a rose.

Dr. Loeb's earlier work had tended, indeed, to show that the mysterious and elaborate structure which present-time physiology attributes to the ganglions and the cells is quite useless, that all we need ask for in a nerve are the most elementary properties of protoplasm, that it will conduct, and react to stimuli. It seems as if the nerve is the least differentiated of all the tissues of the body, has remained the nearest to the primitive plasm with which life begins. It is not needful to add that all this is directly the reverse of the generally accepted idea which would naively endow "thinking matter" with a complexity befitting its high 
rôle. But such views opened the way to simple mechanical conceptions of the processes of sensation.

When Dr. Loeb had shown that frog's muscles might be made to beat or stop under the influence of certain ions, it was but a step to suppose that these same ions might have an equal effect on the tissue of the nerves. That step was taken by Dr. Albert P. Mathews, a colleague with Professor Loeb, who had come back to his native city of Chicago after a varied wanderjahr, to take the post of physiological chemistry in its university.

A mass of observation and experimental material was already at hand. Half a century ago Thomas Graham, a highly original English chemist, struck out a broad line of distinction between those substances which crystallize when they solidify and those which do not. The latter he called the colloids, the gluelike substances. An ordinary hen's egg, or gelatine, are good examples. When the cook stirs up fat or jelly in hot water she makes a colloid solution. Speaking broadly, the human body is such an affair. That is, it is about seventyfive per cent. water, the rest jelly and bones. The nerves and the brain cells are eighty or eighty-five per cent. water.

The action of the colloids in water was long a bothersome puzzle. Much light came when Hardy, 
of old Cambridge, in England, demonstrated that the colloid particles bear an electrical charge, that these complex molecules (some chemists suppose the ordinary white-of-egg molecules to contain five or six thousand atoms) act just like a simple ion. Further, Hardy showed that the colloids carry a positive charge, and are then precipitated by the negative ions.

There was another notable work being done, by Overton and others, on the effect of anæsthetics; chloroform, ether-all their like dissolve fats. Their action on the nerves is to deaden, to stop sensation-that is, to retard the progress of the nerve impulse. And the nerves are, to put it crudely, simply highly phosphorized fats in a weak salt solution.

To bridge over from the one to the other of these striking facts needed but a constructive imagination, and that the quick mind of Professor Mathews supplied If, he said, the nerves consist of colloid particles in suspension, and the effect of chloroform is to make a solution thinner by dissolving the particles further, that must be the process by which a nerve loses its ability to be excited. The thinner the solution in the nerve the less easily it conducts. The process of stimulation must be just the opposite. A nerve conducts better, is more easily stimulated, the nearer it 218 
approaches a state of jelly. This would be brought about by precipitation of the colloid particles. And if the latter are positively charged, as Hardy has shown, then it would be a negative current which would offset such a precipitation, and hence a negative current that produces a stimulus of a nerve.

It was precisely this that Professor Mathews found to be true, that the stimulus of a nerve by an electric current always proceeds from the negative pole, the cathode. Here seemed quite striking proof that his theory was well grounded. It seemed the opening towards a complete explanation of nerve action. Slight wonder if a young man of thirty, keen to enter the front of the lists, should sit up nights thinking about it, and Professor Mathews did.

Taking the muscles of a frog, to which the motor nerve was still attached by one end, he undertook the systematic study of various solutions of salts, such as Professor Loeb had used to make the muscles beat directly without the intervention of the nerves. The muscle itself was hung so that when it contracted it made a lever work up and down, and the latter, with a pencil attached, would trace the jerks on a revolving drum. The nerve was bathed in the solution. To see the thing in action with one's own eyes gives one an uncanny feeling. 
It soon was clear that Dr. Mathews was right in his belief, that it was the negative ions which made the frog's legs jerk. Their action through the nerve, and on the muscle direct, is the same. The nerve, then, must somehow effect a release of negative ions at the point where it blends with the muscular tissue. How?

If, said Dr. Mathews, the negative ions be in excess in the solution, and the positive and negative ions in the nerve be just balanced, the effect would be the precipitation of the first layer of colloid particles bearing positive charges and in contact with the solution. This would release a certain number of negative ions lying next in the nerve sheath, and these in turn would precipitate the adjoining colloids. This would result in a kind of wave of precipitation, travelling along the nerve, and at the end would be a set of free negative ions, ready to call the muscle into action. The nerve impulse, then, would appear to be a consecutive series of precipitations.

But it remained to be explained how a mere mechanical stimulus, a push or a blow, could set up this wave. This can be accounted for by supposing the effect is the same as when rain-drops on a window are made to coalesce when the window is struck. Two or more colloid particles coming together would have their surfaces reduced, hence their electrical 
charge reduced, and hence the release of a corresponding number of negative charges. The wave is started.

All this, it should be understood, is as yet simply a working hypothesis. Whether it turn out to be true depends on how well it agrees with such facts as may come to light later. But on the basis of such material as exists, Professor Mathews has reached an extremely elaborate and ingenious theory. He found that different quantities of different solutions were required to produce the same effect. Comparing his figures, Dr. Mathews found here, as Dr. Loeb had found in previous work, an apparent influence of the valences. Some of the doubly charged atoms appeared to produce twice the effect of the singly charged, and so with three and four charges.

Yet this simple relation would not explain all. The single and double and triple charged ions varied among themselves. Among the salt-forming elements there seemed to be a curious relationship with their atomic weights. Bromine atoms were more effective than the chlorine atoms, iodine than the bromine. But fluorine, the lightest of the group, was the most active of all.

Professor Mathews has essayed to account for these differences by an appeal to the very newest theories of electricity. Taking a hint from Lar- 


\section{NEW CONCEPTIONS IN SCIENCE}

mor's hypothesis of electrons, which supposes a kind of an electric atom, a charge not associated with ordinary matter, he believes that, for example, the electron rotates about the atom of fluorine twice as fast as about the chlorine atom, and hence develops a more powerful field of action.

But all this is merely mathematical speculation. It is interesting, but not proved. Still, the general theory does link together, apparently, a wide number of related facts. Heat, for example, would make the colloid solution thinner, hence the nerve would be less easily stimulated than when cold. At high temperature the colloids would turn into jelly, and the nerve be excited. So the excess of negative ions, speeding along the nerve, would explain what physiologists call negative variation. There are other matters of much too technical a nature to be entered on here-the effect of the different kinds of light and the like.

To sum it up, Professor Mathews's theory is that what happens to a nerve when it is excited is nothing less than a tendency to "jell," just as happens to the housewife's jams and custards when they are left to cool. And this effect depends on four factors :

r. The kind of electricity, negative or positive, carried on the colloid particles of the nerve, and by the atoms in the solution which surround them; 


\section{MYSTERIES OF LIFE AND MIND}

2. The number of charges the colloids and atoms bear;

3. The rate of rotation of the charge, or electron, round its atom;

4. The size of the orbit of this rotating electron.

These last are for scientific folk to puzzle over. Simple people will be more interested in the way the theory might explain some every-day affairs.

Chloroform, carried into the blood through the lungs, and so to the brain, tends to dissolve further the highly sensitive brain-cells. While this state lasts there can be no sensation. Little by little the chloroform is swept away, consciousness returns. Quite comparable is the rather familiar fact of intoxication. Alcohol carried from the stomach through the arteries to the brain has the same effect.

In this same easy fashion one may explain the action of whiskey when a man has been bitten by a snake. The effect of the poison is to coagulate the substance of the nerves. Alcohol has the opposite effect, and so may save a man's life. This is important, if true.

It is all very new. It will require long and patient experiment to determine its value. Professor Mathews naturally believes that from it much may come. It would, for one thing, afford the basis for a rational pharmacology. By means of the ionic 
theory the effect of drugs would be computable with a mathematical accuracy. So, too, in the field of psychology it would afford an insight into the mechanism of sensation such as at present we have scarcely a trace. It would, too, reach far into the nature of nervous diseases-St. Vitus's dance and its like-and likewise afford a solid foundation for a nervous pathology.

Here, as throughout these pages, is displayed but the effective climaxes of long labors, of days and nights of patient experiment, of ingenious questioning, of slow piecing together the scattered bits of hardly acquired knowledge. In reality it is the work of an army of investigators, scattered over the earth, but all advancing, under the invisible captains of a common purpose and a kindred hope, towards the conquest of the unknown world which lies beyond our primitive senses.

Even the man in the street may now begin to perceive its deep and practical value, and perhaps feel something of admiration for the fruition of a vast effort, directed not by instincts of gain and greed. A high humanity breathes here, larger, if I mistake not, and more intelligent than any prompted by mere sentiment or a naive impulse to set by the hardships and inequalities that crowd this workaday world. 
The very attractive rewards, material and public, especially potent in American life, have turned away the current from study and research. As a result, America has won no such place in the larger spaces of positive knowledge as Germany, France, and other lands. The brilliant example of what a healthier spirit, as exemplified in the work of the University of Chicago, may bring, should be helpful. There is no reason why the Darwins and Kelvins, the Berthelots and Virchows should be born abroad. But the first condition is that a noisy politician, or even a millionaire, shall not be set in honor above the men who, through the slow advance of science, are helping to banish disease and want and fear from out this earth. 

THE NEWEST IDEAS AS TO WHAT IS LIFE 
The presence of all the students of the École Normale brings back to me how dazzling was my first enthusiasm for science. The representatives of the faculty of Lille recall to me my first studies in crystallography and fermentation, which opened up an entirely new world to me. With what hopes I was filled when I first surmised that there were laws behind so many obscure phenomena.

Pasteur, Jubilee Speech.

It is the cell to which the consideration of every bodily function sooner or later drives us. In the muscle-cell lies the riddle of the heart-beat, or of muscular contraction; in the gland-cell are the causes of secretion; in the epithelial-cell, in the white blood-cell, lie the problem of the absorption of food, and the secrets of the mind are slumbering in the ganglion-cell.

VERWORN, quoted by Wilson, The Cell in Development and Heredity. 


\section{THE NEWEST IDEAS AS TO WHAT IS LIFE}

Not very long ago one of the stock-in-trade illustrations of the poverty or bankruptcy of science, or of our ignorance in general, was the lack of any sort of notion of what is life. Probably in many circles it is so still. There are types of minds that find a curious joy in ignorance, that cling to it tenaciously, for whom the riddle of life has always been a sort of a trump card.

The physical process of life is no longer a riddle. It is possible now to define and describe life as precisely as, let us say, the making of bread or the brewing of beer. These illustrations have been chosen advisedly. If it be urged that we do not yet know what is fermentation, that we know as little of the working of the housewife's yeast or the brewer's malt as of life itself, there will be no one to gainsay. For, curiously enough, they seem one and the same thing.

Physiology's present answer to the old riddle is, very simply: Life is a series of fermentations. 
This conception, which represents the very latest results in biology, has, as any one might guess, not been reached at a bound. It has been gained by very slow steps. And incidentally this advance has served to show that fermentation, which once seemed so comparatively simple, is in reality a wonderful thing. Positive knowledge runs back only about sixty years. The beginning was with a French crystallographer. Not many, perhaps, will recognize under this designation the great bacteriologist Pasteur, to whom we owe the whole germ theory of disease. Yet it was precisely his studies of fermentation which led him to his immortalizing discovery of microbes; and it was, in turn, his study of crystals which led him to the study of fermenting malt.

Pasteur started out to be a chemist. He took up the puzzling question of why one sort of tartaric acid, in solution, will twist a beam of light out of a straight path to the right, another sort to the left. One day he chanced to observe that a certain kind of yeast-cells would thrive in the one medium, not in the other; this seemed to indicate that the structure of the living yeast-plant was closely related to the queer actions of his right- and left-handed acids.

When, forty years later, that most fruitful career in the last century had closed, Pasteur and those who followed his lead had gone deviously 
and far. He, and they, had revealed the prevalence of these invisible fungus-like growths throughout the whole of nature, had traced the good and evil effects of their presence in the human body, in the air we breathe, in the water we drink, the food we eat, and had shown that some of these are the cause of disease.

Yet Pasteur, on the crucial point, was utterly wrong. A single experiment served to overthrow the ideas towards which he had devoted a good portion of his life-work. Like many another, his mind seemed to rebel against mechanical or physical explanations of such. phenomena as those of life. It was he who had revealed the intimate relations of life and fermentation; chemist though he was, he yet shrank from a chemical explanation of both.

For Pasteur, fermentation was always and ever a vital action, a product of the activity of living things. Chemical that product might be, but the process, never. A German savant, Buchner, came to the problem without this prejudice. He took a culture of these same yeast-cells with which Pasteur had done so much, mixed them with a very fine, very hard quartz sand, then put the whole under enormous pressure. Of course the sand crushed the yeast-cells to pulp. From this pulp flowed a sap, or liquor, which, carefully strained, 
produced exactly the same fermentive action as the yeast-cells themselves. Obviously fermentation is due to the presence in the yeast-plants of a chemical substance which may be expressed out of them. Pasteur's mysterious "vital action," then, seemed a myth.

This decisive experiment derived especial importance from the fact that it came as a sort of climax to a long series of researches which had already disclosed the far-reaching rôle of fermentive action. Long before the days of Pasteur two French investigators had succeeded in isolating from germinating grain a substance that seemed to possess almost unlimited capacity for splitting up starch into simpler compounds. Later it was found that the saliva of the mouth contains a substance possessing the same power. Its discoverer, not knowing much about it, named it ptyalin.

Then came the discovery, in the stomach, of the substance familiar now to every one under the name of pepsin. It acts especially on the proteids, the meat- and egg-like foods. In the bile secreted by the liver was found another, whose work it is to make an emulsion of the fat foods, so that they may be taken up by the blood; the pancreas manufactures another, which completes in the intestines the work begun by the ptyalin of the mouth; and 
very recently it has become clear that the walls of the intestines themselves secrete a substance whose office is to complete the work of the stomach; which may explain why it is that dried pepsin from the pig's stomach is not the dyspeptic's digest-it-all that had been hoped.

Like animals, the plants were found to contain similar substances; and of the same sort are the rennet which curdles milk, the active part of brewer's malt, and some of the powerful vegetable and animal poisons even.

The common property of all of these peculiar substances is their ability to digest or split up quantities of the substances they attack, out of all proportion to their own mass. A given amount of the active principle of malt will, for example, break up a million times its own weight of sugar.

So close was the resemblance in their effects of these near-related families of substances to the ordinary fermentation of yeast-cells and the microbes that they came to be called the soluble or formless ferments, as opposed to the organized or living ferments, the bacteria and fungi. French workers patriotically call them diastases, after the parent discovery; Germans prefer enzymes; others. zymases.

It fell to Buchner's admirably conceived experiment to disclose the identity in principle of all 
these fermentive actions - in a word, to demonstrate that they are alike due to specific substances, the ferments. Half a century of toilsomely gathered materials was that day fused in a unified body of knowledge.

Meanwhile, almost in the same year, an ingenious young Frenchman, Gabriel Bertrand by name, made a curious observation that was most upsetting. From the days of Lavoisier's celebrated experiments, more than a century old, the physiologist had been led to regard the taking up of oxygen and the giving off of carbonic-acid gas by the lungs and in the cells as the simple play of chemical mechanics, a mere question of the varying pressures at the surface of the body (the lungs) and the interior (the cells) The ordinary method of manufacture of commercial oxygen from the air was supposed to be identical. Bertrand found that one condition for the taking up of oxygen by the lungs was the presence of a specific substance, which was itself unaltered, could be destroyed by heating or by various acids and poisons, temporarily rendered inactive by ether and other anæsthetics-in brief, comported itself exactly as a ferment. Destroy this ferment, and you cannot breathe-you will die. Bertrand named it, accordingly, oxydase.

But the idea that a ferment was necessary to seize the oxygen in the lungs and hand it over to 
the red corpuscles of the blood-that, in short, even so simple a process as respiration was, at base, a sort of fermentation-was, to physiologists, most untoward. But to a few a glimmer of the truth must have come.

But a difficulty stood as a gulf. Just as the single experiment of Buchner's on yeast-cells meant certainly that every form of fermentation by microbes, fungi, or other living things was due to a specific chemical substance, so did Bertrand's discovery foreshadow the belief that all vital actions are in the nature of fermentations. But fermentation is destructive. Nothing could be more firmly based than that. The ferment of malt splits up sugar into alcohol and carbonic acid; the pepsin of the stomach breaks down the albuminous foods into simpler molecules, peptones, etc. So all through. On the other hand, side by side with the incessant destruction which is one of the two most striking characteristics of the lifeprocess, is incessant construction. Before catabolism there must be anabolism. Indeed, the destruction, the analysis, is death, rather; it is the upbuilding, the synthesis, which is life. But a constructive ferment was a plain contradiction in terms.

Scientific nomenclature - or, rather, scientific short-hand-is a little forbidding at times, and so 
it was that Croft Hill's bold announcement, three or four years ago, of the discovery of "reversible zymohydrolysis" was not starred in large type in the public prints the next morning. But this young Englishman had shown that a constructive ferment exists; or, rather, that under given conditions the destructive action of the ferment is reversible.

When starch, or dextrine, is submitted to fermentation by the malt enzyme, it is hydrolyzedthat is to say, split-by taking up water, into one of the simpler sugars, glycose. But if the resulting product is not removed, the action soon comes to a stand-still. Add more starch, it will begin again; but add to the quantity of sugar, and the reverse process is begun; the glycose is converted into starch. The enzyme, then, is able to rebuild the molecule it has pulled apart.

Very recently a German chemist, Emmerling, has found a yet more striking example. Under the influence of one ferment, an extract of almondsamygdaline-may be broken up into sugar, hydrocyanic acid, and the essence of bitter almonds. Another ferment, that of malt, again, will put these products together to form the original compound. Still other of these curious jacks-of-alltrades seem able, in many cases simply by the extraction of water, to solder together the simpler 
NEWEST IDEAS AS TO WHAT IS LIFE

food products into that highly complex protoplasm which Huxley named so well the physical basis of life.

Is the reader a little staggered at the multifarious activity of the ferments? - let him compress his vision so that he may take note of what goes on in the space of the hundred-thousandth part of a needle's point. That is the size of the cells of the liver-there are millions and millions of them, absolutely identical, alike in form and function. In the invisible compartments of these microscopically minute workshops at least ten or twelve distinct ferments have been found, manufacturing various kinds of sugar and acids and urea and bile and color-stuffs; they take up various poisons and render them harmless, bind up the acids with diverse substances to form others more complex, and in the meanwhile must see that they themselves get a proper supply of food and water and oxygen, and that all these are churned up in a state proper to assimilation.

What is true of the liver seems equally true of all the other glands and organs of the body-the kidneys, the spleen, the pancreas-and for each of them there may be a dozen or more distinct ferments, each with a special and appointed work to do. Even the brain and the nervous system have their specific ferments, and these are certainly 
necessary to, if they do not actually share in, the processes of sensation, and thought itself.

In brief, for every vital function, a ferment. That is the latest word of biological chemistry. In broader terms, the sum of activities we collectively call life is a series of fermentations.

Naturally the very first question is, what are these ferments, these enzymes or zymases or diastases? That is the biochemical problem of the hour. So far they have utterly baffled inquiry. Their activity seems bound up rather with the peculiarities of their atomic structure, of their chemical architecture, so to speak, than with any mystery of ingredients. They are compounded of the simple elements of water, air, and carbon. It is how these are put together that is so puzzling.

But the solution is not far off. Some German chemists, Bredig and others, have been able very closely to imitate some of the ferment actions by means of solutions of finely divided metals, such as platinum and gold. It has been found possible, too, to produce enzymes not normally found in the organism. This is a step further. We may learn of the chemical synthesis of an enzyme any day, and that will be but the prelude to the manufacture of life in the laboratory.

If this seems hazarding much, let it be noted that such faith in no wise implies the chemical synthesis 
of puppies or chickens; not of figs or thistles even. In the present state of our knowledge the step from a coral polyp to an oyster, for example, let alone a human being, the number of whose brain-cells alone outruns the number of people who dwell upon this earth, is immeasurably greater than from a piece of coal-tar to the coral polyp.

But this close pressing of the most intimate secrets of life has another implication of far more interest to the men and women of to-day. The matter I touch on now is so extremely new that it has been reached, so to speak, only by the outermost line of pickets. Here and there men of lively and daring imaginations, such as Newton and Faraday had, have caught sight of it, but their previsions seem as bizarre to their fellows as to the layman who reads and dreams merely. It is, in brief, that perhaps all the processes of life are reversiblegrowth even; that under given conditions the oak might become an acorn, the grown man a child, the adult organism led back through the successive stages of its development to the primitive germ from which it sprang.

Recent research has shown that every step in the process of assimilation, or nutrition, is presided over by a special ferment. And what we call growth is but cell division, a mechanical splittingup of one cell to form two, when, through an in- 
crease in size, the cellular equilibrium has been broken. This process, endlessly repeated through long years, builds up from a single parent cell the tall figure of the giraffe, the huge bulk of the whale, the chalk-beds of England, or some vast reef of coral in the Pacific.

The discovery by the English chemist Hill that the active enzyme of starch fermentation was reversible, the discovery by the German Emmerling of a ferment which will undo the work of another, give earnest of the day when, the mode of action of the ferments being as well known as the working of rennet in the making of cheese now, the action of the cellular ferments may be reversed at will; the fabric they have reared would go down piece by piece, the separate parts shrink, coalesce, decrease, until, perhaps, naught remained save a formless clot of jelly-like stuff-the jelly of life.

Are these but Faust dreams? No; rather a simple statement of fact. On a miniature scale, at least one or two such instances are known. A plantlike little affair, Campanularia, living and developing normally in the water, undergoes an amazing transformation simply upon being brought into contact with some solid substance. First the little buds or shoots along its extended arms or branches begin to retract, and finally disappear: 
then the arms or branches themselves slowly draw in, until only the trunk or body remains; finally that, too, shrivels little by little, until this welldeveloped organism, having a perfectly distinct and characteristic form, has been reduced to an inchoate huddle of gelatine-like stuff that can no more be thought of as Campanularia than the Temple of Diana might be inferred from the heaps of mouldering stones about its site.

But remove this formless mass from contact with the solid substance, and restore it to its normal conditions - the huddle begins to take on shape, to extend, to grow, to throw out its arms, and from these again the little fingers shoot out. Large as life and twice as natural, one beholds Campanularia again. Nor is this recession and redevelopment a mere mechanical unfolding and refolding, like unto some of the ingenious affairs devised for conjurers; for the formless mass of primitive substance may be turned over, shaken up, and altogether so differently placed that the idea of a reappearance of the old form with exactly the same parts is untenable. It is a wholly new Campanularia, whose structure and shape and parts are not due simply to its internal organization, but, so far from that, are so much a direct reaction to external forces and conditions that the point where the regrowth shall begin may be fixed at the will of the experimenter. In plainest word, this bit 
of protoplasm is almost potter's clay, to be moulded to what shape he pleases.

Here the sole condition of reversibility in the evolution or devolution of this organism appears to be that of contact. What may be the vital, or, in more precise phrase, the molecular processes which determine this curious spectacle lie as yet far beyond the ken of the biologist. But that slowly yet surely he will penetrate the mystery is beyond doubt. Once gained-the magic word, the wizard wand, which shall call forth or banish form, structure, parts, or organs in the lower types of lifeshall he not rise progressively in the scale, until perchance all life phenomena shall be within his control-until it will be within his power to "take life in his hands and play with it"?

That day may be distant, but meanwhile there is one phase of the problem that seems nearer to our day and time. That is, the realization of Ponce de Leon's quest of prolonged youth. Arrest of growth, the stunted plant, the deformed or undeveloped child, the idiot, the cripple, the prematurely senile -are not all these painfully familiar to our daily view? Yet why should the mechanism of nature, so seeming sure, turning out a thousand perfect specimens, slip so sadly with the thousand-andfirst? We know in part, and can in part control. An impoverished soil, consumptive, syphilitic, or 
otherwise diseased tissue, lack of sunlight and air -these are the producers of the physically, mentally, and morally maimed. With narcotics and poisons we may stop development, whether it be that of a plant or a child.

But what may be arrested may perchance be influenced in other ways. We have seen how the whole drift of present-day physiology is to reduce life to the connected and concerted play of the ferments. The identity of the two processes holds in most unexpected ways. Heat and cold, chloroform, the poisons, the toxins secreted by the virulent microbes even, act upon the test-tube fermentations of the laboratory in precisely the same way as upon the living organism. Even the curious ferment-like solutions of fine platinum and gold may be "poisoned," "chloroformed," or "killed," as if they were alive. What is dis-ease, mal-action, and death for the one is the same for the other.

It seems to be clear, too, that the condition of growth, whether of a grain of wheat or the germ of a man, is the production, or appearance, of distinct enzymes-ferments-at each stage. Cessation of growth must mean the disappearance or lapse in activity of these special enzymes. What we call growing old seems merely a series of destructive fermentations. It is probable that these are present from the beginning - that throughout all life there is 
a struggle, so to speak, between the two; that in some sense, as Professor Loeb once remarked, death is a physical agent, the material antithesis of life.

If the action of the malt enzyme upon starch is reversible, so is that of the ferments which convert the active tissue, the living protoplasm, into the relatively dead, fatty, or connective, or cartilage, or bone tissue - the characteristic, as the great Russian biologist, Metchnikoff, has shown, of advancing years. As the discovery of the constructive ferments gave at last a clew to a complete account of the whole life process, so those who have closely and reflectively followed the development of biochemistry feel the discovery of reversibility in fermentation may in time disclose the reversibility of the life process: in more concrete phrase, the arrest of death, the prevention of old age, the preservation of youth.

\section{ON THE NUMBER OF MOLECULES IN THE} LIVER-CELL

It was set down by the philosopher Kant that the development of a science may be gauged by the amount of mathematics it contains. Probably mere dimensional statistics were not the sort of mathematics Kant had in mind; nevertheless, numerical calculations help wonderfully to clear thinking, and clear-headed people always make them if they can. They help to visualize a subject.

It may be of interest, therefore, to make some sort of 
an estimate of how many co-operating units are represented in the activities of a single liver-cell. The latter ranges in size from seventy-five to one hundred cubic mi-

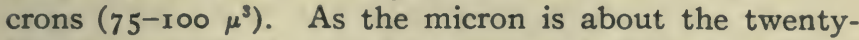
five thousandth of an inch, a cubic inch of liver contains, then, around 156,000 million cells. As the human liver contains about 90 cubic inches, it will be seen that it is a rather complex body, at least in point of numbers.

Nevertheless, although these minute cells are invisible to the naked eye, they are perfectly visible and open to study under the microscope. They are made up, like all other cells, of a nucleus or kernel, and a surrounding mass of semiliquid substance. The whole cell assumes a granular appearance under high magnification.

Probably, like living matter in general, they average about one-fifth solid substance, the rest being water; but this water is incorporated as an integral part of the living molecule. Gautier and others estimate that the white-ofegg molecule contains five or six thousand atoms. We have seen, in the chapter on "What This World Is Made of," that the average molecule in a gas is about one-fifth of a micro-micron in diameter $(0.2 \mu \mu)$, so if each of these gaseous molecules contains two atoms, we may take onetenth of a micro-micron $(0.1 \mu \mu)$ as the average atomic diameter.

Of course this is only the roughest sort of a figure, but the actual size is probably not more than five or ten times more or less than this. On this basis, the albumen molecule, containing five thousand atoms of carbon, hydrogen, nitrogen, and oxygen, might be somewhere around one and three-quarter micro-microns $(1.75 \mu \mu)$ in diameter. It is probable that the living molecule is rather larger than this, but we have as yet no means of knowing. I will take this figure provisionally. If the size of the liver-cell is from seventy-five to one hundred cubic microns, its diameter will be around seven microns $(7 \mu)$, or four thousand times the diameter assumed for the albumen molecule. 
The number of living units in a single microscopic livercell would, on this computation, be above 64,000 millions. The total number of atoms would be around $300,000,000$ millions. The number, I think, is sufficient to account for a tolerable amount of vital activity. With $300,000,000$ million atoms of varying size and quality, grouped to. gether in almost infinite variety into 64,000 million molecules, one might do a good deal of explaining.

Perhaps it will be worth while to offer another calculation of a little different sort. Living substance, protoplasm, is supposed by Butschli and others to have a honeycomb-like structure. Suppose that the figure of one and three-quarter micro-microns for the living molecule is somewhere around the reality, and that we use these to build little compartments, as in a honeycomb. We will make the walls of each compartment four molecules, or $7 \mu \mu$ thick; one might compare it to a brick wall, four bricks, or around one foot, thick. The diameter of each compartment we may suppose ten times that of the walls, or, say, $70 \mu \mu$, and filled with water, oxygen, food, sugar, bile, waste products, poisons, mineral salts, and other things, just as is the living liver-cell. This would make each cell eighty per cent. or more water and other things, ten or twenty per cent. protoplasm. In a single liver-cell of one hundred cubic microns we should have a million of these honeycomb-like compartments. Supposing that each liver-cell contains as many distinct organs as the human body, say twelve or fifteen, each of these separate organs of the liver-cell might contain near a hundred thousand chambers or compartments. Whatever may be the actual number, it is certainly enormous.

And the liver-cell is small. Beside it, the human germcell is huge. The speck from which we spring is little enough. It is practically invisible to the naked eyeonly 0.2 of a millimetre in diameter. But that is $200 \mu$, or nearly thirty times the diameter of a liver-cell. Its bulk is, therefore, 27,000 times as great. In a single microscopic 
germ - cell we might install 27,000 liver - cells, each containing 64,000 million living units, and each of these, in turn, made up of 5000 atoms of various sorts.

The writer has often heard intelligent people descant upon the impossibility of obtaining any mechanical picture of the germ-cell that will tally with the supposed facts of heredity. They either lack imagination or are mentally lazy. It may be added that the supposed facts of heredity mostly do not exist.

As all the assumptions involved in these calculations have been explicitly stated, it will hardly be necessary to warn the reader that these figures are only to be taken for what they are worth. But they help to show the possibilities that lie in the purely physical explanation of the life processes. And in another twenty-five or fifty years, at the present rate of advancement, this explanation will be complete. Molecular physics will have reduced all the phenomena of life to the play of known mechanical forces. 

HOW THE BRAIN THINKS 
If matter can fall to the ground, then it can also think.

Schopenhauer. 


\section{HOW THE BRAIN THINKS}

THE idea of a chemistry of the living body, of bones and muscles and secreting glands, is not new. It was Lavoisier, for example, who showed that the work of the lungs, taking up oxygen and giving off carbonic acid, is a simple chemical process, much like the burning of coal in the grate or the rusting of iron. And the butchers of the French Revolution had stilled the workings of his splendid brain before the eighteenth century closed.

The chemistry of mind is more recent. It was about a half-century ago that a reflective German, gathering together the scant results of his day, formulated his famous aphorism:

"Ohne Phosphor, kein Gedanke" - without phosphorus, no thought.

That was not the beginning of the endeavor to find out how we think. The anatomists had been busy for a half-century before. And they have been still more industrious since. Thanks to them, we have now a marvellous picture of the minute structure of the brain and the nerves. They can 
follow more or less definitely the path of every exterior sensation, whether it be one of sight or sound or touch. They can trace even the course of the twinge of pain that comes, say, when an unprotected finger meets with a careless thorn, and they can follow more or less the resulting stimulus that makes you cry out Oh!-or something else. And the experimental psychologist of the day will time this and every other mental process to the fraction of a second.

Nevertheless, we are as yet only just beginning to see the whole of the picture; it may take another quarter or half century before we shall "see it clearly and see it whole," as the late Matthew Arnold was wont to say. Meanwhile it is curious to note that the daring guess of Moleschott, of a half-century ago, might still serve fairly well to describe what we know of the chemistry of the brain:

"Ohne Phosphor, kein Gedanke."

This is not the way a physiologist of to-day would phrase it exactly. The patient investigator is shy of a pat phrase, that, after all, tells little. Still, it is a matter of some interest to know that there is a substance, as chemically definable, let us say, as cheese or anthracite coal, which does our thinking. The physical basis of thought and sensation is the brain and the nerves. And the vital part 
of the brain and the nerves seems to be a highly phosphorized fat, and without the phosphorus this fat does not seem to think.

The world of science was a long time accepting the notion of a living substance, a chemically analyzable basis of life. Huxley's celebrated "protoplasm" lecture did much to reconcile men's minds to this materialistic conception. But it has been a great deal harder to bring men to conceive of a thinking substance, a form of matter, like salt or sugar or gunpowder, whose business it is to feel and think and dream. To many the notion is uncanny.

The conclusion, however, seems inevitable. So far as we know, the processes of thought and consciousness are associated only with a special form of living substance, a particular kind of Huxley's "protoplasm." And protoplasm is a more or less definite substance that can be, and has been, analyzed in the chemist's tube. It is, as we have seen, made up, in varying proportions, of the water we drink, the oxygen and nitrogen of the air we breathe, the carbon of the food we eat. Add a trace of mineral salts, the salts of iron and others, a little sulphur and phosphorus, and the list of elements is complete. The analysis is difficultnot yet, perhaps, absolutely exact.

But the main facts are clear. The chief constit- 
uent is water. Barring bone, which is only a very little alive, our bodies are more than three-fourths water. Even bone is more than half, while our brains are about nine-tenths water. Mixed with water into a sort of gluelike solution, which may become as hard as the enamel of the teeth, are the various compounds of the four elements-carbon, oxygen, nitrogen, and hydrogen, which we daily take in.

This peculiar substance exhibits two especial characteristics. Its assemblages of atoms, its molecules, as chemists say, may grow, and by splitting in two, reproduce; that is what happens when the grains of corn become a waving field; it is what happens when the egg becomes a soaring eagle. This is the first vital characteristic; the second is that this living substance is irritable.

This power of reacting to stimuli, which Claude Bernard called irritabilite, is in some sort possessed by all matter, but by living substance in a paramount degree. It is this characteristic which, more than anything else, distinguishes the living organism. Thinking substance is a kind of intensified living substance.

At first the line of demarcation is wholly absent. The different parts of a coral polyp react equally well to any outside influence. But very early in the scale a difference begins to appear; we find what 
answers to a head and body, or root and stalk. The leaves of a plant will turn towards the light; so will the head of a silk-worm. The parts take on special duties and powers. And with this come the rudiments of a nervous system.

In worms and other lowly types, the different parts of the animal are connected by thin threads of a highly sensitive substance which conveys a stimulus much more swiftly than the rest of the body. They are nerves. When two or three nerves meet at a common point, we have a little bunch or bulb of nervous substance called a ganglion. It is usually found near the end which answers to the head. Other ganglia appear as we rise in the scale, but always the one near the head is the largest, and it acts as a common centre for all the others. It is the beginning of the brain.

From this to the brain of a Helmholtz or a Shakespeare is but a steady and uninterrupted development, through fish and bird and beast to the highly endowed ape, and thence, by insensible gradations, to the finest type of civilized man. It is, apparently, merely an increase in the number and arrangement of the concerting units of ganglia and connecting nerves. And in this orderly evolution there is no break, no link missing anywhere.

Whether it be the brain-cell of a glowworm or one trembling with the harmonies of Tristan und 
Isolde, the stuff it is made of is much the same; it is a difference of structure, apparently, rather than of material. And the chemical difference between a brain or nerve cell and that of the muscles or the skin seems reducible, mainly, to a difference in the proportion of two substances, water and phosphorus. Lean beef, for example, is from seventy to eighty per cent. water; the brain is from ninety to ninety-five per cent. water. And a brain or nerve cell may contain from five to ten times as much phosphorus as, let us say, the cells of the liver or the heart. The actual quantity is, of course, extremely small, by weight but a fraction of one per cent.

About three pounds, avoirdupois, of this very complex, phosphorized stuff make up an average human brain. There is a lot more of it distributed down one's spinal column; and in little plexi all over the body, wherever a group of muscles are to be moved; and, again, in the motor and sensory or feeling nerves, which are everywhere. It is hard to find a cubical half-inch outside the bones where they are not.

All told, this nervous substance, which, for the sake of making its functions clear, I have called matter which thinks, forms a not inconsiderable portion of the body, outside of the bony skeleton. It is made up of distinct and separated units, for the 256 
most part extremely minute, though some attain a length of two or three feet. These units, for lack of a more misleading name, are called cells. The "cells" which run from the small of your back down into your toes, and wiggle the same, or inform you when a member of the family is stubbed, are the longest. Those of the brain are mostly so small as to tax the powers of the microscope; their average length would be measured in thousandths of an inch. There have been many attempts to get at their actual number; it is certainly large. Computations, for the brain alone, range from six hundred millions upward. One, due, I think, to Waldeyer, sets the total number of brain-cells (average) at one thousand six hundred millions. This would mean a brain population exceeding the known population of the earth.

Of course, the number varies enormously, for the size and weight of the normal brain varies greatly. A great deal of nonsense has been written on this subject, and attempts made to trace a connection between size and capability. This is obviously absurd, for some of the largest brains known belonged to idiots. The sizes of comparatively few distinguished brains are known, and most published figures are worthless. The list on the following page is authoritative, and speaks for itself. The sizes are given in cubic centimetres: 
Average human brain, 1400 (49 oz. avoirdupois). Dr. Döllinger . . I 1207 Agassiz . . . I $12^{12}$ Harley . . . . 1238 Thackeray . . 1644 Gambetta . . . I294 Schiller . . . I78I Liebig .. . . . 1352 Cuvier. . . . 1829 Bischoff . . . . $145^{2}$ Tourgenief . . 2012 Broca . . . . 1485 Byron . . . 2238 Gauss . . . . . 1492

It will be seen that Byron, who was commonly supposed to have a small head, is highest on the list; and whatever may be thought of his poetry, he seems to have been a man of rather mediocre intellectual attainments, as poets generally are; while Baron Liebig, who possessed one of the bestequipped brains of the last century, was below the average. So, too, there is but a slight difference in the average size of the male and female brain; though the general inferiority of the latter was evident enough up to the latter part of the nineteenth century. Directions for computing the size of your own brain, if you are interested, ought to be found in any good encyclopædia, though they probably are not. As the brain is so nearly all water, it is evident that the figures for size, in cubic centimetres, express, with some rough approximation, the weight in grams, and this may be quickly reduced to the ounces and pounds of our antiquated system.

In general, the size and weight of the brain varies $25^{8}$ 
directly with the size and weight of the body. It is obvious that a big body will need a big brain to run it right, for nine-tenths of nervous activity or "mental" action is devoted to the promotion and control of the muscles. A little man with a big head, then, is apt to possess more of what we call brains than a big man with a relatively small head.

But there seems another anatomical characteristic of far more importance than size. That is the appearance of the brain surface-the cortex, or rind. When the brain of a highly developed man or woman is examined, it is found to be creased and folded in an extraordinary way, thrown into convolutions, as the neurologists say. And so it seems as if "brains" are a matter of area of brain surface, for the effect of the folding and creasing is to afford more area in a given space. In the matter of brain anatomy it is the superficial man, then, who is the great man. And, in general, the more folds and kinks he has the greater will he be.

But it is not until we penetrate into the finer structure of the brain that we begin to catch a glimpse of the mechanism of brain-action. Countless attempts had been made to unveil this complicated structure, but it was not until an Italian, Professor Golgi, took up the matter, about twenty years ago, that any real progress was made. Pro- 
fessor Golgi found that the inner substance of the nerves, the nervous substance par excellence, was very greedy of certain salts of silver, so that if a piece of brain or a nerve be soaked in a solution of these salts, the inner parts are stained a vivid black.

The revelations of this simple method, since extended in various ways, have been of extraordinary interest. Speaking broadly, a nerve resembles nothing so much as a vigorous tree, with a big tap root and a short, fat trunk, and crowned with a wonderful arborescence. And if you take a bit of brain and soak it in the staining solution, then harden it, cut it into extremely thin slices, say a few hundredths of an inch thick, and put this thin bit under a powerful microscope, the picture you get is like a cross-section of an immense forest. The trees are crowded together, and roots and the myriad branches interlace in apparently inextricable confusion.

Yet as the methods grew more and more delicate, so that microscopes of greater power could be used, it was seen that this confusion is only apparent. The nerves do branch in a bewildering way, but there seems plenty of room, and just now the patient, persevering students of brain anatomy are divided into two warring camps over the question as to whether the nerves ever touch one another at all. 


\section{HOW THE BRAIN THINKS}

The matter is important, as shedding light on the means by which a nerve-wave, what we call a sensation or an impulse, travels. An impulse going up or down a single nerve follows a simple path. If, for example, in your stocking feet or otherwise, you impinge upon the active end of a tack, you get a sharp sensation of pain, and there is an answering jerk of your foot off the ground, and perhaps a howl. It is comparatively easy to find the nerve which carries this pain-wave, and trace it, say, as far as the lower end of your spine. There it enters the network of nerves which make up the spinal ganglia.

From here an automatic response is sent back over another nerve, a motor-nerve, or rather a set of them, which contracts the muscles of your leg and foot violently and pulls it away from the tack. This is what is called simple reflex action, and with it your brain has nothing to do. Meanwhile, the pain-wave entering the ganglion has set other nerves which also enter the ganglion into action, and the impulse goes travelling up to the brain, and it is only when it reaches the brain-rind, or cortex, that you become conscious of the hubbub down in your foot.

Put very crudely, it is as if there had been a smash-up on a railroad and the nearest station had been notified and had sent back what help 
it could, and meanwhile sent headquarters an account of the smash.

But the remarkable thing is that the message to headquarters does not go through on a direct wire, but through a chain of them, apparently linked together. You see now why the question as to whether there is actual contact between one nerve and another is so important. If there is no actual contact, how does the nerve-wave travel from one to another, as it surely does? And if there is contact, how does an impulse ever stop, as it surely seems to do?

A great variety of answers have been given to these and allied questions, according as different experimenters have reached different results. Some have thought to find on the branches of nerves, killed in the moment of intense action, little beadlike protrusions, which they have considered sufficient to effect a momentary union between closelying nerves. Others, more recent still, have observed, in the watery-like substance in which the nerve material proper is embedded, thin filaments reaching through from one nerve to another.

And others deny all these results in toto.

Some, theorizing on rather scant evidence, have thought that the nerve in action may pulsate like an amøeba, and throw out little arms, which are quickly retracted, and that it is by means of this 262 


\section{HOW THE BRAIN THINKS}

amœboid motion, as it is called, that a nervewave travels. And yet others have found no need of any such protractions and retractions whatever. They compare a nerve-wave to an electric current, and say that just as there is a field of disturbance round every electric current, or body, so probably there is a field of disturbance round every nerve in action, and that this disturbance may affect the close-lying nerves. One difficulty with this theory is that it would imply a weakening of the nerve-current as it flies from one nerve-end to the next, while, in some cases at least, the fact seems just the reverse; a nerve-wave often seems to gain power as it rushes along, so that an impulse, very weak at the beginning, may result in a bodily cataclysm, meaning paralysis or death.

An ingeniously minded Frenchman, M. Jules Soury, of the Sorbonne, has suggested a solution of all these conflicting ideas by supposing that both sides may have a part of the truth. In other words, he believes that in some cases there is contact, or continuity, and that in others there is a leap. And from this he draws a possible conclusion that is of extreme interest. He suggests that in the case of unconscious nervous or cerebral action (by far the greater part of the nervous activity) there is contact; that we become aware 
of what is going on only when the continuity is broken; that the leap is consciousness.

Such a view would throw back the seat of "the divine faculty" from the nerves to the thin waterand-jelly-like substance in which they are immersed. Or, supposing that this especial colloid cannot be fixed upon as the seat of the highest powers of man, they might be thrown upon that extraordinary and rather hypothetical ether, of which the physicists talk so much and know so little. It is too weighty a matter for these pages, for this volume attempts rather a résumé of acquired knowledge than a voyage into the dim unknown.

Whatever be the way the nerve-wave travels, it is certain that something travels, and that this something is what we call an impulse or a wave. For the rate of its travelling can be accurately timed, and, by an ingenious process, Professor Richet, of Paris, believes that he can measure its amplitude as you can the waves of sound or light.

"Quick as thought" does not mean much. A light-wave would travel seven times round the equator in a second; and the speed of electricity, unretarded, is the same. Even slow-going sound, so slow that you can observe the flash of a gun long before the report comes, does a thousand feet a second. The nerve-wave makes only about a 264 
hundred feet a second. If you count very fast you can count ten in a second, and it takes about a tenth of a second for a grown man to find out that some one is jabbing his toe with a pin and get an order back to pull his toe away. "Slow as thought" would be a likelier phrase.

And now we come to the very marrow of the question: What is this wave, or impulse? What is thought?

Up to a year ago the best answer that could be made was this: A nerve may be stimulated by an electric current and muscles set in action; and, conversely, a nerve in action is always accompanied by an electrical disturbance, slight, it is true, but strong enough to be measured with accuracy. In an unprejudiced mind the inference was easy. The ways of nature are simple. The whole advance of knowledge has been an identification of things seemingly unrelated. In the present instance it is allowable to assume that two forces which accomplish the same result and are inseparable are very near of kin. As there is no nerve action without the evident presence of electrification, it is possible that we shall some day find that nerve action, thought, and consciousness, and what in our present ignorance we call electricity, are one and the same.

This view gained heavy reinforcements a year 265 
ago from some brilliant experiments of Professor Albert P. Mathews, of the University of Chicago, which I have already recounted. It will be remembered that Professor Loeb and others had shown that in certain salt solutions an excised heart could be kept beating for hours; further, that a piece of ordinary muscle-frog's muscle, for example-dipped in these same solutions would beat rhythmically, like a heart. All of these curious manifestations could be varied, the rhythmical play hastened, retarded, or stopped, simply by changing the quantity of salts in the solution or by adding different salts. A pinch of one salt, like a potassium salt, would hinder the effect of another, such as ordinary table-salt (sodium chloride).

Professor Mathews took a step further. Instead of cutting away the nerves from the muscles, he left them joined at one end, merely separating the nerve enough to let it hang in a cup of salt solution while the frog's legs were suspended on a frame. The rhythmical beat began in a short time, just as if the muscles themselves were in the salt-bath. Plainly the nerve carried the stimulus, and, so far as any mortal could see, that stimulus was the same as that which makes a live frog's muscles contract when it jumps. Whence came this stimulus?

The only solutions which give this effect are those which generate an electrical current. A suc266 
cession of electrical impulses from a dynamo, for example, will make the frog's legs twitch rhythmically, just as do the salt solutions. If we use old William of Occam's razor-that we shall cut out all needless assumptions or suppositions whatsoever-then we shall say that the electric current from a machine and the nervous disturbance generated by the solution are identical. And as the twitch aroused by dipping the end of the nerve in a salt-bath is exactly the same as occurs when the frog is alive, then we must say that a nerve current, or nerve-wave, is electrical in character.

If this frightens no one, then we may add that the excitation which moves the legs of a frog and that which winks your eye or twirls your flying fingers over the piano-keys is absolutely the same and is due to the same cause.

And now for the final plunge into what Huxley satirically called the dank morasses of materialism. You are seated at the piano; the reflection of a jumble of dots on the page of music falls upon the retina of your eye; their position, size, and shape are telegraphed to your brain; thence comes a series of orders to arms and fingers; you are playing a Chopin nocturne. Providing you have spent months or years in patient and often painful practice, you can do all this and be talking to a friend at the same time, hardly conscious either of the 267 
action of your hands or of the glowing melody they thus mechanically produce.

But between this astonishing achievement and the beginning there have been countless hours where every crook of a finger and every twisty note was a matter of the most laborious consciousness. This we call thought. In terms of brain physiology, it was the stimulation of a wide area of brain-cells, either by nerve currents from other cells of the brain or from without the brain, as, for example, from the retina. Whatever thought, or consciousness, may be in itself, it seems probable that its physical basis is the stimulation of a relatively wide area of the brain-that is to say, the simultaneous activity of a large number of braincells. In this view, the action becomes unconscious when the area or number is lessened.

This stimulation of a wide area can be effected only by means of nerve connections between the different cells. These connections are known as association fibres, and are perfectly discernible by the microscope. Their number is immense. Many cells have scores and even hundreds, and, as the cells are numbered by hundreds of millions, it is easy to see that they reach to an unthinkable sum.

It is by means of these association fibres that we have what is called association of ideas. Clever people evidently are well provided with association 268 
fibres. Where these fibres are lacking there will be no stimulation of a wide area, and therefore no consciousness. This is the case of the lower forms of life, and in new-born animals, including babes. In all of these the anatomical demonstration is perfectly clear. To ascribe consciousness, in the ordinary sense, to worms, oysters, or new-born children is manifestly absurd.

In the case of conscious action becoming automatic and unconscious, as in learning the piano, learning to write, etc., we may infer that constant use (stimulation) tends to establish a direct path, which the nerve-wave will follow exclusively rather than spread out over a wide area, as when the resistance of all the paths was more or less equal.

Be this as it may, the especial thing to note is that the currents, or waves, which stimulate the cells of the brain differ no whit from those which set jumping the dead muscles of the hind legs of a dead frog. In the one case as in the other, it is caused by-or, rather, is - a variation of electric potential.

There are some to whom new definitions are distasteful. To define the highest faculties of the human mind in terms of what they contemptuously term brute force is, for them, a reprehensible proceeding calling for opprobrious names. 
NEW CONCEPTIONS IN SCIENCE

So, when Huxley, forty years ago, defined life in terms of water, ammonia, and salt, unpleasant things were said. To rid himself of the epithet of "crass materialist," he had recourse to the subtleties of the good Bishop Berkeley.

For this there is no need now. In a recent book, The Response of Matter, the distinguished physicist of Calcutta, J. Chunder Bose, has done much to strike down the last distinction between living matter and dead. Just as there is no longer a "missing link" in the chain of Darwinian evolution, so there is no longer a dividing line between plant and animal, between mineral and vegetable, between the animate and the inanimate. There is no "dead" matter.

In some obscure degree, all matter lives. 


\section{THE WAY THE HUMAN BODY FIGHTS DISEASE}




\section{PASTEUR'S GRAVE}

[The tomb is built at the end of a long corridor in the great institute which bears his name, and is shut off by magnificent gates of wrought iron. The archway over these gates is decorated with irises on a gold ground, and the simple words are inscribed, "Ici repose Pasteur."]

No cypress-shadowed church-yard nor the gloom Of haunted cloisters doth immortalize

The dust of him whose patience proved more wise

To save than Death to slay. The busy loom Glancing with silk, the teeming herd, the bloom Of purpling vineyards, and the grateful eyes Of souls reprieved at Death's most dread assize Shall make eternal gladness round his tomb. Not mid the dead should he be laid asleep

Who wageth still with Death triumphant strife, Who sowed the good that centuries shall reap, And took its terrors from the healers' knife; Defender of the living, he shall keep

His slumber in the arsenal of life.

Alfred Hayes. 


\section{THE WAY THE HUMAN BODY FIGHTS DISEASE}

Scattered over the world, even to far Siam and the jungles of Africa, bodies of men are at work, not in quest of gold, or loot, or territory, but of means to help their fellows, you and me, to ward off sickness and unneedful death. Stately pageants and triumphal arches are not for such as these, for they make war, not upon men, not upon the weak, but upon the malignant hosts of disease.

Their efforts tend in two directions: the first to ward off infection by a perfected hygiene, as, for example, in the disappearance of yellow-fever from Havana; that came through the destruction of the yellow-fever carrier, the mosquito; the second, in arming the body with new weapons of defence when the infection has come. Between these two much has been, much more may be, achieved.

Rather more than a century ago, a very young physician thought to test a very old-folk remedy against the greatest scourge of that day-smallpox. His method, slightly elaborated, has served to 
banish that disease from cleanly lands. But it was merely a fluke, a ten-strike in the dark; to use a large word, a purely empirical discovery. No one had the slightest idea how the vaccine worked, for no one, up to thirty or forty years ago, had so much as a suspicion as to the nature or cause of any disease. Jenner's discovery was not the forerunner of a host of others; it opened no new line of inquiry. The physicians of his time and after were far more interested in the fancies of Hahnemann than in a patient, scientific investigation of these new and amazingly fertile results.

Here, again, it fell to the chemist Pasteur to take up this work half a century after Jenner was dead. Knowing nothing of medicine or the stockin-trade absurdities taught in its name, and coming fresh to the subject, he was able to reveal that disease is essentially a fermentation, due, like the fermenting of yeast, to the presence of a minute fungus. Following the customary method of preparing the small-pox vaccine, Pasteur and his aids found that by deliberately cultivating his microbes through a succession of young animals he was able so to attenuate the poison they secrete as to make the latter relatively harmless. Nevertheless, as in the case of vaccination, the fungus thus modified was able, by inducing a mild form of the disease, to confer immunity against a more virulent attack. 
His dramatic cures of the dreaded hydrophobia instantly gave his ideas a world-wide vogue, and in scarce any land of the earth were there lacking eager spirits to follow out and explore the paths thus so brilliantly opened up.

A little later came the discovery, at the hands of two of Pasteur's disciples, that the serum of inoculated animals-the colorless fluid of the blood after the red corpuscles which it contains have been strained out-contains an anti-poison, or, as it has come to be known, an antitoxin, which, injected into an animal, confers immunity in the same manner as inoculation itself. This was the beginning of "the new medicine," of the so-called "sero-therapy." If the new methods have not yet realized all that was hoped from them, it may still be noted that a single one of the new serums, the preparation of the diphtheria antitoxin, has already saved thousands of little lives, and that the horrible fate of death from hydrophobia is now almost unknown. Anti-poisons for many of the serpent venoms are known, so that the other day, when Dr. Calmette, of Lille, who has made this latter field so much his own, was bitten in the careless handling of a deadly adder, he had merely to step across the room and inject into his arm the serum of his own preparation. Without the latter, in a few moments he would have been dead; with 
it, the crisis was soon past, and within an hour he was back at work. "Epatant," murmured France; and so it was.

Pasteur had unveiled the cause of disease; he and his disciples had found new means of combating it. It remained to inquire what was the mechanism by which the cure works. We may take a concrete instance. The microbe of diphtheria Professor Behring believes to be ubiquitous - that is to say, always more or less present. Under favorable circumstances, as, for example, a weakened condition of the body, it finds lodgment in the throat, begins to multiply with extraordinary rapidity, and covers its fungus-like growth with the well - known white membrane. As a part of its vital activity, it secretes a powerful poison, as, let us say, the cells of a cow's udder secrete milk, or the poison glands of a rattlesnake produce venom. This poison, seeping through the membrane, permeates the system, paralyzes the bodily functions, and causes death.

Given that there is time, an injection of the antitoxin causes the body to rally against the poison; the patient recovers. In many instances there is recovery when no antitoxin has been administered. What is the process?

More than a decade ago Elias Metchnikoff, the eminent Russian pathologist, undertook an ex- 
haustive study of inflammations. Whether they occur from a wound or from disease, always he noted the presence, in abnormal quantity, of the big white corpuscles which float about in the blood and the lymph. Inside these white cells he would find great numbers of the microbes specific to the inflammation under view. The microbes were in various stages of digestion; it seemed as if the big corpuscles' office was to devour the microbes and, if possible, kill them. Sometimes the number ingested was too great; then the corpuscle itself was destroyed; and, if this were general, the inflammation extended, the victim died.

In his picturesque Northern imagination, Metchnikoff came to view infection and immunity as a war of microbes and white cells. Against the invading hosts of disease the corpuscles went out to battle-to conquer or die. This was the way in which the body fights disease. The great Russian gave to the white corpuscles the name of phagocytes - the "devouring cells" - and styled the process phagocytosis. His ideas were stimulative; they aroused adherents and doubters alike, and a splendid work has followed.

All sought to penetrate yet deeper. Granted, said the doubters, that the white corpuscles of the blood are in reality microbicides, is this all? When the serum of an inoculated animal is injected 
into another, it is entirely rid alike of red corpuscles and white. Clearly the lymph, then, must contain some chemical substance which protects the inoculated animal. And the serum of the latter may in turn confer immunity upon other animals. How has this curious result been brought about?

Incidentally it is to be noted that often the action of the serum is not bactericidal; the fungi continue to thrive and multiply, although their harmful powers seem destroyed. It appears here as if the serum merely neutralized the poison the microbes secrete. Moreover, a puzzling fact, disclosed by Bordet, was that the benign powers of the serum may be destroyed simply by heating, but that this power was instantly recovered by the addition of a small quantity of serum from an animal which had never been inoculated. In other words, the serum of a non-inoculated animal, itself powerless to confer immunity, could still restore the immunizing power to serum in which that power had just been destroyed. Slight wonder if, before such baffling paradoxes as these, the heads of the investigators sometimes began to swim. Metchnikoff still held to the main lines of his theory. In his view it was always the devouring cells which intervene, either directly or in a less obvious fashion, as in the case of the serums. To speak with more precision, for him the process of im- 


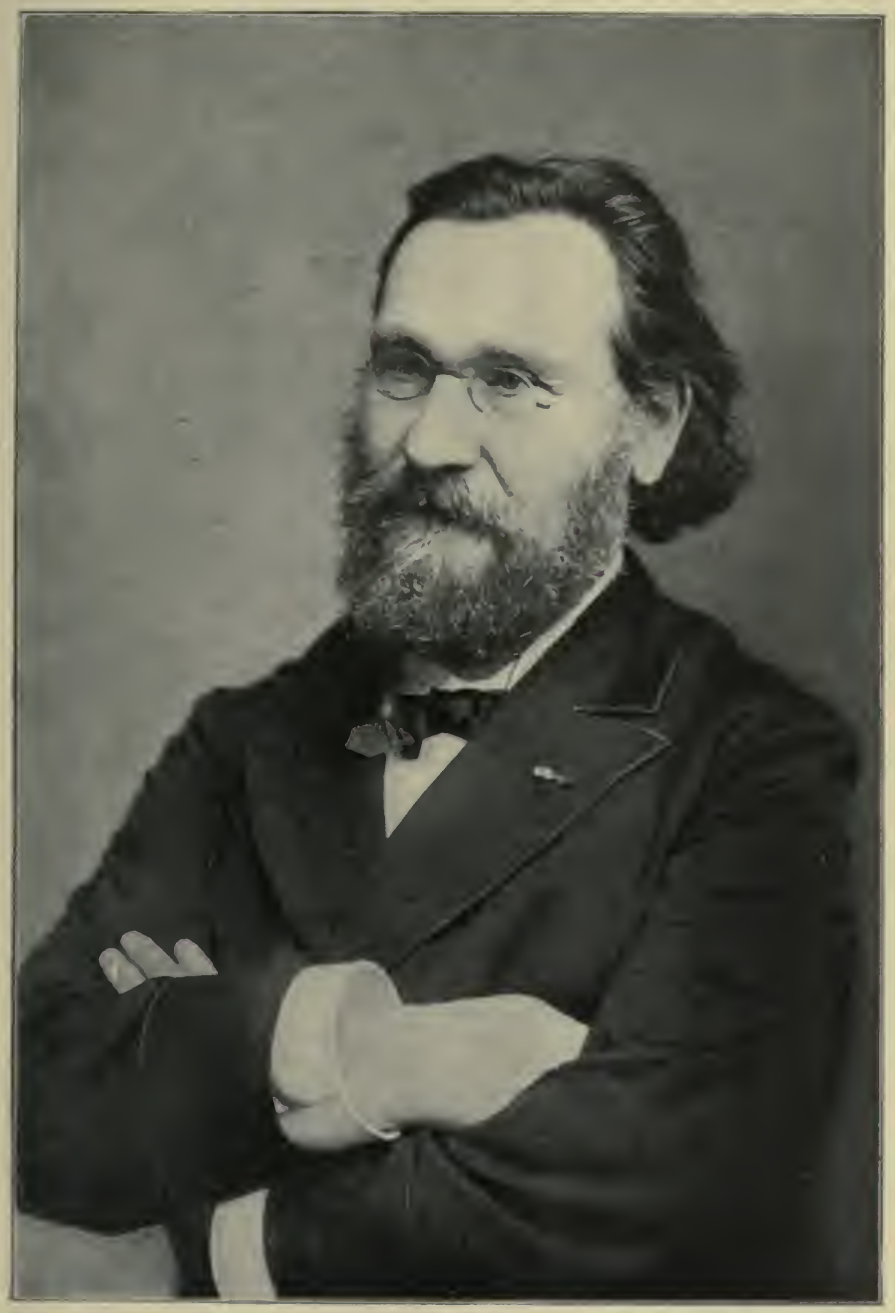

EI.IAS METCHNIKOFF

Pasteur Institute, Paris, famous for his researches in immunity. 

munity is always essentially fermentive in character; the germicidal properties of the serum from an inoculated animal are due to the presence of fermentive substances secreted by the "phagocytes," just as the stomach cells secrete pepsin and free hydrochloric acid, the liver cells bile and other ferments, and so on. These are thrown into the blood-stream and carried about through the body, and may act there in destroying the microbes, or in disturbing their normal functions, or simply by neutralizing the bacterial poison. The effect of the inoculation of a fresh animal or the injection of the serum from an inoculated animal is to stimulate the white corpuscles to greater activity, and hence of the production of greater quantities of the bactericidal ferments.

It will be seen that in view of Metchnikoff the whole process is one of vital action. We need not attribute intelligence to the white corpuscles in their war upon the microbes, but they nevertheless comport themselves in many ways like living beings, and seem like independent units colonized in the organism.

But modern physiology is no longer content with merely "vitalistic" explanations of the bodily processes. For it, the vital processes, whether of digestion, absorption, growth, or reproduction, are simply and solely a complex series of chemical re- 
actions, proceeding in a regularly ordered way. All this is not nearly so interesting as the idea of prodigious wars and bloody struggles going on within the body, though all invisible to the eye. And to the minds of many folk it is disagreeable; it creaks of machinery, or, as many say, smacks of materialism; it seems to destroy something of the mystery which shrouds the life processes, and it appears as if a good portion of the world, for some reason or another, prefers ignorance to knowledge.

All this is more or less a matter of taste; meanwhile it is worth noting that all the advance that has been made in our ideas of vital phenomena has lain entirely in an identification of bodily processes and forces with the simple processes and forces of the inanimate world. Lavoisier began this when he showed that the combustions which go on in the lungs and in the grate or the stove are one and the same. If the chemistry of the living cell is still obscure and full of difficulties, we know enough to know that all future gain will come along the same lines.

One great step has been made, and that of a most unexpected sort. So bewildering is the variety of the things which go on in an animal, or even in a plant; so vastly different, let us say, the forms and functions of a coral polyp and a whale, that one is led almost inevitably to suppose a corresponding 280 


\section{HOW THE BODY FIGHTS DISEASE}

complexity in the materials of which these are composed. The development of organic chemistry has revealed precisely the opposite. The world of the non-living is made up of a rather large variety of elements, put together for the most part in a very simple way; the world of living things, on the contrary, seems composed of a very few elementary substances, put together in a most intricate way. A little carbonic acid, water, ammonia, oxygen, a trace of some mineral salts, and perhaps a dash of sulphur and phosphorus, and you have the physical bases of life. Such varied articles as the white of an egg, cheese, or lean beefsteak hardly differ at all in their constituents; it is simply a question of chemical structure, or, as one might say, architecture.

After this one will not be surprised to learn that many of the organic poisons-that is to say, the poisons elaborated by the living organism-differ so slightly from the ordinary foods of the body as to have for a long time baffled the chemist in his efforts towards a satisfactory analysis. They are in many instances substances made up not merely of identically the same elements, but incidentally in the same proportions. In more technical language, they are what the chemists call isomeres-i.e., made out of the same parts. Their differing physiological and chemical reactions, therefore, may be 
solely explained on grounds of a differing arrangement or grouping.

At a first thought it seems absurd that, for example, the same number of atoms of carbon, hydrogen, oxygen, and nitrogen put together in two different fashions could make one substance highly nutritious to the bodily economy, the other a deadly poison. It is not easy to understand how mere structure could play such a decisive rôle.

It is probably a simple question of chemical mechanics. The most characteristic thing about atoms is their ability to grab hold, so to say, of other atoms; but this ability is unequally shared. Some atoms seem to be one-handed, some twohanded, some three, four, five, or six. The natural propensity of an atom is to get its hands full; in this condition it is said to be saturated, and it is no longer in a position to create a disturbance. When all the atoms of creation find their atom-grabbing proclivities satisfied, all chemical action, and consequently all life, will cease. Saturation is death.

Roused from their torpor by the sunlight, the inert atoms of the air and the soil take on that condition of unstable equilibrium we call life. Under the influence of the bodily ferments the plant materials are raised to a yet higher state of complexity characteristic of the animal world. To the chemist's eye the body is a scene of incessant and rapid 282 
change, where a gay sort of Virginia reel is going on, the atoms, or rather groups of atoms, flinging off their partners and taking new ones with the precision and dexterity of a practised band. But woe if some clumsy or evil-minded disturber comes in to break up this rhythmic play. For the price of life is that this molecular dance shall not for one briefest instant cease or swerve.

The poisons are the disturbers. Though they be all in faultless attire, resembling the other guests so closely that no police will step in to show them the door, something in their disposition, some evil ineptitude, brings ruin in their train.

Perhaps this is carrying a fanciful analogy too far. A great German chemist makes use of the simile of a lock and key. Here the microscopic cells of which the body is composed may be pictured as furnished with many doors, these doors with locks; in ordinary normal conditions the doors swing wide, the traffic of the body goes on without let or hinderance. But suppose a structure so adapted as just to fit the lock or release a spring-the door is closed, traffic stops.

But lively pictures of this sort have the inconvenience of being a little too concrete-that is to say, they imply things which do not tally with all the facts. In the case of infection and the process of immunization the facts seem simple and toler283 
ably clear. On the basis of what is now known, Professor Ehrlich, the distinguished head of the institute of experimental medicine at Frankfort, in Germany, has constructed a theory which represents the very latest in this branch of scientific work. Ehrlich supposes that, attached to the extraordinarily complex structure of the animal cell (a single cell may contain millions of atoms), there exist what he terms "side-chains," or partly saturated groups of atoms, whose normal function it is to enable the cells to take up from the blood-stream their food elements, which, passed on into the interior, become a part of the cell itself. The condition here is that the bond of momentary union between the "side-chains" and the food elements shall be easily formed and as lightly broken. These side-chains he designates "receivers."

Professor Ehrlich supposes the poisons to possess a greater aptitude for fixing themselves to these receivers, or, in chemical phraseology, to offer a greater number of unsaturated affinities. Attaching themselves to the receivers, they bar the way to the entry of normal food materials, if, indeed, they do not penetrate farther into the inner structure of the cell. In consequence, the activity of the latter is disturbed; death intervenes.

Under certain conditions, however, the combination of side-chain and poison molecule is thrown 284 
off from the cell, and new receivers, new sidechains, being formed, the cell resumes its orderly life. But the peculiarity appears to be that, if the cell succeeds in throwing off this harmful combination, it not only forms new receivers, but a superabundance of them, and these surplus receivers are sloughed off into the blood-stream, there to float about as free units. Given, then, that a poison is introduced into the system, these free side-chains in the blood will fix the poison before ever it reaches the cells at all. The poison will be "neutralized," and no harm will come.

It is, then, the presence of these free side-chains in the blood which confers immunity against disease. Naturally, as the microbes of each disease secrete a specific poison, there must be as many different receivers as there are poisons, and this would explain why, for example, vaccination against small-pox does not protect one against diphtheria or the grippe. What remains now, therefore, is to study closely the conditions under which these protecting agents are formed, and, further, kept in active condition. For the immunity conferred is naturally not permanent. In some cases, as in that of cholera, the effect of the antitoxin serum seems not to last more than a few weeks; in the case of the small-pox vaccine it may endure a year, or for a lifetime even.

$$
285
$$


Such is the story of the beginning. Confessedly it is no more than a beginning. The problem of immunity is, at bottom, a chemical problem. But as to what is the chemical nature of the antitoxins or the toxins, we have as yet but little idea. The subject has not yet passed out of the purely observational, or, as one might say, physiological stage. So far as that goes, however, neither have any other of the vital processes. So we need not reproach these patient, unflagging workers, that they must still talk somewhat vaguely of "receivers" and "anti-bodies" and "complement" without being able to define these more precisely.

It is a great beginning none the less. For in the end it means that all contagious and infectious disease will be banished from this earth. True, the number of successful antitoxins is not yet great; they may be counted on the fingers of one hand. But this may be said: medicine must have been the earliest of the arts; witness the place of the medicine-man in our now disappearing savage tribes. In some rude fashion, it must have been practised for tens of thousands of years. All these uncounted centuries of mingled guesswork and experiment came to this, that at the opening of the twentieth century A.D. there were, aside from the new antitoxins, two real specifics for two of all the diseases that man is heir to. These were quinine, for ague, 286 
and mercury or iodide, for syphilis. That was all. If in ten or twenty years the new medicine has found five or six more, it has not done badly.

And it is only within the last forty years that any mortal man has had the least idea of the nature of disease. It is curious to think that not even the wisest of men before this had so much as a suspicion of the truth. In many other lines of physical inquiry there were shrewd guesses that turned out not far from the mark. But when the invisible air, the crystal spring, the unsuspected dust, were shown swarming, teeming, feculent with microbes, some benign, some indifferent, some of them malignant, it was as if the walls of the unseen had dropped.

Let us, then, be patient. The new methods promise much; moreover, they are the sole promise. In another ten or twenty years medicine may have ceased to be an art. It may become a science. 

THE SPIRIT-RAPPERS, THE TEL. EPATHS, AND THE GAL. VANOMETER 
Science, whose aim is to understand nature, must set out with the assurance that nature is understandable.

VON HELMHOLTZ.

Is there any phenomenon which works upon neither our natural senses, nor upon their extensions, our present-day instruments and apparatus? Then, unless it be out of relation with things, must it still be bound up with other phenomena which do work upon our senses or our instruments. Thus it must sooner or later become perceptible to us.

OtTo WIENER, Die Erweiterung unserer Sinne. 


\section{THE SPIRIT-RAPPERS, THE TEL- EPATHS, AND THE GAL- VANOMETER}

Many clever people have a habit of thinking, and saying, that we know as yet very little of the world about us; and they like to quote Sir Isaac Newton's famous simile that, with all his knowledge, he felt like a child gathering shells on the shores of an infinite sea.

On this supposed gap between the whole of things and the little part we know about, much has been built. It has been used to silence doubts as to the truths of telepathy, mental science, spiritism, and the like. It has been employed to break down the atheistical tendencies of modern science. It seems a sort of aggressive agnosticism, behind which the most curious of fancies find a convenient shelter.

Sometimes such modes of thought are to be found associated either with an ignorance of the real conquests of science or with a lack of what 
may be called a logical imagination. I will offer an illustration:

Sir Isaac Newton was not merely the most powerful genius of his time, but, as many references in the foregoing pages have disclosed, the range of his inquiries and his speculations was extraordinary. His stock of information must have wellnigh exhausted the possibilities of his day. Yet could he return now, when scarce a century and a half have gone by, he would own himself a most puzzled and ignorant man.

Newton laid the foundations of the science of light, yet of the nature of light - that it is simply a form of electricity-he had no mortal idea. He had no idea of the action of light on certain metallic salts, so if he were shown a photograph of Lord Kelvin, for example, he would have no notion of how it was made. He seems to have been the first to study the effect of a glass prism upon a beam of light; he was practically the inventor of the spectroscope. Yet he would probably have regarded a man as clean daft who would have told him that this simple device would one day tell us what the sun is made of, and measure the speed of the most distant stars; would reveal to us new kinds of matter, new substances of whose existence no one had dreamed before, and perhaps give us a clew to the origin of worlds. Were he shown Professor 
Langley's wonderful bolometer and told that it will measure the heat of a candle a mile or more away, he would be sure you were making game of the old man.

Newton invented a new electrical machine and performed many interesting electrical experiments; but his knowledge of electricity and magnetism was necessarily of the most meagre sort. He did not know of any relation between an electrified body and a loadstone; he did not know of such a thing as an electrical current; and if he were shown a common Morse telegraph instrument, and told that a current sent round a piece of soft iron makes this a magnet and pulls down a key, and that this can be done at a distance of thousands of miles, he would not understand what you were talking about. He did not know that zinc and copper plates dipped in a salt or acid water may generate a current, so he could not explain a common voltaic battery. As no one before Faraday had any idea of electrical induction, if Newton were shown a bar of soft iron whirling in front of a magnet he would not know that it could produce an electrical current strong enough to kill a man. He could make no mental picture whatever of an ordinary dynamo.

Not knowing that a vibrating iron plate can, under proper conditions, vary the character of an electrical current in its vicinity, Newton would be 293 
as puzzled as a Hottentot if put in front of a telephone. Were he on board a Cunard liner and, three hundred miles at sea, were shown the instruments of Marconi's wireless telegraphy communicating with the land, it would leave him as blankly gasping as it does a yokel now. Could he step into a psychological laboratory and be shown the delicate mechanism which can be made to register on a sheet of paper the precise degree of interest we take in this or that word in a spoken series, or in a given subject of conversation; or that will reveal bodily motions of which we are neither conscious nor can control, he might suspect you of diablerie. His suspicions would grow if he saw you take a stick of sealing-wax from your pocket and, by rubbing it smartly, cause a fountain of water, breaking gracefully in scattered drops as it leaps in the air, so to hold together as to come to the ground in a solid stream.

In fine, in a well-equipped laboratory, or before a collection of modern scientific instruments, this great man would feel himself just the child by the sea-shore he once described. Such has been the advance of five or six generations. Between the discoverer of the law of gravitation and a man of like powers of mind living now, lies a gap almost as great as lay between Newton and an aboriginal inhabitant of Great Britain. We have, literally, not 


\section{THE SPIRIT-RAPPERS}

merely new tools but new senses. Every new instrument, every new discovery in experimental science, represents, as Herbert Spencer long ago pointed out, either a great widening of our original six senses or the creation of new ones. Every discovery brings with it a new weapon of scientific conquest. The last four or five years have offered a number of beautiful examples. We may select one of a special import:

Early in 1896 - that is, a few months after Professor Röntgen's amazing announcement of the performances of the X-rays-Professor Becquerel, of the Natural History Museum, in Paris, followed with another of an even more puzzling nature. Studying the action of the salts of a rare and very heavy mineral, uranium, Professor Becquerel observed that these substances give off an invisible radiation which, like the Röntgen rays, traverse metals and other bodies opaque to light, as well as glass and other transparent substance.

This was the first found of the so-called "radioactive" substances, of which the much-discussed radium is now the most notable. Nothing within a century has proven so great a puzzle to the scientific world - a puzzle, because these substances seemed, in the beginning, to disprove the first principles of natural science. They were endowed with tremendous energy, yet what was the source 
of that energy was a mystery. More or less, it is so still, though some tentative explanations have been offered by their discoverer, Sir William Crookes, and others.

Here was, as it turned out, a wholly new series of natural phenomena. These were just as open to Newton for study as to Professor Becquerel. Why, then, did it require a century and a half of scientific development to learn of this new and peculiar property of matter? Newton, we know, experimented with almost every substance known to his day, testing each to see if it strictly obeyed his famous law of inverse squares. He seems to have been a good chemist, as chemists went in his day, and was certainly abreast of the science of his time. Why did he not find these radiating bodies?

One need not voyage far afield for an answer. These new radiations affect none of our primal senses. Though, in following up Becquerel's discovery, M. and Mme. Curie have latterly found other radioactive minerals, like radium, which give off a visible light, those discovered by Becquerel do not. They afford so little appreciable heat that it has only just recently been possible to find a way to detect or measure it; they arouse no sensations of touch, taste, sound, or smell. How, then, may we become aware that they exist? Solely by means of our new senses. They impress a photographic plate, one of 296 


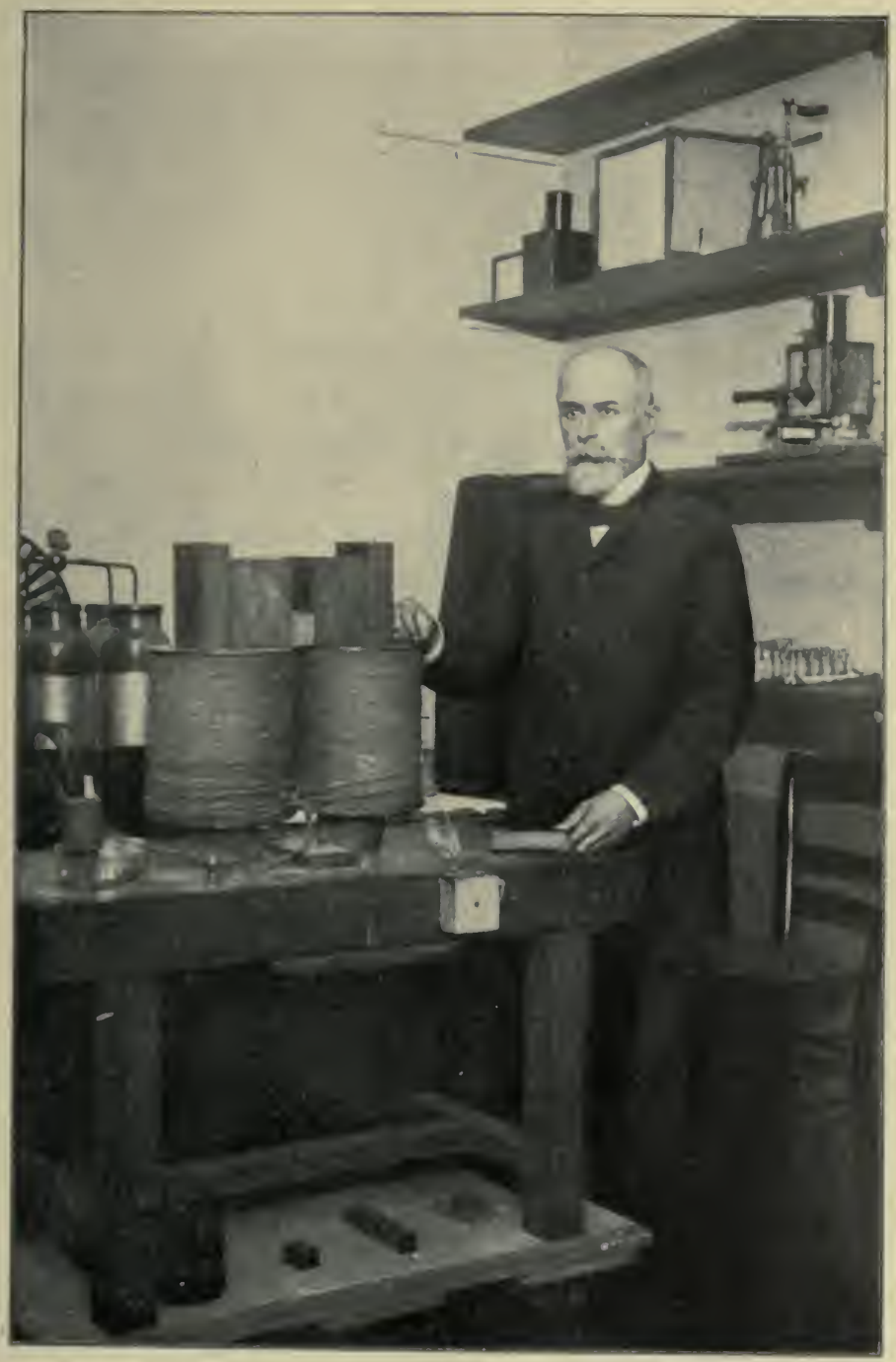

PROFESSOR IENRI BECQUEREL

Discoverer of the "Becquerel rays," or radio-active substances, in his laboratory at the Jardin des Plantes, Paris. 

the most useful of our acquired weapons; they will discharge an electroscope, which serves us for a lacking electrical sense; they are twisted and turned, pushed or pulled, by a magnet, which supplies our absent magnetic sense; they produce a variety of chemical effects - they may produce burns and virulent sores, they color glass, generate ozone, make the air and other gases good conductors of electricity, and even transport large quantities of the latter from point to point themselves; for these "radiations" are clearly matter, and not merely a new form of ether vibrations, like light. Finally, a way has been found to weigh and count these particles, compute their speed, likewise their electrical capacity; and other of their physical properties are known.

In short, in four or five years we have learned to know almost as much of these substances which lie out of the reach of our natural senses as though we could taste and see and handle them, like sugar or sand.

Yet their existence even was not so much as suspected until we had come to devise and use instruments and processes unknown to Sir Isaac Newton's age. Until the development of the sciences of chemistry and electricity, and magnetism, and photography, and the physics of molecules, Becquerel's discovery would not merely have been useless but impossible. It cannot be doubted that 
this discovery will lead to others of equal import; it may deeply modify our present physical conceptions of matter; it may even give rise to a mighty industry, as did Faraday's discovery of electrical induction. Already Sir William Crookes sees here a possible source of light, heat, and power sufficient to supply the world.

This is no isolated instance. Hertz's discovery of electric-waves, revealing the identity of light and electricity; Tesla's marvellous performances with high-frequency currents; Poulsen's magnetic phonograph; Professor Röntgen's find of the X-rays; Simon's observation that an ordinary electric arc can be made to talk like a telephone, sing like a bird, and be used for wireless telephoning; all these marvels of the last ten years were due to the steady advance of electrical science. They were inevitable, not accidents. It is the same in every field of scientific endeavor. Schleiden and Schwann's discovery, that all living bodies, animal or vegetable, are made up of minute cells, or Pasteur's proof of the unsuspected microbe, came with the perfecting of the microscope; it opened up to man whole new realms, of which we have realized as yet only the first-fruits. Without the telescope, the camera, and the spectroscope, astronomy would have remained where it was left by Ptolemy. Instances of like import might be multiplied endlessly. 
This advance in knowledge of the world about us strikes different minds in differing ways. For some it is but an earnest of what is to come. What has been acquired is little; our present ideas will appear absurd enough a century hence. Before Oersted we had no thought of the intimate relations between electricity and magnetism; a single fortunate observation makes possible the telegraph and binds together distant continents. Until Faraday came, with his extraordinary powers as an experimenter, no one so much as dreamed of winning vast stores of electricity from spinning magnets; to-day an industry whose invested capital amounts to hundreds of millions rests upon his discovery. Before Röntgen, we had no conceivable means of lighting the interior of our bodies; before Hertz, no suspicion that we might signal hundreds of miles without wires; before Morton, no hopes of anæsthesia; before Wöhler, that we might one day fabricate living substances in the laboratory. Who, then, shall set bounds the upon possibilities of human achievement?

We know well the fate of the prophets of bankruptcy. Within a few years after Comte had announced that astronomy had reached its utmost limits, that nothing new could be expected there, Kirchhoff stood trembling in his laboratory before his splendid discovery of the powers of the spec- 
troscope. The real astronomy had but begun. Even as Johannes Müller, the greatest physiologist of his epoch; was setting it down that the phenomena of nervous action could never be measured, the rate at which a sensation travels from hand or eye to the brain was being calculated.

A wayfarer or a fool may read the folly of attempting to forecast what the morrow may not bring. Who, then, shall say that we may not be on the brink of new unveilings, before which all that we know now will seem but an introduction?

There are others who go further. They look upon the wonders of later-day science and they ask: Who shall dogmatically assert that one brain may not act upon another-for example, as far as from Nevada to New York, in the incident exploited by Mark Twain? Who has proof that we may not have converse with the disembodied dead? What intelligent physician shall say that his drugs or wafers are more efficacious than Mrs. Eddy's gentle art?

Yet he who has taken due account of the actual state of knowledge will rather pause. 'Within even a few years many of our ideas about this world have been notably clarified. In particular, we have come to know not merely a great deal of the chemistry and physics of lifeless things, but of living things-ay, of the mind as well. Our notions about 
nervous action, or, as the larger-sounding phrase goes nowadays, of psychic phenomena, are growing clearer. The arguments that may be drawn from recent progress in this direction will scarcely appeal to the believing hosts; they may appear a little tenuous before the prodigious successes of Mrs. Piper and her kind. But inasmuch as certain recent observations seem to have escaped the attention they might merit, it may be worth while here to set them forth.

One of the earliest steps towards a rational psychology lay in Weber's discovery of the curious limitations of our senses. There seems to be a threshold of sensation - that we knew well of old; a body must have a certain weight ere we can appreciate its existence by lifting it. But what Weber found was that there is a kind of a "differencethreshold" as well. If, for example, the smallest difference in weight we may detect with the hand be, say, between twelve and thirteen ounces, we may appreciate the difference between double these weights, but not between twenty-four and twentyfive, or twenty-five and twenty-six ounces. A similar relation seems to hold true for all the senses; this threshold of difference represents always a constant quantity, varying slightly with individuals and with the state of fatigue. With a machine-a pair of scales, for example-we find no such limita- 
tions. There is no difficulty in weighing even fractions between, say, twenty-four and twenty-five ounces. The report of well-made machines is always identical, and they never weary.

But before a given sensation, whether of light or heat, touch or smell, taste or sound, can affect our organs of perception, it must gain a certain intensity, and between varying degrees of this intensity of sensation we can, by natural means, measure only proportionate quantities.

This limit of capabilities seems to be, at least with regard to primitive sensations, rigidly set. Thus, for example, if a sensation occur too rapidly, as when a note is struck more than ten or eleven times a second, it appears to us continuous. A series of dots less than a thousandth of an inch apart appear to us as a continuous line. These limits appear to be fixed in the nature of nervous action itself, because, for example, although we can by mechanical means produce a muscular contraction of much greater frequency, we cannot count out loud more than ten or eleven a second; and this is equally true if we try to count silently. It is the limit of speed of mental action.

The rate at which a sensation travels along a nerve up to the brain or back again is comparatively very slow. Light and electricity, under ordinary circumstances, travel a hundred and eighty- 
four thousand miles per second - eight times around the earth while you say "Ah!" A nerve - wave only travels about a hundred feet per second, so that if you are five feet high and can count ten in one second, the sensation of your foot being sharply pricked can only travel up to the brain and the response thereto travel back again in the time you are counting one-that is, a distance of ten feet. If we could think with the rapidity of light, life would seem to us about $\mathrm{I} 800$ times as long as it does now.

Such are the general conditions of nervous, or "mental," action. The same narrow limitations are true of especial organs.

The eye and the ear have long been regarded as marvels of mechanism, quite the most wonderful things in the world. But, compared with the implements of a present-day laboratory, the sensitiveness of all human organs seems gross enough. A photographic plate, coupled with a telescope, will reveal the presence of millions of stars whose light does not affect the retina in the least. The microscope too, with its revelations of the world of the infinitely small, tells us how crude, after all, is this most delicate of the senses. Indeed, we may liken it to a piano where only a single octave, towards the middle, sounds. From the ultraviolet to the lowest reaches of the spectrum is a range of some nine octaves of light vibrations, of 
which, save for our new mechanical senses, we should never have been conscious of but one.

The ear hears little of what is going on around us. By means oi a microphone the tread of a fly sounds like the ramp of cavalry. Our heat sense is very vague; we need a variation of at least one-fifth of a degree on a thermometer to realize any difference in temperature. Professor Langley's little bolometer will note the difference of a millionth of a degree. It is two hundred thousand times as sensitive as our skin. A galvanometer will flex its finger at the current generated simply by deforming a drop of mercury - pressing it out from a sphere to the shape of an egg. The amount of work done by a wink of the eye would equal a hundred billion of the units marked on the scale of a very delicate instrument. It is at least ten thousand times as sensitive as the eye or the ear. But even this astonishing performance is far surpassed by the exquisitely sensitive coherers, discovered by Professor Branly, of Paris, by which the Hertz waves of wireless telegraphy are caught in their pulsings through space. And these, in turn, seem clumsy and coarse beside Professor Rutherford's magnetic detector, which made possible Signor Marconi's first sending of actual messages across the Atlantic; or the "hot wire" receiver invented by Professor Reginald A. Fessenden. The 
latter is estimated by Professor Fessenden to be 40,000 times as sensitive as the best type of coherers.

Again, the range of impressions which we get from lifting an object in the hand is rather small. An ordinary chemist's balance is about twenty million times as sensitive. It will weigh down to the two hundredth part of a milligramme. If we had as delicate a sense for gravity effects, we should notice the difference in the weight of our hands in lifting them an inch off the table, or, to employ an ingenious comparison of Professor Wiener's, we should be able to feel with our bodies the presence of a lump of gold buried in the earth not too deep as we walked over it. Kohlrausch and Töpler have devised barometers so sensitive to variations of air-pressure that a person walking through an open doorway, at the opposite side of a room, will set the indicator swinging. It will betray a variation of the hundredth part of the millionth of an atmosphere. So, too, in comparison with our ability to count about ten or eleven per second, Feddersen has been able to devise an instrument which will count down to the hundredth part of a millionth of a second.

Wherever we turn we shall find instruments which surpass each and all of our senses in a most humiliating way. Without them we should know very little of the world about us. Lacking them, 
Sir Isaac Newton knew very little of the world about him. But with them-and this is a capital point-we have come to know a great deal. We have come, for one thing, to see that our senses give us reports only of a comparatively small number of comparatively gross stimuli. Professor Sully has written an entertaining book, illustrating the way in which our senses habitually delude us. It is entitled Illusions, and is a healthy piece of reading for people who are filled up on some of the literature very popular at this day. This study of illusions is instructive enough and may well give us pause.

But it seems as if now we might go a little further and affirm. Here might be a set of propositions to which I fancy there could, in the light of present knowledge, be very little dissent:

r. Sensation, thought, or consciousness cannot be demonstrated, except as it is associated with the physical substance of the brain and the nerves.

2. This nerve substance is the sole path to the mind-it is the mind, and an exterior stimulus can only reach us through the known organs of sense.

3. While, on the one hand, we now know a great number of stimuli which do not affect any of the organs of sense, but do affect various instruments, there are no stimuli known that affect the sense organs which cannot be made to affect some instrument in a far greater degree. It is only by means 306 
of these instruments that we arrive at any precision and certainty.

4. If spirits, thought-waves, silent healings, or any other of the so-called psychic manifestations can influence human beings, they can also influence delicate machines in a far greater degree.

5. In the absence of such proofs, "mental" science and all its like are slightly incongruous terms. They do not happen to be sciences. They are nothing but dreams.

I do not think that the telepaths or the spiritrappers have ever thought of materializing on a galvanometer. It is their characteristic that they fight shy of each and all of the familiar means by which the body of human knowledge has, in a century and a half, come to be something more than Sir Isaac Newton's pebble on the shores of the sea. I have friends who surmise that many "Christian," or "mental," scientists do not know what a galvanometer is, nor how it works. Yet in view of the indubitable grossness of our senses, and consequently of the gross character of the stimuli required to excite sensation and produce consciousness, until the galvanometer or some similar simple mechanism has been shown to respond to the "psychic forces," the latter can hardly be regarded as other than the childish fancies of childish minds. 



\section{WIRELESS TELEGRAPHY}


I sent a message to my dear-

A thousand leagues and more to $\mathrm{Her}$ The dumb sea-levels thrilled to hear, And lost Atlantis bore to Her.

Kipling.

Great inventions are never, and great discoveries are seldom, the work of any one mind. Every great invention is really either an aggregation of minor inventions or the final step of a progression. It is not a creation, but a growth-as truly so as is that of the trees in the forest. ... We shall see, as we examine the records of its history, that although James Watt was an inventor, and probably the greatest of the inventors of the steam-engine, he was still but one of the many men who have aided in perfecting it.

Thurston, History of the Growth of the SteamEngine. 


\section{WIRELESS TELEGRAPHY}

At noon, on December I 2, I90I, the two thousand miles of the Atlantic from Cornwall to Nova Scotia were spanned with invisible fingers. The first wireless signal had crossed. True, it was faint, intermittent, just a signal - the three Morse dots which stand for the letter "S." But they came, that day and the next, sometimes slowly, sometimes in quick repetition, as had been arranged. There could be no mistaking the fact. Cables might now be coiled up and sold for junk. Wireless telegraphy had come for all the world.

And Marconi was but twenty-seven. At an age when most men are just beginning, he had outstripped all competitors, and there were a host. His is a name now known in all the lands of Christendom. The ablest and most famous electricians acclaim his success. In the public mind, Marconi and wireless telegraphy are one; he is its creator.

The latter is an error. In the tremendous burst of applause which came with his triumph, the nat- 
ure of Signor Marconi's contributions to this wonderful work has become slightly mixed. $\mathrm{He}$ is neither the discoverer of electric-waves nor the sole inventor of the apparatus which has made wireless telegraphy possible. He would be the first to disavow such claims. They have been ascribed to him by persons ignorant alike of his own work and that of others.

These are matters of history which should be made clear. Signor Marconi did not conceive the existence of electric-waves, of near kin to those of light, and thus reach the belief that electricity and light are one. That was worked out by Professor Clerk-Maxwell, of Cambridge, England, nine-andthirty years ago-ten years before Marconi was born.

He did not experimentally prove the existence of such waves and find a way to detect and measure and study them. That was the discovery which made the fame of von Helmholtz's brilliant protégé, Heinrich Hertz, a young German professor at Karlsruhe, just turned thirty. Marconi was then a boy of thirteen.

He did not devise the ball-oscillator, which made it possible to send out waves of great powereventually to bridge the Atlantic. That was an idea which came to the Italian professor Righi, of Genoa. 
He did not invent the delicate "coherer," which first made wireless telegraphy possible. That was done by Professor Édouard Branly, of the Catholic University of Paris.

He did not contrive the ingenious little tapper, or "decoherer," which first suggested that ordinary Morse letters could be registered with the Hertz waves. The credit for that belongs to Sir Oliver Lodge, now of Birmingham, to whom the name of the "coherer" is also due.

$\mathrm{He}$ was not the first to conceive the idea of utilizing these waves for wireless telegraphy. That seems to have come independently to several minds. Professor Lodge was one of these; and there was the young Hindoo professor, Jagadis Chunder Bose, of Calcutta, who has made so profound a study of the subject and contrived many curious and startling experiments.

He was not the first in the practical field. Marconi, and Popoff, in Russia, seem to have begun almost at the same time, independently, of course. Their two systems, simply a combining of all preceding work, are for the rest, in their main features at least, identical.

He did not originate the idea of "syntony"tuning two instruments to act in unison, like a pair of tuning-forks-which, if it can be attained, would insure secrecy and make possible the receiving of 
any number of messages at the same station simultaneously. That is chiefly due, again, to Professor Lodge.

He has contributed but little to the scientific side of the subject, or to the explanation of the working of these mysterious waves. Here, along with the many investigators already named, stand, in front line, Professor Fleming, of London; Poincaré and Turpain, of Paris; and, on the more practical side, Lieutenant Tissot, of Brest.

$\mathrm{He}$ has, since the Salisbury Plain trials with kites, taken to the water wholly. The work of making wireless telegraphy practicable on land has been mainly carried on by Slaby and Arco, and Professor Braun, and, with his ingenious "relays," by Guarini, of Brussels.

And the Marconi system is but one of a score. There are two from Russia, two or more from Germany, one from France, one in Spain, several in England-how many in this country, 'twould be hard to count. The De Forest system, worked out on new and original lines by Dr. Lee de Forest, is one of the most successful now in use. The Weather Bureau has been experimenting for some time with the system worked out by Professor R. A. Fessenden, of Pittsburg, and this is said to have been going successfully, along the coast, at distances reaching one hundred and fifty miles. The 


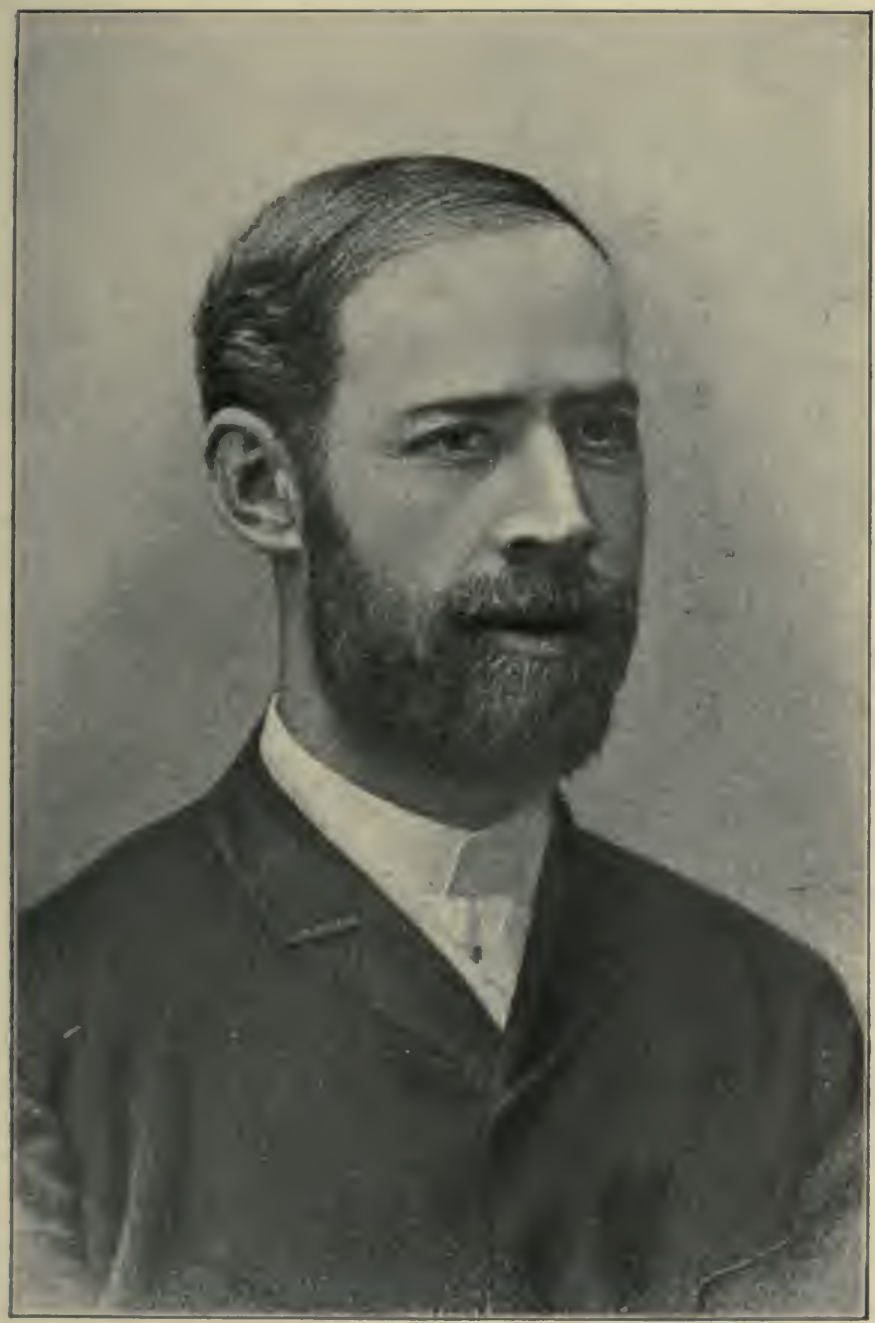

HEIXRICH HERTZ

Discoverer of electrical oscillations, or Hertz waves; died 1894 . 

Patent Office at Washington has been deluged with new contrivances and new plans.

Whence comes it, then, that hardly one in the long list of those whose discoveries have made wireless telegraphy possible is known to the larger public, while that of Signor Marconi must be familiar from Siberia to the isles of the South Seas? Simply because he has done the practical things-the obvious and the dramatic things.

Signor Marconi was probably the first to signal at a distance of more than a mile, certainly the first to reach across eight or nine miles. This was at the time so incredible that his claims were doubted-ridiculed even. But what did he care? He had plenty of money; nothing else interested him so much; the field of electricity had been his predilection from a boy, and he stuck to his guns and went ahead.

Signalling across the Isle of Wight to the mainland below Bournemouth came next; that was seventeen miles. Then across the English Channel from Dover; that was twenty-one miles. Step by step the distance lengthened. Finally, in the spring of I90I, he had sent a message from the Isle of Wight to near Land's End; that was over one hundred and eighty miles. Then the tireless experimenter looked out over waste seas, saw in fancy the foggy banks of Newfoundland, and said, confidently, "That's the next." 
But he kept his own counsel. Only his closest friends knew of his hopes or his plans. He came quietly, gave it out that he intended to try signalling to the ships passing the Banks on their way across, and so sent up his kites and balloons with hardly a single spectator present.

Anxious were the days that followed. The balloon broke its moorings and sailed away; the great kite followed. Signor Marconi believed then it was necessary to hang a wire high in the air, to catch the waves as they flashed by. That, the success of the experiments proved, was needless. The curvature of the earth between the coast of England and Newfoundland makes a hill one hundred and ten miles high. Professor Fleming believes that water is opaque to these electric-waves; and, if that be true, they would seem to follow the curving water-line. So, unless the difference in the density of the air counts, he would have caught his signals just as well at the foot of the cliff as three hundred feet above it.

All that the long, vertical wire seems to do is to afford greater surface. These waves strike it, and are absorbed. The current set up in the receiving wire is intensified, until it becomes strong enough to affect the coherer.

But when an explorer steps out into the unknown, he does not go marching boldly with 316 
"giant strides." He creeps. Marconi, with his kites and high masts, had won all his successes. Thanks to them-and they are wholly his own conception-he has outrun all his competitors. With them he was the first to send a signal two thousand miles.

He had instructed his assistant, stationed on the coast of Cornwall, to send the signals for three hours each day. Cabling that he was ready, he climbed the hill where his station stood, took down the telephone receiver, which magnifies immensely the sound of the instruments, and listened. For half an hour no sound broke the anxious silence. Then a sharp click, then more. Sometimes too faint to be heard, there were enough to brush away all doubt. The three little dots, speeding from the distant Cornish cliffs, were coming down the wire into the room, exciting the coherer-but the listeners at its side far more. Repeatedly, indubitably, they were there. The work of seven long years-years of many disappointments, vexations, setbacks, as well as unequalled success-had found its fitting climax.

Such news could not keep. The quiet, patient, cautious inventor wished to hold his secret. $\mathrm{He}$ was overruled. A few days later all the world heard, marvelled, then broke in vast applause.

The mechanism, alike of sender and receiver, is 


\section{NEW CONCEPTIONS IN SCIENCE}

simple in the extreme. Here is a row of ordinary electric batteries, such as are used with the telephone, the telegraph, or an electric fan. When they are joined together they make what is called a circuit. Through this a current flows.

But if the wire joining the two poles of the battery be cut the current stops. It will not jump even a very small gap. The air acts as a resistance, and the current is too weak to break it down. A high "tension" is needed.

To obtain this, the current is made to pass through a transformer. The effect of this is just as if a stream of water flowing through, say, a three-inch nozzle with a force of one hundred pounds were converted into a thin stream-say a quarter of an inch in diameter-rushing out with a force of one thousand two hundred pounds. The quantity of water that goes through the nozzle is in each case the same. Electricity appears to act in a similar way. A high-tension current will jump a wide gap. Tesla has contrived currents of such high voltage that they will leap across a gap of five or six feet. A spark or a flash is the result.

No such long sparks are needed here. In the Marconi instruments the current is made to cross a gap of but a fraction of an inch. It leaps between two polished brass balls rather larger than 
your fist. These sparks, Hertz showed, have a peculiar effect. They seem to set up waves in every direction.

The effect is, apparently, just like dropping a stone in a still pond. Waves go radiating across the water, and if you watch a cork floating on the surface you will notice it bob up and down. If you could not see the waves, the cork might make them known to you. It is a wave-detector. If you could send out long ripples and then short ones, you might combine them in such a way as to make the bobbings of the cork spell out words.

That is what Marconi does with the electric waves. To one of the polished brass balls a wire is attached, which runs up a high mast or hangs from a kite. The electric pulsations set up when a spark leaps from one ball to the other run along the wire, and are thence radiated off into space. Just how large a rôle this suspended wire plays in the sending is not yet very clear. Maybe some day it will not be needed. The sending instrument might be located in the cellar, for these electric-waves seem to go through brick and stone, and almost everything, save the metals.

It is clear enough that if the sending operator can open and close his circuit as he likes, he can make the series of sparks long or short as he 
likes. So you have a long or short series of waves flying through space at the speed of light. While Signor Marconi waited in Newfoundland with the telephone at his ear, this is what his operator in Cornwall was doing. In Newfoundland was an arrangement of a little different sort.

Here were batteries and a circuit, just the same. But instead of the transformer and the polished brass balls, a little glass tube makes a part of the circuit. Into this run the two ends of the wires from the batteries. In the gap between the two are some nickel-silver filings. Ordinarily, these will not let the current from the battery pass. The path is blocked.

But if this little tube, about as big as a quill toothpick, be attached at the same time to the receiving wire, which runs out through the window and up the mast, a curious effect is observed. When the electric-waves strike the high wire and are absorbed, they come running down in a way to make the nickel filings stand up in a hurry. The little particles seem to cohere, and in such a way as to let the other current from the batteries on the floor flow through. Why, nobody knows. Give the tube a little tap and they fall apart again. It is the oddest sort of a performance, and was quite unheard of until Professor Branly's discovery, ten years ago. 
When Professor Lodge heard of the Branly experiments he fixed up a little automatic tapper. It worked on the same principle as an electric door-bell. (I wonder how many people ever stop to think how even that simple every-day affair operates.) The effect of this tapping arrangement was to give the slender tube of filings a smart jog every time the electric-waves made them cohere. It was a decoherer.

The rest was simple. If the battery on the floor could be made to operate the tapper, it could also set a common Morse printing instrument going. According as the series of waves coming down the receiving-wire is short or long, the machine prints a dot or a dash. These you read off on the tape, just as you read the quotations on a stock-ticker, only you have to know the Morse alphabet to understand.

Ordinarily, the waves are strong enough and their effect clear enough, so that no telephone attachment is needed. The clicks can be read off by the ear just as in ordinary telegraphy. But the waves seem to weaken with the distance, and those which had travelled two thousand miles, from Cornwall to Newfoundland, were faint indeed. That was why Signor Marconi held an instrument to his ear.

The odd thing about it is that had Marconi 
been in Cuba, or Rio Janeiro, or Cape Town, or perhaps Port Arthur or Manila, he might, save for the mere question of distance, have heard clicks equally well. It was perfectly clear from the start that the waves are radiated in every direction. How do they travel? That is what no one knows precisely. Professor Fleming's views have been already noted. ${ }^{1}$ They differ only slightly from Blochmann's theory that the waves follow a plane of equal magnetic potential-that is, that they run along a kind of surface, as the ripples on a pond. If either of these suppositions be true, then Marconi's daring dream, of uniting all the colonies of Great Britain to the mother-land with these invisible threads - of telegraphing to South Africa, or Melbourne, or New Zealand, equally with Canada or Jamaica - seems now not far from realization. It appears merely a question of waves of sufficient strength. That, in turn, depends simply upon the power used to reel the waves in space. They could go straight around the earth; and if they did, they would go eight times around in a second. They have a rapid gait.

With all this quickly comes a vision of flying pulsations, coming from a thousand stations, and arriving with superb indifference anywhere over

${ }^{1}$ See "The World Beyond Our Senses," page 41. 
the earth. One remembers how, with only two sets of instruments, during the yacht races each pair picked up the other's signals, to the confusion of both. One is led to surmise that not much good can come from such a muddle as that.

Now that Marconi has erased distance, this is the great problem. Happily, there is hardly any nation without its corps of experimenters, and both Professor Slaby and Marconi, to say nothing of scores of others, already believe they see their way out. Indeed, a single mast, if such be needed, may perhaps serve as the receiver for an indefinite number of messages, coming from every point of the compass. And here again the arrangement would be simple.

The first electric-waves measured by Hertz vibrated back and forth-transversely, of course, to their path through space-at the rate of about fifty million times per second. Their wave-length - that is, the distance between two ridges and two hollows-was about twenty feet. The waves used by Marconi to signal Newfoundland, Professor Fleming estimates at about one thousand feet long. Professor Bose, of Calcutta, has with his tiny oscillators produced others of but a tenth of an inch. There is a corresponding difference in the number of vibrations per second. This is a wide range. 
Two tuning-forks which have the same width of vibration-amplitude is a better word-will set each other going if one be silent. They will have no effect on a fork of differing amplitude.

As with the sound-waves, so with the electric. A sender and a receiver must be "tuned," so to speak, or within certain limits one will not act on the other. This is what is called syntony. It is towards narrowing these limits of sympathy that all the workers in this field are now striving. Signor Marconi feels that the problem is largely solved. It is easy to see that this would settle two points at once-first, preventing any mix-up in messages; second, insuring a large measure of secrecy.

In order to "steal" a message, it would be necessary to know the rate of vibration of the sender, and at the same time possess an instrument which could be syntonized to respond.

That this difference of vibration is effective has been demonstrated in another field by Professor Mercadier's researches. Over an ordinary wire it is now possible to send four messages each way at the same time. Mercadier, employing Hertz waves, sends eight wave messages each way simultaneously with the others, and without the other operators being aware of what is going on. That is twenty-four superimposed sets of disturbances in 
a single wire, no one of which interferes in the least with its neighbors.

This seems wonderful enough, but, as Wheatstone showed long ago, the same thing can be done with sound-waves. Wheatstone took a thin, long rod of wood, a quarter of an inch thick, and joined one end to the sounding-board of a piano, the other to a separate sounding-board in a distant room. Here were ten strings, often struck at once. Each vibrates thirty - two times or more, distinctly. The intervening rooms through which the rod ran were silent as a tomb; in the last, all these varied sounds were perfectly and harmoniously reproduced. It would need but a sufficient variety of tuning-forks to duplicate the Mercadier multiplex telegraphy with the waves of sound.

It is rather needless to say that Marconi's splendid demonstration of transoceanic signalling means, in the near future, a big reduction in cable tolls. Marconi himself says that a cent a word is within sight. But even this is a purely arbitrary figure.

In England, where the public telegraph is not run to enrich rich people, it is possible to send a twelve-word message anywhere in the kingdom for sixpence. From the Marconi station in Cornwall to London is about two hundred and fifty 
miles, from London to Aberdeen five hundred miles, the total distance being nearly as far as from New York to Chicago. The rate is less than onethird. So far as one can see, there is no good reason why, with healthy competition, a twentyword message from New York to London, Paris, or Manila should not be sent and delivered for a dime; or, for that matter, anywhere in the United States.

The first cost is small. A wireless-telegraph station is more complicated than an ordinary Morse station, and costs more. But, needing neither cables, wires, insulators, nor rows of poles, the stations are practically the whole of the expense. Such an installation as those of the Marconi company on board the ocean ships probably costs between two and three hundred dollars at retail. The largest expense is a good induction coil, which, for a twelve-inch spark, costs between one hundred and fifty and two hundred dollars; the rest of the apparatus any clever mechanic, once he has seen it and read the descriptions with which the scientific journals teem, can rig up for himself.

And the field is free. The shower of patents has been large; Signor Marconi alone has taken out one hundred and thirty-two. But they relate chiefly to minor improvements and special devices, which, while doubtless often of individual value, 
are not a block to others to try their hand. If, for example, Professor Branly had patented his discovery, and had applied it to the reception of signals himself, instead of leaving that to Professor Lodge and others, then we might have had another Bell telephone monopoly. As it is, wireless telegraphy has been made possible by men who do not take out patents and whose work is not done for money.

Meanwhile, one may wonder a little why the practical development of this new field should have been left to a young Italian still in his twenties. As I write, a cable company is sending its lawyers before Congress to ask a huge subsidy for a cable to the Philippines. Wireless telegraphy was a demonstrated success five or six years ago. Supposing there had been in Congress one single man possessing the rudiments of a scientific education, and that through his lead a prize of a million dollars had been offered to the first man who signalled across the Atlantic, or from New York to Chicago. There would have been ten thousand electricians in the field within six months, instead of fifty or a hundred. Instead of six years, it would have taken one or two. But a Congressman with intelligence enough to do a thing like that would find Washington uncomfortable.

For that matter, it is not too late now. Why 
NEW CONCEPTIONS IN SCIENCE

should it cost a dollar to send ten words from New York to Tacoma? A successful land system of wireless telegraphy would save the public a million dollars in a week. Eventually, it will be as cheap as carrying mail. 
AMERICA'S INFERIOR POSITION

IN THE SCIENTIFIC WORLD

(I902) 
Messieurs, my first thought in the midst of this brilliant scene carries me back with melancholy to the memory of the many men of science who have known nothing but trials. In the past they had to contend against prejudices which stifled their ideas. These prejudices vanquished, they had still to encounter obstacles and difficulties of all kinds.

Only a few years since, before the public authorities and the Municipal Council had given magnificent dwellings to science, a man whom I greatly loved and admired, Claude Bernard, had, but a short distance from here, nothing but a damp and low cellar for a laboratory. Perhaps it was there that he was attacked with the malady which removed him from us!

On learning what you had here arranged for me, the thought of him at once arose before me. I salute this great memory!

Speech of the aged Pasteur at his Jubilee.

Literature has its limits, the sciences of observation and calculation have none. Below a certain degree of talent, the taste for literary occupations produces either ridiculous pride or a mean jealousy towards such talents as one cannot attain. In the sciences, on the contrary, it is not with the opinion of men but with nature that we have to engage in a contest, the triumph of which is nearly always certain, and where every victory predicts a new one.

CONDORCET, quoted by Merz, History of European Thought. 


\section{AMERICA'S INFERIOR POSITION IN THE SCIENTIFIC WORLD}

IT cannot be said that America has produced no great men of science. It was the discoveries of Franklin that gave an impetus to the early study of electricity. The work of Benjamin Thompson, Count Rumford, was done chiefly in Europe; but he was born in Massachusetts. In a sense, Joseph Henry was the co-discoverer with Faraday of electrical induction, from which the dynamo and the greater part of our vast electrical industries have sprung. Cope, Leidy, and Marsh were potent factors in establishing the truth of evolution. To whomsoever one may care to ascribe the discovery of anæsthesia-Morton, Wells, or Long - they were all Americans. Draper was the first to photograph the stars. The calculation of Professor Newton, of Yale, first drew attention to the importance of meteorites; they may yet give us a clew to the origin of worlds.

The number of men of parts is to-day greater than ever; they are to be found in every field. Simon 
Newcomb is, aside from Lord Kelvin, the only English-speaking associate of the French Academy. The achievements of Professor Willard Gibbs are better known in Europe than in our country; and the same is true of the mathematical work of G. W. Hill. Professor Langley's bolometer and the marvellous things he has done with it are a vital part of modern physics; the like may be said of the ingenious contrivances of Rowland and Michelson. Such astronomers as Pickering, Burnham, and Keeler put America in the front rank in astronomy. I might lengthily extend the list.

We have had-we have-men who have done a genuine and lasting work; the list is distinguished and worthy. Yet it is all too brief. Despite many notable figures, despite much notable achievement, America's position in the world of science is inferior. The count of our universities and colleges of the first rank outnumbers that of England or France two or three to one. Germany alone has more. The sums expended upon them are proportionately greater; Germany alone is as liberal as we. Even eliminating the recent outpouring of subscriptions, the endowments of our chief institutions of learning compare more than favorably with those of any other country, centuries older though they may be. Neither the state nor our rich men have been niggardly. Stephen Girard was born a cen- 
AMERICA'S INFERIOR POSITION

tury before Mr. Rockefeller. And the number of our students has always been large. We have lacked neither incentive, means, nor material. Nor, it would appear, has the quality of gray matter been lacking. In the field of applied science no other nation has a prouder record. We do not forget that it was Fulton who ran the first successful steamboat; that, had not Napoleon been possessed of a contemptuous stupidity in refusing Fulton's offer, the Corsican might have invaded England and rewritten some pages of history. Morse may not have been the sole inventor of the electromagnetic telegraph; but if any one man is entitled to that honor, surely it is he. His system superseded all others. Graham Bell is a Scotchman, it is true; but he is a typical American "for a' that." All his work on the telephone, and his lesser known work with the phonograph, the radiophone, and the like, were done in this country. His only competitor in the invention of the telephone was Elisha Gray, of pathetic memory. These are but instances from a crowd.

Why, then, has the United States so slight a share in the marvellous scientific advance of the century? Why, even in the face of a fine roll of names, can it be said with truth that our position is inferior? With some needful repetition of foregoing pages, I shall try to illustrate.

Pasteur's memorable discovery that the fermen- 
tation of beer was due solely to the presence of minute organisms, microbes, was made early in the sixties. That was forty years ago. Step by step the ideas of Pasteur grew and broadened. Applied to the disease of the vines, then to dying silk-worms, then to sheep-cholera, they are estimated, before his death, to have saved to France alone a sum greater than the cost of the Prussian War, with the colossal indemnity demanded by Bismarck thrown in. Pasteur's own researches culminated in the germ theory of contagions. A young English surgeon, now Lord Lister, applied his idea to the method of surgical operations; this step was enormous. To-day operations are common that were unheard of thirty or forty years ago; unknown diseases, such as appendicitis, have been discovered and a radical cure has been found for them. Germans, like Behring and Koch; Japanese, like Kitasato; a crowd of disciples and followers of the Master, as he is lovingly known in France, have extended Pasteur's ideas to the treatment of diphtheria, lockjaw, anthrax, and many other scourges. Thanks to him, too, hydrophobia has been robbed of its terrors. At last, medicine begins dimly to emerge from quackery and empiricism, and bids fair, in time, to become a true science. All this belongs to the present day, most of it to the last decade or so, yet in all this brilliant list of discoveries and applications no 
American name is to be found, even though we have a larger number of medical schools, medical professors, and medical students than any other country in the world.

In another field. To-day, ocean travellers two hundred miles from land talk with friends by a telegraph that crosses space with invisible feet. Marconi's admirable triumphs are merely the culmination of a long train of patient researches on the part of many workers in many lands. ClerkMaxwell, the English physicist, had predicted the common nature of electricity and light before our civil war came to an end. Seeking to verify this surmise, Hertz, aided and advised by his patron, the veteran von Helmholtz, made his epochal discoveries at Karlsruhe. All the world knew of it by the fall of 1888 .

A host of experimenters were instantly in the field. The delicate coherer which made wireless telegraphy possible was the discovery of Professor Branly, of the Catholic University of Paris; it was first applied to signalling by Sir Oliver Lodge, of Liverpool. Notable contributions have been made by Popoff, of Russia; by the Italian professor Righi; by the Germans-Professor Slaby, Count Arco, Professor Braun; by Guarini, of Brussels; by Lieutenant Tissot in France, and Professor Bose, of Calcutta, in India, to name but a few. It is to be 
noted that Marconi, like Morse, was an untrained amateur. It was a free field; it was late before an American entered. Even with all the stimulating examples of Edison, Tesla, Elihu Thompson, Marconi had practically bridged the Atlantic before an American system was heard of.

Another instance. We have become the first steel-makers on earth. Every school-boy knows the importance of the slightest admixtures in this industry - that one per cent. of carbon means one kind of steel; two per cent., another; four per cent., something wholly different. Within a few years the fantastic "art" of metallurgy has been transformed from a collection of housewives' receipts to a science. To-day we may make a gold that will melt in a candle-flame, another that will cut glass. A mixture of metals, like lead, tin, and bismuth, which melt, separately, at three hundred to five hundred degrees, dissolves in boiling water. A scant trace of one substance introduced in another gives the latter unheard-of qualities. Two metals like gold and iron, simply placed in contact, slowly interpenetrate and mix with each other as if they were so much water and wine. An up-to-date, matter-of-fact text-book of the science reads like the prescriptions of the old alchemists. Our ideas of the solid world about us have been irradiated with a new light. 


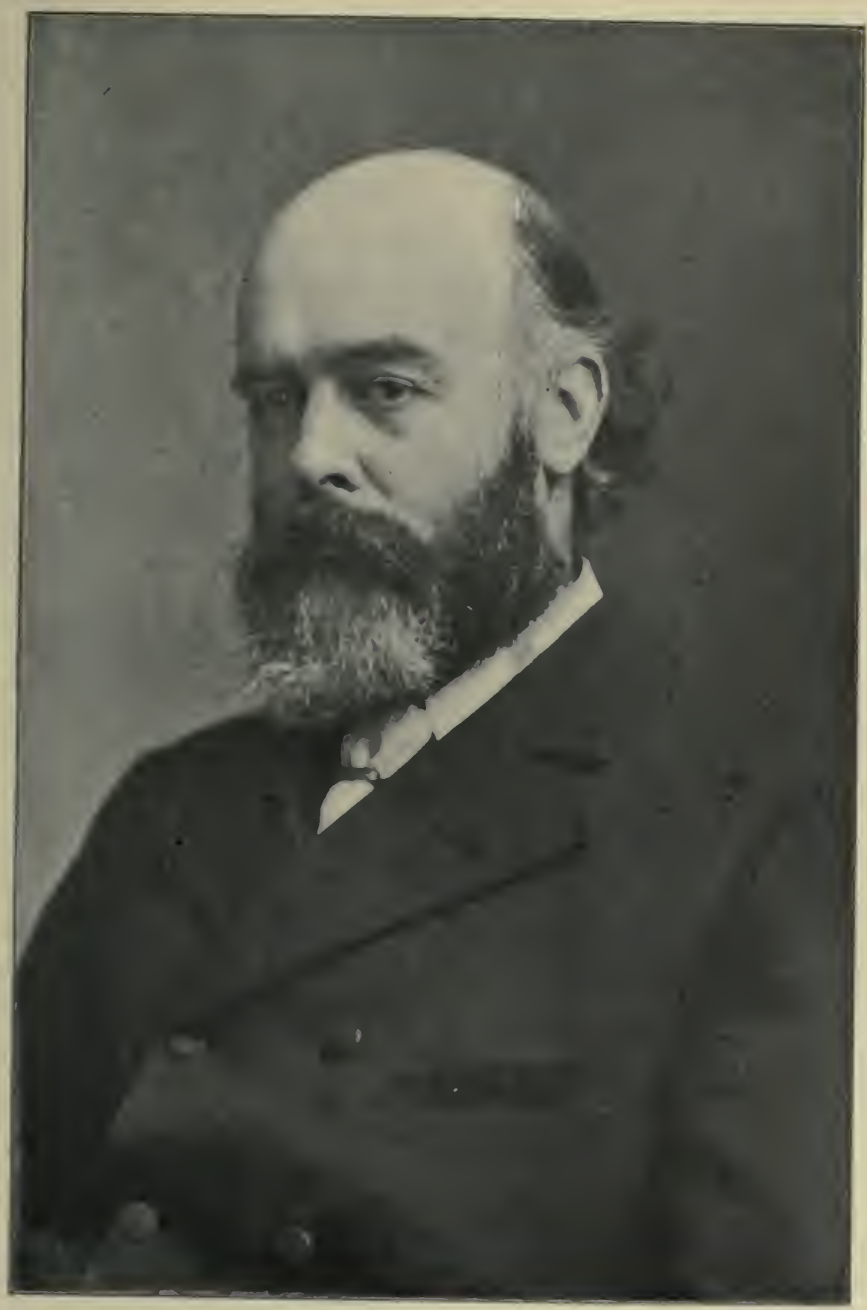

SIR OI,IVER LODGE

Principal of the University of Birmingham, one of the first to demonstrate the prossibility of wireless telegraphy. 

I have before me the latest volume on metallurgy, even-handedly summing up twenty years of splendid work. From almost a dictionary of names, Belgian, Netherlandish, German, English, French, Russian, I can find but two Americans-Professor Gibbs, whose contribution was most indirect, and Professor Howe. Not even a science upon which rests a billion-dollar trust seems to arouse the interest of one original, inventive American mind.

Mention of the old alchemists recalls the amazing results recently brought to view by Professor J. J. Thomson, of Cambridge, which have been already described. Nowadays, every one has come to know a little at least of the high vacuum Crookes tubes, and the velvet glow that comes from them when the tubes are electrified, which gives rise to the Röntgen rays of familiar use. Sir William Crookes long ago showed that this glow is made up of streams of minute missiles. Bombarding a fluorescent screen, they produce the Röntgen light. Putting two and two and three and three together in the most ingenious way, Professor Thomson has been able to measure both the mass and speed of these flying particles, to count them, tell the measure of the electrical charge that each bears-a charge that is enormous. The Cambridge professor has shown that these bits of matter are certainly a thousand times smaller than the smallest and light- 
est atom known to chemists; from whatever source they come, they are all alike, identical in every way. Is this primal matter at last? Is here the stuff from which all known substances are compounded? May we look forward to the time when we may build up any substance-gold, for example-from the elements of any other? Have we realized the philosopher's stone?

However this may turn out, it is certain that these cathode rays, or "corpuscles," as Professor Thomson calls them, are destined to play a leading part in all future conceptions alike of chemistry and physics. From their first recognition by a German, Hittorf, in 1868 , there has been a long line of investigators, whose results fill bulky volumes. If, as now seems not improbable, this should turn out to be the most far-reaching discovery of the century, the historian of the future will be rather puzzled to explain why, among scores of names and observations, not one name, not one observation, has been contributed by the nation which boasts itself the best educated, the most progressive and enlightened of all. The tribute of America is conspicuous by its absence.

But slight significance could lie in such a detail of the facts were the cases exceptional. In sketching out this none too flattering picture, I have 
picked the instances merely as they have occurred to me-not for the purposes of an indictment. Take an instance or two more.

Within the last quarter of a century-that is, within a period during which the United States have been easily abreast of the other nations and tribes-an immense work has been done in trying to unravel the mechanism of the brain. We may never solve the mystery of thinking, conscious matter. But we are certainly in sight of a working theory as to how the substances in the myriad cells of the brain perform their work. The possibility of attaining to such an intimate knowledge of the mind dawned with the discovery by the Italian, Golgi, of new staining reactions. Fascinating to the last degree are the pictures of the brain revealed by the microscope in the hands of a multitude of workers. The cosmopolitan character of science was never more admirably illustrated. The Spanish neurologist, Ramon y Cajal, vies with Bethe of Germany, Van Gehuchten of Belgium, Forel of Switzerland, Waldeyer of Austria. A whole library could be filled with monographs, memoirs, journals, and great books on this single subject. Scarce any land beneath the sun is unrepresented, save America. In all this wealth of literature you search in vain for a reference to one American's work. Another illustration takes us farther afield. 
Scarce any science has taken on so prodigious a development in later years as chemistry. As a science, it dates from Lavoisier, the French farmer of the taxes whose head fell in the Terror. The pivot of modern chemistry is the atom imagined by John Dalton, a learned Quaker of Manchester, whose book appeared in 1808 . So vast a field does this science now cover that hardly any man is master of more than a part. A German chemical dictionary, Beilstein's, dealing with but a single branch, organic chemistry, treats of fifty thousand distinct compounds. There are half a dozen other important branches, each with its own huge literature-with special journals, even. It is almost a world by itself. Primacy here has shifted about from one country to another throughout the century, and chiefs and leaders have come from every point of the compass. Obscure lands, like Sweden, Norway, Russia, have been often at the fore. Yet the history of this wonderful science could be written in full detail without mention, perhaps, of more than a single American name. It will better indicate the state of the work in this country to note that the work of this single American, Professor Willard Gibbs, was unrecognized, was unknown, until it had been dug from the Connecticut archives by a Dutch chemist, after it had lain buried for nearly twenty years. 


\section{AMERICA'S INFERIOR POSITION}

Perhaps in the minds of some, obsessed with the notion that a new country necessarily means a new people, and that the gentler nurture of the intelligence which we call the sciences and the arts had small show in America until recent years, it will be judged that I have had here under view a time too long. It will not be difficult to find a science that belongs wholly to recent years, where, therefore, our own country has had an equal chance with any other. Take a special province of chemistry that has become of great commercial importance within a very few years-electro-chemistry.

Whatever scattered processes might have existed prior to 1885 , the science itself was then a thin and meagre affair. All that was known might have been acquired in an hour or two of close application. Though Clausius in Germany and Williamson in England made tentative efforts at a consistent scientific theory about the middle of the century, the discoveries of Faraday in the thirties represented the sole progress from the conceptions of Grotthaus, which date from 1805 , and are still to be found in many American text-books in current use. The moot question was one that had the greatest importance to chemistry in general, and particularly to the chemical explanation of life processes: What happens when a substance is dissolved in water or other liquid? 
Almost every one knows that pure water does not conduct electricity. A lump of table-salt dissolved in the water, or a spoonful of sulphuric acid, not merely makes the water a conductor, but, with metal plates, may itself give rise to an electric current. This was the essence of the discoveries of Galvani and Volta. A lump of sugar so dissolved has no such effect.

The explanation of these phenomena, and the practical founding of a new science as well, was the joint work of van't Hoff, a Dutchman; Arrhenius, a Swede; Ostwald, a Baltic German; Raoult, a Frenchman. Extended by eager investigators in every direction, the new theories have worked a genuine revolution in chemistry itself; they have given rise to a number of new industries, which, if we add to them the aluminum and calcium carbide industries, born of the electric furnace, are already worth millions of dollars to America alonemillions more to Europe. The new theories, moreover, seem to throw a flood of light on the most puzzling problems of life. Thanks to them, we are on the way now to a connected account of all vital actions, whether of digestion or reproduction, growth or death, on a simple mechanical or chemical basis. Our bodies and our brains consist very largely of water; the blood carries in solution all the materials which maintain life, so that if we 
have a complete theory of solutions, we shall have a complete theory of life. We may be able to answer without embarrassment the old, old question, What is life?

The astonishing development of this province of knowledge within a space of time so brief, a development thoroughly international in character, is a striking example of that admirable organization of modern society which permits a degree of cooperation and an ease of communication, coupled with the stimulus of friendly rivalry, which would have been impossible a few centuries ago. Nowhere is this splendid solidarity, this intelligent "community of interest," so much in evidence as in this especial field; nowhere is the remarkable isolation of the United States from the rest of the scientific world more clearly illustrated. A list which would include the names of even the lesser builders of this imposing fabric would hardly include that of one American.

It would be easy to multiply examples. Here is the far-reaching theory of the ether, explaining, or at least offering, the only existing explanation of the phenomena of light, heat, electricity, and magnetism, of the Marconi telegraph and X-ray photography. Whether it stand, or whether a simpler and better theory shall replace it later, it is assuredly the most brilliant example we possess 
of the fruitful union of scientific experiment and the scientific imagination. Wise men from among many peoples have come bearing their gifts; but, in the long line from Kelvin and Helmholtz to Lorenz and Poincaré, you discover no faces out of the desert of the western continent.

It is pretty much the same story wherever we turn. What is the cause? Why is it that this people, now marching to the industrial conquest of the earth, has done so little, comparatively, in the realms of science? I leave the answer to others who may love large generalizations more. My purpose was rather to indicate a condition than to propose a remedy. It is certain we do not lack for colleges and institutions of "higher culture." The sums which our Crosuses scatter with lavish hand are the wonderment of Europe. We are a clever people, undoubtedly; this is not new; our newspapers and orators do not miss an opportunity of telling us so. We have done big things; and it is, perhaps, just for that reason, just because of the rich prizes of business, that the Faradays and Claude Bernards are not to be found among us.

Not long ago France did honor to one of the century's notable men, her great chemist, M. Berthelot. The President of the Republic was there to preside; it was a national affair. I suppose M. Berthelot may be accounted the greatest 
experimental genius since Faraday; the list of his discoveries, the range of his work, the fertility of his resources have been amazing; and it is the boast of his countrymen that he never took out a patent. One of his eulogists said that his work had been done for mankind. He has long been a senator of France; he was for a time Minister of Foreign Affairs; yet it is told of him that visitors in winter are invited to his bedroom when they call, the single fire meaning a slight economy of coals! It is a little difficult to assimilate such a character to American ideas of success, yet even our Midases may feel dimly the greatness of such simplicity as that.

The life of M. Berthelot recalls that of Pasteur, or again that of the great physiologist, Claude Bernard. They, like Faraday, might each have had millions; they declined prizes that it needed but a lifted hand to grasp. They labored for the race, and perhaps some day we shall come to honor them as much as we now honor a slayer of men or a millionaire. The work of Berthelot, like that of Bernard, has been done chiefly at the Collège de France; that of Faraday was done at the Royal Institution ui London. Every one knows of the Pasteur Institute, though not many know how widely its activity has been extended and the multitude of novel things done there in recent years. 


\section{NEW CONCEPTIONS IN SCIENCE}

We lack in America anything just like these three institutions, as we lack anything like the German university system, which gives German professors so wide a latitude of time for original experimental work. It may be that one cause of our inferiority in a scientific way lies in this want.

Each of these celebrated seats has a history that is unique. The Pasteur Institute was founded as a national memorial to the illustrious man whose name it bears. That restless, tireless genius had saved France millions of treasure and thousands of lives. The silk industry, the wine industry, medicine, surgery, the dairy, stock-raising, the most intimate sources of national wealth, well-being and happiness even, had felt the impress of his mighty hand. Scorning the rich rewards which might have been his had he chosen to put his discoveries under the seal of letters patent, Pasteur deserved well of his people. They understood it; they honored him as few men of science have ever been honored while they were alive. But medals and decorations did not suffice. So, when one of the great newspapers opened a subscription for a splendid memorial, for an institution wherein Pasteur and his disciples might carry on their work under the most favorable conditions, the response was instantaneous and touching. There was hardly a humble home in France which was not, in some 


\section{AMERICA'S INFERIOR POSITION}

way, indebted to Pasteur, and there was hardly a humble home in France from which a slender subscription did not come. The Institute was the result.

Thanks to the munificence of the Baroness Hirsch, a new building has been recently completed, devoted wholly to biological chemistry and doubling the capacity of the institution. Workers come there now from every part of the earth. Show that you have a work to do, and all the resources of the most perfectly equipped laboratory, all the aids of modern technical and scientific instruments-grown exceeding complicated now and expensive-are at your disposal.

It would be strange if such an institution did not yield rich fruit, and under the guidance of the present director, M. Duclaux, aided by men of splendid talent, like Roux, Chamberlain, Metchnikoff, Gabriel Bertrand, Mazé, and many others, a great work is being done. The whole theory of fermentation, and the varied rôle of the ferments in every phase of animal and vegetable life, as well as in many industries, is being worked out. So far do its labors extend that very recently, under Metchnikoff and his special aids, the senility of the cells and the causes of old age are being investigated. Perhaps we may look forward to the day when we shall find agents able to counteract the growing 
years. Science has many dreams, and the everlasting fountain of Ponce de Leon is assuredly one.

The main body of the work of the Pasteur Institute has now grown too severely technical to admit of brief description; it is enough to say that nowhere else, perhaps, has so close an approach been made to the solution of the most intimate problems of hygiene, of health, and of life.

Is it needful to add that we have no institution in America comparable to the Pasteur Institute, no great working laboratory where the investigator may go with his hopes and his plans, and work upon them advantageously and in peace?

France has yet another institution of a slightly different character, yet contributing to the same end, the unimpeded pursuit of experimental science. That is the Collège de France. Founded in the days of the Splendor, and originally devoted chiefly to theology and philosophy, it has within the century taken on more and more the stamp of a research institution. There the work of Magendie and his great pupil, Claude Bernard, was done. There Renan sat and taught. There M. Berthelot has pursued uninterruptedly his fertile and fruitful career. Each of its professors is expected to give, once or twice a year, a series of lectures; and these have come to be more and more a summing up and synthesis of the most recent work in each especial 
field. These lectures are free to all; you may go or stay, or drop in now and then as your leisure and inclination decree. There are no entrance examinations, no fees to pay. If you care to enroll yourself regularly and attend a given number of series, a diploma is at your disposal. Whether you take it or no, a liberal education is yours for the asking, or rather for the attending. Within the wide leisure of these classic halls you may gather the latest results from every domain of human knowledge.

The labor of the series of lectures entails no great drain upon the time of the occupants of the various chairs; it serves rather as an excellent drill and as an incentive to clear popular exposition of special studies. For the rest, the professors are free to pursue their tasks and their dreams, with never an account to give either to the public or to the state. Is it any wonder that under such a system some of the finest research of the century has been done there? Scarce any single institution of the world can show so proud a roll of memorable names and of achievements that mark an epoch. If there is anything in America which may be likened to the Collège de France, it is, perhaps, the Smithsonian Institution at Washington. Much notable work has been done there; America has no more distinguished savant than its secretary, Professor Langley; and yet it would be admittedly un- 
fair to compare for a moment the work of the two. The Smithsonian has no such resources, no such equipment, and, it may be added, no such farreaching aims.

It is to be noted in passing that almost all of the courses of the chief university of France, the Sorbonne, are equally open to the public, with neither formality nor price. There, for the trouble of entering its walls, at almost any time you may hear the chief luminaries of French science and French letters; you may listen to the elegant periods of M. Faguet, or, under the grace of M. Moisson's facile discourse, feel the most recondite subjects take on the allures of romance. So far as I know, this is true of no American university.

Paris has yet a fourth institution very close of kin to the Pasteur and the Collège. A couple of miles to the east of the university stands the old Jardin des Plantes, made famous by the genius of Cuvier. There a large number of professorships, touching all the various departments of scientific instruction, are set aside for original minds who seem to have a work in the scientific world to do. They are "blue ribbon" posts, and afford independence, leisure, and stimulus for that patient, unremitting, undiscouraged toil which is at once the condition and the source of the best scientific work. There Professor Becquerel made his astonishing 
discoveries of substances which give off light and energy without apparent drain, inexhaustible and unceasing, seeming even to contradict the fundamental law of natural phenomena, the conservation of energy. There Maquenne was the first to produce calcium carbide, from which comes acetylene and a new industry; there he now pursues his work upon the chemistry and constitution of the sugars. I cite only two names from a score or more.

Without naming the École Normale, where St. Claire Deville spent his active life, or the School of Arts and Manufactures, or the College of Pharmacy, where both Berthelot and Moisson gained their reputations, nor a number of other minor institutions, here are three great seats of learning, chiefly devoted to experiment and research. This in a single city! Need there be any marvel that France should possess a roll of great names so resounding that, as I have indicated, the comparatively meagre roll which the United States may produce seems inconsiderable indeed?

London has a similarly admirable example to offer. The amount of genuinely scientific work which England has done, from the days of Boyle and Hooke and Newton, has been noteworthy enough in itself; it has been astonishing, when the 
singular indifference to science alike of the English universities and of the English people themselves, taken broadly, is considered. Although it was at Oxford that Sir Robert Boyle laid the foundations of chemistry, the contributions of the old English university to the advancement of knowledge have been humiliatingly small. Cambridge, within the last forty years, has done a very distinguished work; and the same may be said of the Scotch universities.

But the stronghold of English science within the last century has distinctly been the Royal Institution in Albemarle Street. Thence have the most brilliant discoveries in England come. There the singularly varied mind of Dr. Thomas Young elaborated the undulatory theory of light, and deciphered the hieroglyphs from the tombs of the Ptolemies. There the flashing genius of Sir Humphry Davy devised the first electric light, and set the man in the street talking of the latest marvels of chemistry. There the whole life-work of Faraday was done. There the picturesque imagination of Tyndall made the hardest subjects of physics as fascinating as a tale of far Cathay. There Professor Dewar and Lord Rayleigh have made their striking discoveries of new elements and opened up new realms for investigation.

The Royal Institution was founded by an American. Benjamin Thompson, later Count Rumford, 
was born in one of the villages near Boston. His precocious genius and dominating ways aroused enmity against him; and when the War of the Revolution broke out and he started to raise a company of militia, he was literally driven over to the British side. He fled to England to become, at twenty-four, Under-Secretary of State, and at twenty-seven a member of the Royal Society. Knighted, his keen love of adventure took him to the Continent, then drifting towards one of the Eastern wars. Entering the service of the King of $\mathrm{Ba}$ varia, he was made Count Rumford for his genius as an administrator. He was virtually prime-minister; and, for a time, when the King had fled, it was he who ruled. In a single day he banished mendicity from the most beggar - ridden nation in Europe. When he returned to England, just a century ago, he conceived the plan of a great institution whose chief object should be the diffusion of knowledge and of the benefits of science among the people.

The result was the Royal Institution. It has scarcely held to the ideals of its founder. Its chief features are its courses of lectures. Each year, the most notable men of England and the Continent are drawn upon to sketch in an entertaining way the latest steps of the sciences. Travellers and inventors come, too; there are courses for young folk; there is a splendid library, 
and no club in London is more inviting. The membership fee is ten pounds a year, and the list is large. No wonder, for a tolerably assiduous attendance affords an opportunity to listen to and to make the acquaintance of the most famous and most interesting men of the time.

There are but three professorships. Like those of the Collège de France, their duties are light and the opportunities for research are wide. The system is ideal; yet, considering the number of chairs, it is simply a marvel that a single institution in a single century could show such a roster of great names, such an array of genuine achievements. It would be hardly too much to say that, during this hundred years of its existence, the Royal Institution alone has done more for English science than all of the English universities put together. This is certainly true with regard to British industry, for it was here that the discoveries of Faraday were made.

The German university system and the independence and leisure which it affords German professors are too well known to need sketching here. It is pleasing to note that something of this same spirit and of this same system is coming into vogue with our American universities. Of this much good may come. But there is room-nay, if the United States wish to hold the same position 


\section{AMERICA'S INFERIOR POSITION}

in the world of science as they are so proud to hold industrially, commercially, and perhaps in a social and literary way as well, there is a very articulate need for institutions like those of Paris, and like the Royal Institution which an American refugee founded, with such large results, in London.

It would require but the co-operation of those who are broadly interested in scientific progress, and who have a desire to keep abreast of the swiftly advancing knowledge of their day, to achieve the beginnings of a great institution which should be at once a scientific society, a forum where the chief notables alike of Europe and America might be gathered and heard, and a seat of scientific research. It would be a work worthy of any man to undertake the founding of such an institution in the chief city of the New World. 



\section{N D E X}

ACETYlene, synthesis of, $175 . \mid$ Berzelius, 174 .

Actinians, 202.

Adams, 85 .

Affinity, chemical, 182 .

Alexandria, founding of, 3 .

Alexandrian Library, 4.

Alexandrian Museum, 5.

Allotropism, 182 .

Arago, 134 .

Archimedes, 14, 16, 18, 23, 24, $26,29$.

Archytas, 29.

Arco and Slaby, 314.

Aristarchus, 7.

Aristotle, 22, 26, 103 .

Arnold, Matthew, 252.

Arrhenius, $162,208$.

Association-fibres, 268.

Athens, 18 .

Atom, evidence for reality, $9 \mathrm{I}$; what is an, 124-16I; electrical, 137 .

BACON, Roger, 28.

Barus, 91.

Becquerel, 295.

Becquerel rays, 154.

Behring, 30, 276.

Bcilstein, dictionary of organic chemistry, 340.

Belfast address, Tyndall's, quoted, 198.

Bell, Graham, 333 .

Bernard, Claude, 254.

Berthelot, 30, 169, 192.

Bertrand, Gabriel, 234.

Bjerknes, Professor, 82 .

Blondlot, Professor, 8o.

Body, the, as a battery, 214.

Bordet, 278.

Bose, Jagadis Chunder, 52, $270,313,323$.

Brain, beginnings of, 255 ; weight of, 258 ; structure of, 260.

Brain-cells, number of, 257 .

Branly, Edward, 304, 313.

Bredig, 238.

Bruno, 21.

Buchner, 231, 233.

Buckle quoted, 37 .

Buffon, 17.

Byron, brain weight of, 258 .

Calmette, Dr., 275.

Campanularia, 240.

Capillary attraction, II8.

Catalytic action, 183 .

Cathode rays, $47,94,150$.

Cauchy, 117.

Centigrade scale, 53.

Cerianthus, 205.

Chemical mechanics, 180.

Chemistry, synthetic, 169.

Chemo-tactism, 202.

Chloroform, action of, 223.

Christian science, 307 .

Clausius, $34 \mathrm{I}$.

Clerk-Maxwell, 50, 79; quoted, 102, II 5 .

Coherer, 320. 
Collège de France, 193, 348.

Colloids defined, 217.

Comte, 299.

Condorcet quoted, 330 .

Consciousness, what is, 264 .

Contact, effect of, on animal movements, 206 .

Copernican system, 16, I7.

Corpuscles, I37-142, 160.

Crookes, Sir William, 47, 137142.

Crookes tube, II9, 148.

Ctesibius, I I, 26.

Curie, $163,296$.

DAguerre, 45.

Dalton, John, 92, 340.

Darwin, 21, 28.

Davy, 133 .

Democritus, 103.

Descartes, $23,24$.

Dewar, Professor, 57, 352.

"Difference-threshold "in psychology, 301 .

Dinner, the, of the future, 190.

Dinokrates, 3 .

Diophantus, 24.

Diphtheria, ubiquity of microbe of, 276 .

Draper quoted, 27.

EARTu not made for man, 99.

Ehrlich, 284.

Electrical atom, 95 .

Electricity, explanation of, I31; speed of, 133 .

Electro-chemistry, 341.

Electron, 95, 139.

Elements, the nature of the, 93.

Emerson quoted, 72, 102.

Emmerling, 236.

Empedocles, 22.

Enzymes, 233.

Eratosthenes, 6, 8, 26.

Euclid, 5, 17 .
Eudoxus, 29.

Evaporation, electrical, 150.

Explosions, measure of, 184 .

FARADAY, 106, 107, 133.

Fermentation, nature of, 23 I.

Ferments, inorganic, 238 .

Fessenden, R. A., 304, 314.

Fischer, Emil, 93, 176.

Fleming, Professor, 316.

Fluorescein, II 2.

Forest, Dr. Lee de, 3 I 4.

Franklin, Benjamin, 130, 131 .

Fresnel, 136.

Fulton, 333 .

GALEN, 26.

Galileo, $21,23,24,85$.

Galvani, 133 .

Geissler tubes, 148.

Gerhardt, 174 .

German university system, 354.

Germ-cell, size of, 246 .

Gibbs, Professor Willard, 179. 340.

Goethe, ideas of affinity of, I79.

Gold-leaf, thin, 106.

Golgi, explorations of brain by, 259, 339.

Gray, Elisha, 333.

Growth, influence of electricity on, 188 .

HARDY, 2 I 7 .

Harvey, 23.

Heat, upper limit of, 89 .

Heliotropism, 202.

Helmholtz, von, quoted, 97 . 290.

Henry, Joseph, 331.

Heraclitus, 2 .

Hermite, M. 1', 66.

Hero, or Heron, I I.

Herschel, Sir John, I 26.

Herschel, Sir William, 66. 


\section{N D E X}

Hertz, Heinrich, 312.

Hertz waves, 5 x, 79, 137 .

Heydweiler and Landoldt, 165.

Hill, Croft, 236.

Hipparchus, 10, 23, 26.

Hittorf, 148.

Hooke, Robert, 25.

Huxley quoted, 2, 253, 270.

Huygens, 136.

Hydroids, growth of, 205 .

Hypatia, 24.

IMMUNITY, mechanism of, 278 .

Instincts, theory of, 200.

Institute, Pasteur, 346.

Ions, 209, $211,219$.

Irritabilite, 254.

Isomeres, chemical, 173,281 .

Jardin des Plantes, $35^{\circ}$.

Jenner, 274.

KANT, 244.

Kelvin, Lord, 30, 82, II 7, 142.

Kipling quoted, 3 ro.

Kirchhoff, 299:

Kohlrausch, 305.

Kolbe, 145 .

LANGley, Professor S. P., inventor of the bolometer, 49.

Laplace, $21,72$.

Larmor, 221.

Lavoisier, 171, 179, 251.

Layard, 25.

Leeuwenhoek, 24 .

Lehmann quoted, 2.

Lenard, 153.

Leverrier, 85 .

Liebig, Baron, $172,257$.

Liedentopf and Zsigmondy, I 20.

Life, as a fermentation, 229 ; reversibility of, 239.

Light-waves, 88, 109.

Lister, Lord, 334.
Liver cell, activity of, 237 ; size of, 244 .

Living molecules, size of, 245 .

Lockyer, Sir Norman, 64.

Lodge, Sir Oliver, $3^{1} 3$.

Loeb, Jacques, 199.

Lucretius, 103 .

Maquenne, LEon, 351 .

Marconi, 5I, 3 II.

Mathews, Dr. A. P., 199, 217 , 266.

Matter, divisibility of, 89 ; fourth state of, 137 ; radiant, 152.

Mayer, Professor, 122.

Mendeleéf quoted, 168.

Mercadier, 324.

Metallurgy, development of, 336.

Metchnikoff, Elias, 244, 276.

Meudon laboratory of vegetable chemistry, 187 .

Meyer, O. E., II 6 .

Micron, unit of measure, 105.

Mind, chemistry of, $25 \mathrm{I}$.

Molecules, measurement of, I 6.

Moleschott, 252.

Müller, Johannes, 300.

NAPIER, BARON, 24.

Napoleon, 333 .

Nerves, stimulation of, 218 , 265.

Newcomb, Simon, 98.

Newton, 21, 22, 24, 43, 84, 136,144 ; what he knew, 292.

Newton, Professor, of Yale, 331.

Newton's rings, 108 .

Newtonian theory of light, 136.

Niagara Falls, dynamos, 134

Nicetas of Syracuse, 6.

Nitrates, artificial, 189. 


\section{N D E X}

Organic chemistry, Berthelot's, $x 76$.

Overton, 218.

Oxydase, 234.

Parthenogenesis, $200,209$.

Pasteur, 30, 228, 230, 274, 333; jubilee speech of, 330 .

Perrin, Jean, 153, 161 .

Phagocytosis, 277.

Philadelphus, founder of Alexandrian medical school, Io.

Phosphorus, rôle of, 253.

Plato, 29, 30.

Plutarch quoted, 29.

Poisons, organic, 281 .

Powder, smokeless, I 86.

Prolongation of life, 215.

Protoplasm, what is, 253 .

Protoplasmic threads, 104

Prout, 93.

Ptolemy, 4, 10, 23, 26.

Queries, Newton's, 108.

RADIO-ACTIVITY, 296.

Radiometer, 148.

Radium, ${ }^{6} 6_{3}$.

Rayleigh, Lord, Iro.

Reflex action, 26 I.

Renan quoted, title-page, 170 , I9I.

Reversibility of life, 239.

Ribbert, 206.

Richet, Charles, 264.

Righi, 3 I 2.

Romanes, 207.

Röntgen oil-drops, I 10.

Rōntgen rays, $43,80$.

Royal Institution, 345, $35^{2}$.

Rumford, Count, 352 .

SALTS, effect of, on heart-beat, 207.

Schleiden and Schwann, 298.

Senility of the cells, 347 .

Senses, vagueness of our, 303 .

Serums, 278.

Side-chains, 284 .

Soap-bubble, wall of, 107.

Sodium in a flame, I 13.

Solutions, precipitated by electrolytes, 9I; theory of, 208 .

Soury, Jules, 263.

Shakespeare, 103.

Slaby and Arco, 314.

Smithsonian Institution, 349.

Space, temperature of, 87 .

Spectroscope, the, 65 .

Spencer, 28.

Spider's web, 104.

Stereotropism, 203.

Stokes, Sir George, 156.

Stoney, Professor, 139.

Sully, Professor, 306 .

Sun, a ball of gas, 86 .

Syene, 89.

Syntony, 3 I 3, 324 .

Syracuse, 14.

Telepathy, 291.

Thomson, Professor J. J., 47, $82,138,153$.

Thought, what is, 269.

Thought-waves, measure of, 264.

Thurston, R. H., quoted, 3 ro.

Torricelli, 24.

Tyndall quoted, $33,198$.

UNIVERSE not infinite, 98.

Uranium rays, 163 .

Urstoff 95.

VacuUm, highest, 149.

Valency, 213.

Van't Hoff, 206.

Verworn quoted, 228.

Vibration of molecules, I 21 .

Vielle, 186.

Visibility, limits of microscope, 105.

Volta, 133 .

Vortex-ring, 142. 


\section{N D E X}

WALDEYER, 257.

Wallace, A. R., 99.

Warburg, Iro.

Weber's law, 301 .

Wheatstone, 325 .

Wiener, Otto, $290,305$.

William of Occam, 267 .

Williams, H. S., quoted, 2.

Wilson, R. C. T., 155.

Wireless telegraphy, 3 I I.

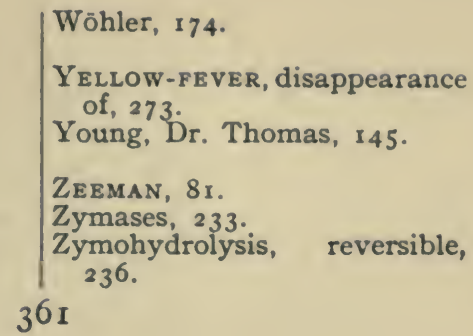

THE END 




\section{PLEASE DO NOT REMOVE CARDS OR SLIPS FROM THIS POCKET}

\section{UNIVERSITY OF TORONTO LIBRARY}

Pra Sci. 


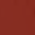

